Portland State University

PDXScholar

$11-2021$

\title{
Developing Strategies to Enhance Mobility and Accessibility for Community-Dwelling Older Adults
}

\author{
Kate Hyun \\ University of Texas at Arlington \\ Kathy Lee \\ University of Texas at Arlington \\ Caroline Krejci \\ University of Texas at Arlington \\ Nilufer Oran Gibson \\ University of Texas at Arlington \\ Troyee Saha \\ University of Texas at Arlington
}

Follow this and additional works at: https://pdxscholar.library.pdx.edu/trec_reports

Part of the Transportation Commons, Urban Studies Commons, and the Urban Studies and Planning Commons

Let us know how access to this document benefits you.

\section{Recommended Citation}

Hyun, Kate, Lee, Kathy, Caroline, Krejci, Oran Gibson, Nilufer and Saha, Troyee, Developing Strategies to Enhance Mobility and Accessibility for Community-Dwelling Older Adults. NITC-RR-1304. Portland, OR: Transportation Research and Education Center (TREC), 2021. https://dx.doi.org/10.15760/trec.267

This Report is brought to you for free and open access. It has been accepted for inclusion in TREC Final Reports by an authorized administrator of PDXScholar. Please contact us if we can make this document more accessible: pdxscholar@pdx.edu. 


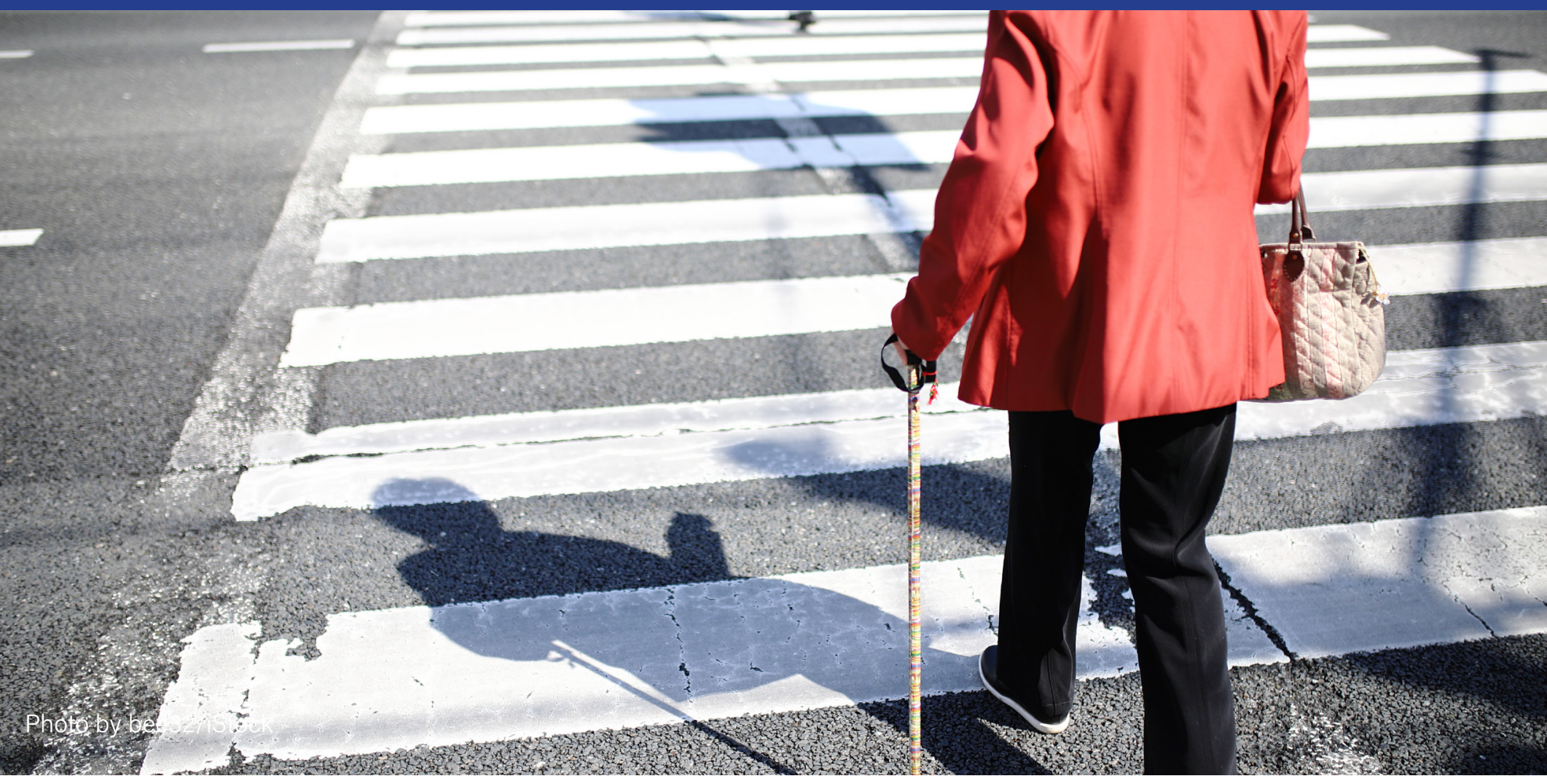

\section{Developing Strategies to Enhance Mobility and Accessibility For Community-Dwelling Older Adults}

Kate Hyun, Ph.D.

Kathy Lee, Ph.D.

Caroline Krejci, Ph.D.

Nilufer Oran Gibson

Troyee Saha 


\section{DEVELOPING STRATEGIES TO ENHANCE MOBILITY AND ACCESSIBILITY FOR COMMUNITY-DWELLING OLDER ADULTS}

Final Report

NITC-RR-1304

by

Kate Hyun, PhD

Kathy Lee, PhD

Caroline Krejci, PhD

with Nilufer Oran Gibson and Troyee Saha

University of Texas at Arlington

for

National Institute for Transportation and Communities (NITC)

P.O. Box 751

Portland, OR 97207
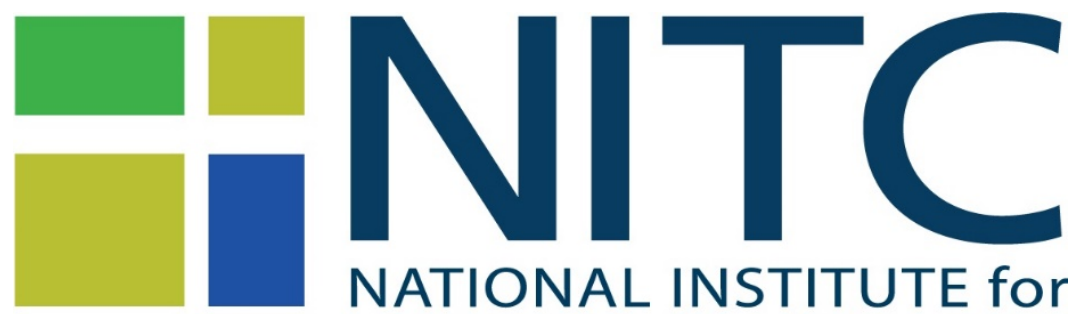

TRANSPORTATION and COMMUNITIES

November 2021 


\begin{tabular}{|c|c|c|c|c|}
\hline $\begin{array}{l}\text { 1. Report No. } \\
\text { NITC-RR-1304 }\end{array}$ & \multicolumn{2}{|l|}{ 2. Government Accession No. } & \multicolumn{2}{|c|}{ 3. Recipient's Catalog No. } \\
\hline \multicolumn{3}{|c|}{$\begin{array}{l}\text { 4. Title and Subtitle } \\
\text { Developing Strategies to Enhance Mobility and Accessibility for Community-Dwelling } \\
\text { Older Adults }\end{array}$} & \multicolumn{2}{|c|}{$\begin{array}{l}\text { 5. Report Date } \\
\text { November } 2021\end{array}$} \\
\hline \multicolumn{3}{|l|}{$\begin{array}{l}\text { 7. Author(s) } \\
\text { Kate Hyun 0000-0001-7432-8058 } \\
\text { Kathy Lee 0000-0001-9603-1685 } \\
\text { Caroline Krejci 0000-0003-0696-1884 } \\
\text { Nilufer Oran Gibson 0000-0001-5224-5200 } \\
\text { Troyee Saha 0000-0001-6350-0342 }\end{array}$} & \multicolumn{2}{|c|}{$\begin{array}{l}\text { 8. Performing Organization Report } \\
\text { No. } \\
\text { NITC-1304 }\end{array}$} \\
\hline \multicolumn{3}{|c|}{$\begin{array}{l}\text { 9. Performing Organization Name and Address } \\
\text { University of Texas at Arlington } \\
701 \mathrm{~S} \text { Nedderman } \mathrm{Dr} \\
\text { Arlington, TX } 76019\end{array}$} & \multicolumn{2}{|c|}{$\begin{array}{l}\text { 11. Contract or Grant No. } \\
\text { NITC-1304 }\end{array}$} \\
\hline \multicolumn{3}{|c|}{$\begin{array}{l}\text { 12. Sponsoring Agency Name and Address } \\
\text { National Institute for Transportation and Communities (NITC) } \\
\text { P.O. Box } 751 \\
\text { Portland, OR } 97207\end{array}$} & \multicolumn{2}{|c|}{$\begin{array}{l}\text { 13. Type of Report and Period } \\
\text { Covered } \\
\text { Final report } 9 / 2019-11 / 2021\end{array}$} \\
\hline \multicolumn{5}{|l|}{ 15. Supplementary Notes } \\
\hline \multicolumn{5}{|c|}{$\begin{array}{l}\text { Mobility disparities among older adults affect their ability to travel and access services. This project seeks to understand challenges, } \\
\text { barriers, and gaps that older adults experience, and develop forms of assistance or educational strategies to fill the varying mobility } \\
\text { gaps and meet mobility needs. This study characterizes older adults' use of existing and potential transportation options, including } \\
\text { conventional transit, paratransit, and ride-hailing systems, based on surveys collected from } 146 \text { low-income older adults in Dallas, } \\
\text { TX. Using the survey data and interview data, we develop two mathematical modeling (a Latent Class Cluster Analysis and agent- } \\
\text { based modeling (ABM)) and conduct content analysis to understand low-income older adults' mode choice decisions, adoption } \\
\text { likelihoods based on their barriers to existing mobility options, and socioeconomic characteristics. Three primary personas are } \\
\text { identified as the voice of the most vulnerable non-driver, community-dwelling older adults. The quantitative mapping of their needs to } \\
\text { the transportation options available to them (public transit, paratransit, taxi, ride share, and rides with family and friends) indicates } \\
\text { that none of the existing options meets all of their mobility needs. Through the interviews during the pandemic, the research team } \\
\text { found that both drivers and non-driver older adults reduced their trip frequency and depended on family and friends for essential } \\
\text { needs. In particular, older adults developed their fear of using public transit and paratransit because they were concerned about } \\
\text { other passengers not maintaining social distance. One of the noticeable differences is that older adults started to use ride-hailing } \\
\text { services and some even preferred it to public transit. Perceptual and knowledge barriers appear to be reduced to adopt ride-hailing } \\
\text { although financial and technology barriers still exist. Based on the findings, we discussed several strategies that can potentially } \\
\text { reduce observed barriers and challenges and enhance mobility to ultimately increase social equity across transportation- } \\
\text { disadvantaged populations, particularly among low-income older adults. }\end{array}$} \\
\hline \multicolumn{2}{|c|}{$\begin{array}{l}\text { 17. Key Words } \\
\text { Low-Income Older Adults, Mobility, Mode, Barriers, Equity }\end{array}$} & \multicolumn{3}{|c|}{$\begin{array}{l}\text { 18. Distribution Statement } \\
\text { No restrictions. Copies available from NITC: } \\
\text { www.nitc-utc.net }\end{array}$} \\
\hline $\begin{array}{l}\text { 19. Security Classification (of this report) } \\
\text { Unclassified }\end{array}$ & $\begin{array}{l}\text { 20. Security Classification (of this } \\
\text { page) } \\
\text { Unclassified }\end{array}$ & & of Pages & 22. Price \\
\hline
\end{tabular}




\section{ACKNOWLEDGEMENTS}

This project was funded by the National Institute for Transportation and Communities (NITC-RR-1304), a U.S. DOT University Transportation Center.

\section{DISCLAIMER}

The contents of this report reflect the views of the authors, who are solely responsible for the facts and the accuracy of the material and information presented herein. This document is disseminated under the sponsorship of the U.S. Department of Transportation University Transportation Centers Program in the interest of information exchange. The U.S. Government assumes no liability for the contents or use thereof. The contents do not necessarily reflect the official views of the U.S. Government. This report does not constitute a standard, specification, or regulation.

\section{RECOMMENDED CITATION}

Hyun, Kate, Lee, Kathy, Caroline, Krejci, Oran Gibson, Nilufer and Saha, Troyee, Developing Strategies to Enhance Mobility and Accessibility for Community-Dwelling Older Adults. NITC-RR-1304. Portland, OR: Transportation Research and Education Center (TREC), 2021. 


\section{TABLE OF CONTENTS}

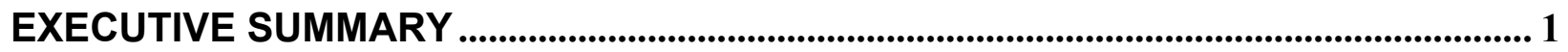

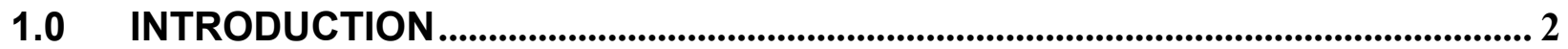

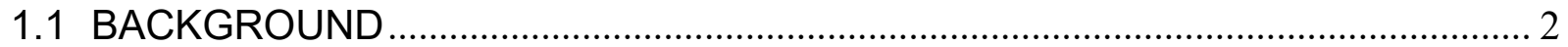

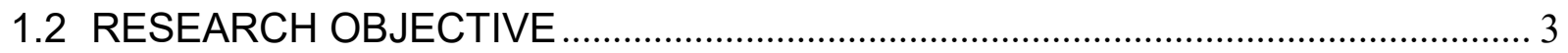

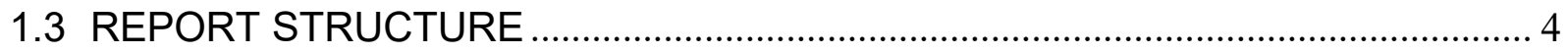

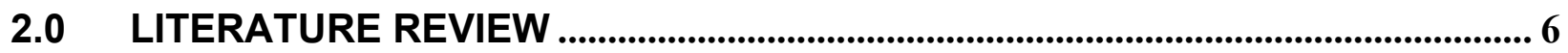

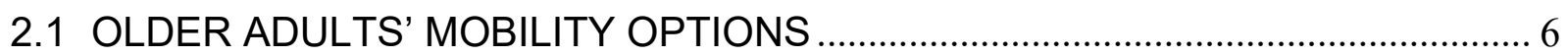

2.2 FACTORS IMPACTING OLDER ADULTS' MOBILITY ......................................... 7

2.2.1 Age and Health ..................................................................................................... 7

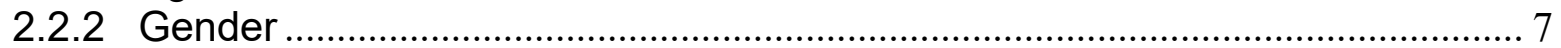

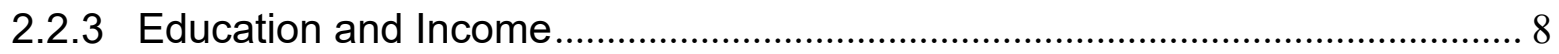

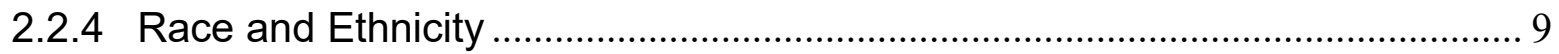

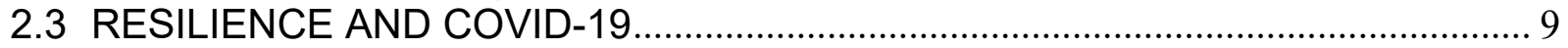

2.4 LITERATURE REVIEW ON MODELING STRATEGIES ....................................... 11

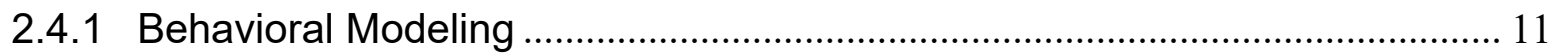

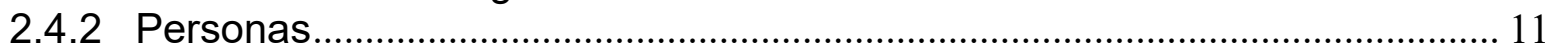

2.4.3 Agent-Based Modeling ………………............................................................. 12

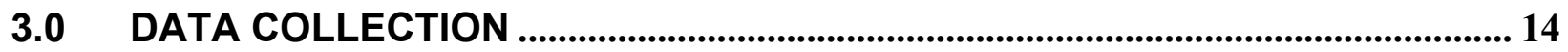

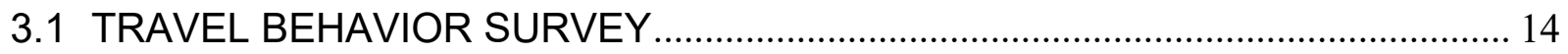

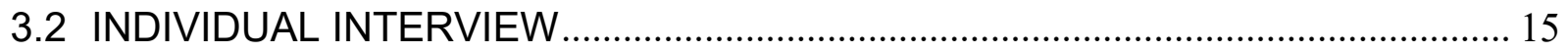

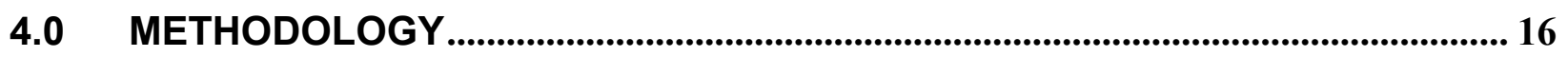

4.1 OLDER ADULTS BEHAVIORAL MODELING .................................................... 16

4.1.1 Latent Class Cluster Analysis to Understand Mode Choice Decisions ......... 16

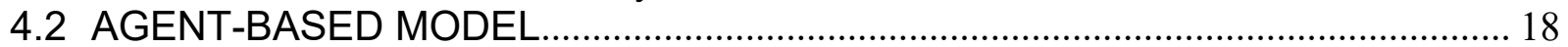

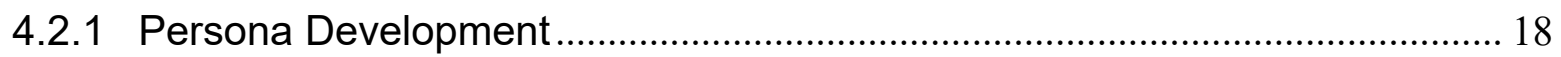

4.2.2 Agent Logic Development........................................................................... 19

4.3 QUALITATIVE ANALYSIS TO EXPLORE FACTORS ENHANCING RESILIENCE

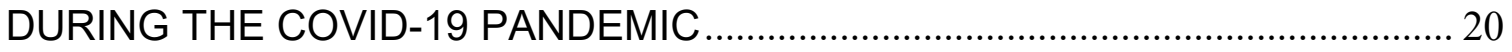

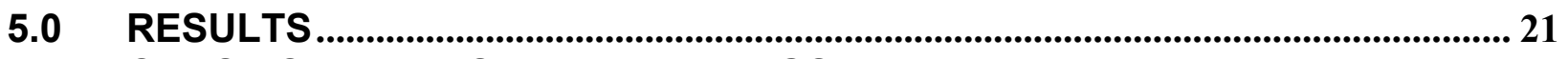

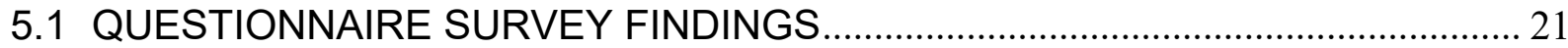

5.2 LATENT CLASS CLUSTER ANALYSIS TO UNDERSTAND MODE CHOICE

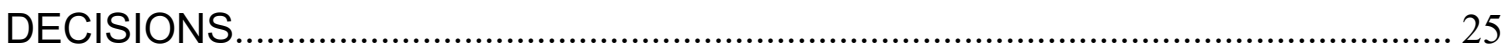

5.3 A STAKEHOLDER-DRIVEN APPROACH TO UNDERSTANDING THE TRANSPORTATION NEEDS ........................................................................... 30

5.4 PERSONA DEVELOPMENT FOR THE COMMUNITY-DWELLING OLDER

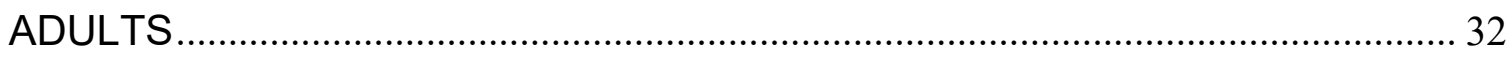

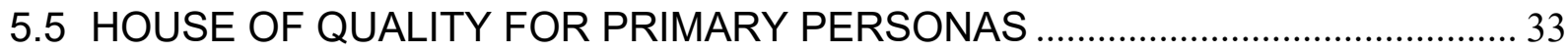

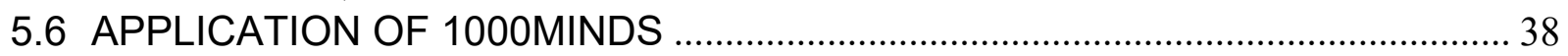

5.7 USING 1000MINDS RESULTS FOR AGENT-BASED MODELING...................... 48

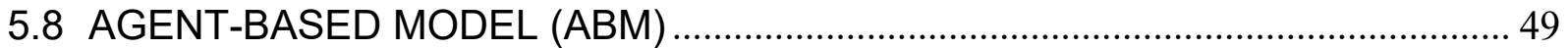

5.9 QUALITATIVE ANALYSIS TO EXPLORE FACTORS ENHANCING RESILIENCE DURING THE COVID-19 PANDEMIC. 


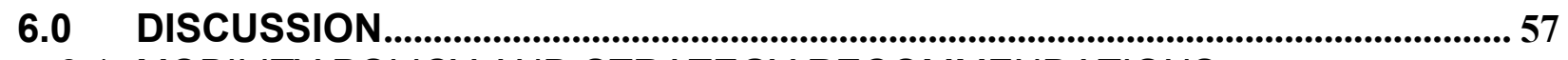

6.1 MOBILITY POLICY AND STRATEGY RECOMMENDATIONS ...........................5 57

6.1.1 Understanding Older Adults' Mobility Needs and Gaps in a Socioeconomic

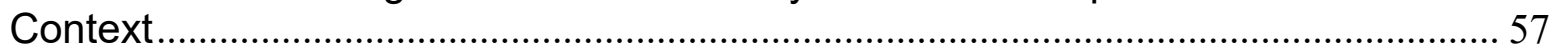

6.1.2 Transportation Education and Technology Training.......................................5 57

6.1.3 Practical Age-Friendly Guidelines and Implementation ................................5 58

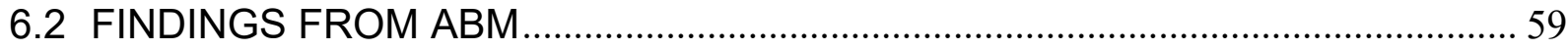

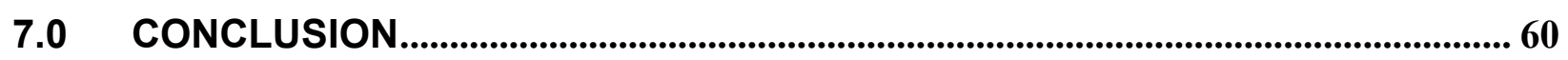

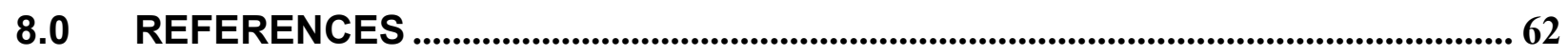

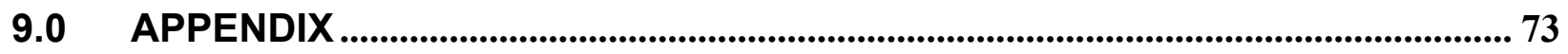




\section{LIST OF TABLES}

Table 5.1: Socioeconomic Characteristics and Health Profiles of the Survey

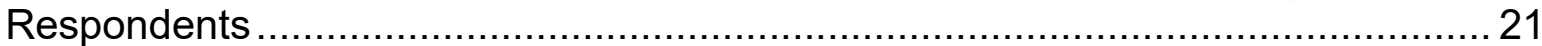

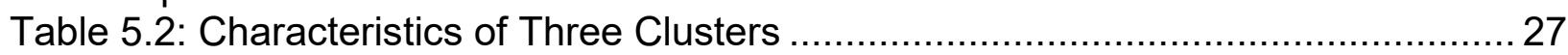

Table 5.3: Covariates of Class Membership Model .................................................... 30

Table 5.4: The Results of Cluster Analysis.............................................................. 31

Table 5.5: The Transportation Needs of the Primary Personas in Their Own Words .... 34

Table 5.6: Importance Ratings of Primary Persona Needs .................................... 35

Table 5.7: The Criteria and the Levels of Each Criterion for the 1000minds Trade-offs 38

Table 5.8: Criterion Levels of Each Transportation Option ........................................ 41

Table 5.9: Criteria Weights and Utilities for Elizabeth........................................... 43

Table 5.10: Criteria Weights and Utilities for Cassandra ....................................... 44

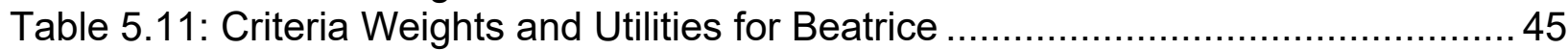

Table 5.12: Agents' Monthly Grocery Trip Schedules ...........................................49

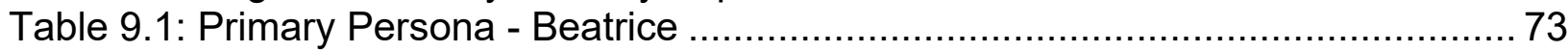

Table 9.2: Primary Persona - Cassandra ........................................................ 74

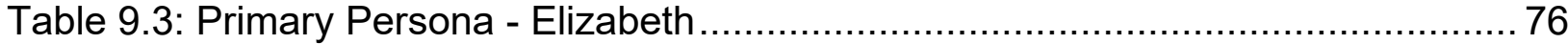

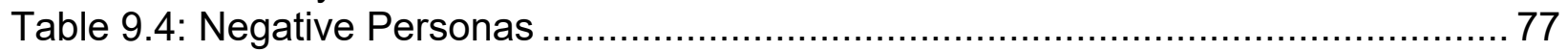

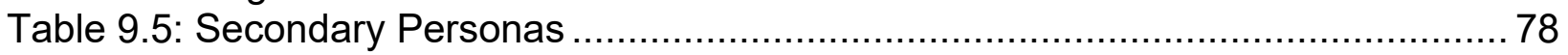




\section{LIST OF FIGURES}

Figure 4.1: A Graphical Framework of LCCA ...................................................... 17

Figure 4.2: The Sequence of Steps in Performing the PAPRIKA Method in 1000minds Software

Figure 5.1: Current Mode Users (left) and Preferred Mode Choice for Non-Drivers (right) .

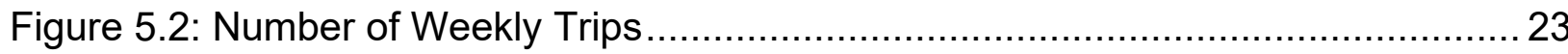

Figure 5.3: Importance of Services for Independent Living ……........................... 23

Figure 5.4: Comparisons of Concerns Between Drivers and Non-Drivers.....................2 24

Figure 5.5: Resources to Obtain Transportation Information................................... 25

Figure 5.6: House of Quality for Older Adult Transportation...................................... 33

Figure 5.7: Example of a Trade-off in 1000minds ............................................. 42

Figure 5.8: Ranked Transportation Options for Elizabeth...................................... 46

Figure 5.9: Ranked Transportation Options for Cassandra .................................... 47

Figure 5.10: Ranked Transportation Options for Beatrice ...................................... 48

Figure 5.11: Primary Personas' Satisfaction with Each Transportation Option .............50

Figure 5.12: Primary Personas' Satisfaction with Each Transportation Option After Improvements 


\section{EXECUTIVE SUMMARY}

Transportation is essential for older adults to provide a social link between home and community and to enable access to living essentials, such as groceries and medicine. This study seeks to understand transportation access, opportunities, and barriers faced by older adults, and investigate how transportation strategies and planning policy can better shape their mobility options. While significant recent research has focused on developing various mobility alternatives for all people, the policy recommendations to support such services to older populations remain unclear.

This study proposes a research collaboration between a transportation engineer, an industrial engineer, and a social worker, with an aim to enhance the impacts of transportation policy and planning on the mobility of older adults. We seek to determine the degree to which educational tools or information reduces any technology barriers to access new, alternative transportation services and how institutional supports, such as providing volunteer-based, on-demand ride-hailing, can promote mobility of communitydwelling older adults. We conducted a survey and in-depth interviews with older adults participating in home- and community-based programs (e.g., caregiver support program, elder financial safety center, retired senior volunteer programs) to understand their mobility needs, the usage of available transportation options, potential barriers, and assistance they expect from public or private entities. Using the survey and interview data, the research team developed two behavioral modeling - Latent Class Cluster Analysis and Persona Development - to understand mobility barriers, gaps, and behaviors among older adults. The developed modeling identifies the relationships among respondents' mobility, neighborhood environments, and accessible transportation service. Lastly, an agent-based model will be developed to predict the impact of enhanced policy and planning strategies on mobility outcomes for older adults.

The results of this study provide policymakers with actionable strategies for improving mobility for community-dwelling older adults, thereby improving their quality of life. The proposed project is closely addressing social equity in transportation access across older populations and identifying strategies that can improve mobility and access among this transportation-disadvantaged population. 


\subsection{INTRODUCTION}

\subsection{BACKGROUND}

Mobility is a critical element of one's quality of life, regardless of one's age. However, aging has been linked to a decrease in travel activities including driving and walking. The National Household Transportation Survey (NHTS) found that $21 \%$ of Americans age 65 and over do not drive because of health reasons and safety concerns (Marx et al., 2010). According to the U.S. Census Bureau (2015), adults aged 65 or older accounted for $15 \%$ (46 million) of the population in 2014 , and this is projected to increase to $21 \%$ ( 74 million) by 2030 . Maintaining mobility for older adults is critical, as it helps them to maintain their independence and quality of life. However, a number of barriers, such as decreased physical/mental capabilities associated with aging, transportation costs, and inadequate transportation options, may preclude them from driving or using other transportation options. While some older adults are able to rely on their family members or friends to go shopping and run errands, others experience access challenges, including unavailability, unawareness, and unaffordability, to the existing transportation options. This is particularly problematic in urban areas where a shortage of affordable housing located near transit, retailers, and other services forces low-income older adults to live in resource-scarce neighborhoods (e.g., food deserts). The advent of shared mobility, such as ride-sharing, car-sharing, and on-demand paratransit, could offer a potential solution for transportation-disadvantaged older adults. However, their willingness and ability to adopt mobility alternatives remain unclear since many potential barriers exist, including a lack of knowledge about technology related to a smartphone application, unbanked or limited electronic payment options, and negative perceptions (e.g., fears) about shared vehicles.

Society recognizes the importance of mobility and has made efforts to assist older adults through various transit programs (e.g., ride-share and on-demand vanpool) to enable older adults to participate in civic, economic, and social activities (Spinney et al., 2009). Public policy and programs for older adults, such as the age-friendly initiative, focus on creating a place that allows individuals to age in place (Greenfield, Oberlink, Scharlach, Neal, \& Stafford, 2015). While an age-friendly community aims to design a safe and secure place for all people, it also highlights affordable and appropriate transportation options to help older adults maintain quality of life (AARP, 2016). According to a survey conducted in a community in Dallas, TX, $87 \%$ of adults age 55 and over drive themselves to maintain daily activity, while $25 \%$ walk or get a ride, and only $5 \%$ use paratransit service (AARP, 2016). The AARP survey results reveal the importance of mobility alternatives because the overreliance on driving could significantly impact their independence when they experience temporary setbacks or are no longer able to drive. Lastly, the survey respondents highlighted that affordable and safe alternative transportation services for older adults and those with disabilities remains important, because many depend on driving for transportation. In April 2019, 
the City of Dallas responded and announced a broad goal to provide residents with the information and educational tools they need to make informed travel choices through a wide range of transportation options, including (i) ride-sharing services (e.g., Uber or Lyft); (ii) door-to-door or curb-to-curb mini buses; (iii) volunteer driver programs; and (iv) transportation voucher programs providing financial support for low-income populations (National Aging and Disability Transportation Center, 2019). However, scant research has evaluated the effectiveness of these enhanced policy and planning strategies on improving the mobility of older individuals. Transportation researchers have rather focused on developing operating strategies to improve the quality and frequency of mobility-enhancing services. Such strategies often fail to understand individual-level requirements and barriers. For example, one study investigating a ride-sharing service for older adults revealed that, while technological knowledge played an important role (Lian \& Yen, 2014), other significant factors, including disabilities, neighborhood insecurity, a lack of resources, and cost affect active utilization of the new ride-sharing services. The proposed project will fill the gap in the literature by focusing on community-dwelling older adults and understanding their differing mobility needs and barriers, and investigating how transportation strategies and planning policy can better assist their mobility.

\subsection{RESEARCH OBJECTIVE}

This study seeks to understand what form of assistance or educational strategies can fill the varying mobility gaps and meet the needs of older adults. Local stakeholders, such as the City of Dallas, are continually striving to provide a wide range of transportation options for older adults. Our work will not only provide the stakeholders with more detailed information about older residents' preferences and unmet needs, but it will also provide strategic solutions to enhance their mobility based on a simulation-based analysis. The overarching goals of this research project are (i) to understand transportation activities, needs, and barriers for community-dwelling older adults; (ii) to develop a suite of potential planning strategies to reduce barriers and enhance mobility of older adults; and (iii) to investigate the potential impacts of these strategies for a given metropolitan region.

Specific research objectives include:

1) To identify available transportation access and mobility options for older adults in the greater Dallas, TX, area, including conventional transit systems and new emerging mobility alternatives such as ride-sharing and on-demand paratransit systems;

2) To evaluate community-dwelling older adults' awareness of each of these mobility options, their willingness to utilize them, actual usage and frequency of available transportation options, and any associated challenges and barriers to accessibility; 
3) To develop policy and planning strategies to enhance the older adults' overall mobility considering their mobility and socioeconomic profiles of neighborhood environments;

4) To develop a simulation tool to predict the impact of the policy and planning interventions on older adults' mobility and accessibility; and

5) To evaluate overall community and individual mobility and accessibility changes resulting from the developed planning strategies.

The findings from survey and behavioral modeling are expanded through the development of an agent-based model (ABM), which performs experiments that predict the impacts of potential transportation policy interventions on older adults' mobility. ABM is a computational simulation modeling method where software agents represent autonomous individuals who are capable of making decisions, interacting and collaborating with other agents, and adapting over time to meet their objectives. These individual-level interactions and adaptations can lead to changes in overall system behavior that are often difficult to predict simply by examining the behavior of the individuals. Thus, ABM is well suited to understanding and predicting the behavior of the complex systems that support urban mobility, which consist of many heterogeneous and interacting stakeholders with behaviors that evolve over time (Maggi \& Vallino, 2016). Rather than using a statistical aggregate to represent travel behaviors, ABM more realistically represents individuals as discrete heterogeneous agents. However, traditional discrete-choice statistical models of travel behavior can be integrated into ABMs to inform agent decision rules (Shiftan et al. 2015). ABM has been used to study urban mobility, typically with an aim of predicting individuals' transport mode choices subject to public policies that are intended to reduce congestion, reduce greenhouse gas emissions, and increase public transit use. However, the literature describing applications of ABM to the mobility requirements of older adults is sparse. Recently, Yang et al. (2018) developed an ABM to study the effects of urban walkability and transit availability on the mental health of older adults with heterogeneous mobilityrelated attributes (e.g., age, car ownership, income level). The proposed project leverages the capabilities of ABM to realistically simulate the dynamic and heterogeneous individual travel behaviors of older adults in an urban setting, as well as the social interactions that occur among older adults that may influence their travel behaviors. The proposed model assists in transportation planning by predicting individual and community-level responses to different transportation policy levers, as well as the overall impacts on older adults' mobility.

\subsection{REPORT STRUCTURE}

This report is structured as described herein. Chapter 2 will discuss previous studies addressing the mobility options for older adults, factors impacting mobility of older adults, the resilience of older adults during COVID-19, behavioral modeling, and agentbased modeling. Chapter 3 will discuss data collection techniques, Chapter 4 will present methodologies of data analysis using Latent Class Cluster, stakeholder-driven 
approach, agent-based modeling, and qualitative analysis, followed by Chapter 5 discussing the results of each modeling. Chapter 6 will provide discussion and recommendations based on the modeling findings, and finally, Chapter 7 provides the conclusion. 


\subsection{LITERATURE REVIEW}

\subsection{OLDER ADULTS' MOBILITY OPTIONS}

For older adults, transportation is an important predictor for independence, quality of life, and personal well-being (Bryanton et al., 2010). Access to safe and reliable transportation services is considered the most important factor in determining the livability of a community for older adults (AARP, 2016). However, many older adults, regardless of their socioeconomic characteristics, tend to rely on driving until they are no longer safe behind the wheel since they lack knowledge of or interest in alternative transportation options (Anstey et al., 2006).

Public transportation, the second most common alternative for those with or without private vehicle ownership, is considered an affordable transportation mode for particularly low-income older adults. Studies showed that public transit is more popular among minorities and low-income populations (Kroesen et al., 2017), compared to nonHispanic Whites and people with high income (Hess, 2009). Public transit access to medical services and social activities gives them a sense of independence and freedom (Kiuchi et al., 2020). However, public transit services often lack practicality and convenience for older adults who live in suburban or rural areas (Anderson, 2016). In addition, long walking distances to transit stops, limited operation hours, inflexible schedules and routes, uncomfortable rides, and difficulties in physically entering and exiting the public vehicles are major barriers for older adults to use public transit services (Coughlin, 2001). There are also mobility services operated by government agencies, transit operators, communities, and private organizations (e.g., paratransit, community/religious center volunteer transportation) that exclusively serve older adults or people with disabilities. Although low-income older adults especially welcome this paratransit service (AARP, 2016), high demand and inflexible operations often resulted in overbooking problems, which makes it very difficult for older adults to reserve the service (Miah, 2020).

Alternatively, low-income older adults may rely on family members or friends for mobility. Although it appears to be the most familiar and convenient mode for older adults who do not drive or do not make regular daily trips, some older adults are disinclined to adopt this option because it makes them feel dependent and beholden to others (Coughlin, 2001). Formal ride-hailing businesses, such as Uber or Lyft, may appeal to older adults by providing a similar level of convenience with curb-to-curb or door-to-door services that also include wheelchair accessible vans. However, researchers documented that high cost and safety concerns hinder some older adults from adopting such services (Coughlin, 2001). Lack of knowledge (Vivoda et al., 2018) and affordability (Robinson et al, 2020) also demotivate low-income older adults to use ride-hailing services. 


\subsection{FACTORS IMPACTING OLDER ADULTS' MOBILITY}

The population of older adults in the U.S. is more heterogeneous than ever, resulting in diverse mobility and transportation needs. Therefore, one of the main goals of using personas in this study is to identify the most vital factors affecting the mobility needs of the most vulnerable older adults from a diverse population. According to the gerontology and transportation literature, the most frequently studied demographic factors impacting older adults' mobility include age, health, gender, education, income, race, and ethnicity.

\subsubsection{Age and Health}

While age is not the sole predictor of older adults' transportation mode choices, their preferences evolve and change as they step into older age cohorts (Kim, 2011). In particular, older adults reduce their driving activities incrementally until driving cessation (Rosenbloom, 2003; Rimmö \& Hakamies-Blomqvist, 2002). Younger older adults, aged 65 to 75 , are not significantly different from adults aged 18 to 59 in terms of car usage, and they travel longer distances by car after entering retirement (Alsnih \& Hensher, 2003). By contrast, Rosenbloom (2003) indicates that $80 \%$ of those aged 85 and over only drive for half of their trips and avoid driving at night, during hazardous weather conditions, and at rush hour. Compared to previous generations, older adults today are expected to experience longer durations of relative wellness while coping with multiple chronic diseases (Coughlin, 2009). However, it is inevitable that older adults will experience a decline in physical and cognitive health with increasing age, and vision impairment and slowed reaction time will eventually lead to driving cessation (Adler \& Rottunda, 2009). However, the health of older adults in the same age cohorts differs greatly (Kim \& Ulfarsson, 2004), and their transportation preferences and decisions depend on their self-perceived health, rather than their chronological age.

In general, as older adults age, they tend to avoid using public transportation (Rosenbloom \& Waldorf, 2001). The trouble of walking to a bus stop outweighs the difficulties of driving a car (Rosenbloom, 2003; Hjorthol, 2013). Other health-related reasons to avoid public transportation include the inability to maintain balance during rapid acceleration and deceleration and issues with getting on and off the vehicle (Coughlin, 2001). As a result, many older adults persist with driving until they are no longer able to operate a car safely. According to Adler and Rottunda (2006), older people cease driving by self-acknowledging the hazardous impacts of driving with their declining health, or they are influenced by their family and friends to give up driving. At that point, they may consider using special transportation services, such as paratransit and senior vans, to meet their transportation needs (Kim, 2011).

\subsubsection{Gender}

Research has determined that older women have less mobility than men primarily because they outlive their male counterparts (Kim, 2011; Hjorthol, 2013; Rimmö \& Hakamies-Blomqvist, 2002; Kim, 2003). As women live longer, their disability rate 
increases (Alsnih \& Hensher, 2003), which creates a greater need for transportation assistance. However, older women are reluctant to utilize public transportation and walking after giving up driving (Kim, 2011), and women aged 65 and older are twice as likely to live alone, due to being widowed and not having children nearby to live with them (Rosenbloom \& Winsten-Bartlett, 2002).

Older men are less likely than older women to voluntarily cease driving (Hjorthol, 2013). Older women tend to self-regulate and reduce their driving activities (Bauer, Adler, Kuskowski, \& Rottunda, 2003), and they also cease driving sooner than men (Freund \& Szinovacz, 2002). However, according to Edwards, Bart, O'Connor, \& Cissell (2010), the rates of driving cessation among modern cohorts of older women are declining, with women managing most of the household activities outside the home that require travel (Coughlin, 2009). In addition, $70 \%$ of women work either part time or full time and, therefore, engage in more driving, thanks to higher professional engagement, income, and education (Bauer et al., 2003).

\subsubsection{Education and Income}

Transportation mobility of older adults is positively correlated with their education levels (Kim, 2003). However, while the general assumption is that income level is strongly associated with education level, Kim also determined that income is not significantly associated with the mobility of older adults. Coughlin (2009) explains this contradiction: older adults with more education are engaged in community and volunteer activities, visit family and friends, and go to libraries for their self-development. Therefore, advanced levels of education are associated with larger social networks (Marin-Lamellet \& Haustein, 2015), which encourage older adults to undertake additional trips, rather than traveling only for basic needs. In another study, Kim (2011) indicated that the household income of the elderly is often related to education levels. Regardless of the relationship between education and income levels, many studies show that low income leads to mobility deficiency (Rosenbloom \& Waldorf, 2001; Rosenbloom \& WinstenBartlett, 2002; Dupuis, Weiss, \& Wolfson, 2007; Ramsay, 2008).

Older adults with incomes of $\$ 35,000$ or higher prefer to drive their personal cars, or they will utilize carpools and vanpools if their health condition limits their driving abilities (Kim \& Ulfarsson, 2004) - public transportation is their least-preferred option. By contrast, older adults with incomes of $\$ 20,000$ or less are less likely to drive a car (Rosenbloom \& Waldorf, 2001), because they cannot afford the cost of owning, maintaining, and operating a car even if they are still able to drive (Rosenbloom, 1988). Regardless, most non-driving older adults are likely to be among the oldest, living alone and having less than 14 years of education (Anstey, Windsor, Luszcz, \& Andrews, 2006). Women are more likely to live in poverty and, therefore, lack transportation options that enable them to have access to the services and goods they need (Rosenbloom \& Winsten-Bartlett, 2002). Compared to men, older women have relatively more financial vulnerability, with limited disposable income after retirement. Hence, this income inequality creates a transportation gender discrepancy (Dupuis, Weiss, \& Wolfson, 2007). 


\subsubsection{Race and Ethnicity}

Race and ethnicity have an important impact on the mobility of older adults and their transportation activities and preferences. White older adults make longer and more frequent trips than older adults from other racial and ethnic backgrounds (Rosenbloom, 2003). In the case of driving cessation, White older adults favor getting a ride with a friend or family member over using public transportation or walking (Kim, 2011), while Asian-American and Black older adults are likely to choose public transportation more often than older White people (Rosenbloom \& Waldorf, 2001). Freund and Szinovacz (2002) found that Black and Hispanic older adults are more likely to avoid driving a car and prefer to limit their driving to short distances. In addition, older Black adults lean towards using paratransit and senior vans, and older Hispanic adults are more likely to use public transportation when they can no longer drive (Kim, 2011).

There is a significant mobility difference between men and women across racial and ethnic groups (Rosenbloom, 2003). Older Black men travel 32\% less than older White men, and older White women make trips three times more frequently than older Black women (Kim, 2003). This discrepancy is observed across all income levels.

Furthermore, older Hispanic women with less than $\$ 20,000$ in annual household income are $50 \%$ less likely to make daily trips than older Black women (Rosenbloom \& Waldorf, 2001).

\subsection{RESILIENCE AND COVID-19}

Older adults have been perceived as the group most vulnerable to the effects of COVID-19, with high mortality and infection rates (Shahid et al., 2020). Prior to COVID19 , social isolation was already established as a major health concern for older adults that results in an increased risk of cognitive decline, mortality, and re-hospitalization (Nicholson, 2012). Researchers argue that social distancing and stay-at-home orders have disproportionately affected older adults, making this population more socially isolated than ever (Morrow-Howell et al., 2020; Berg-Weger \& Morley, 2020).

Due to fears of the virus as well as social distancing guidelines, older adults were likely to struggle with fulfilling spiritual and emotional needs (Vernooij-Dassen et al., 2020). Moreover, physical activity in the older adult population was affected, with $53.4 \%$ of respondents aged 70 and over reporting a decrease in exercise since COVID-19 began (Central Statistics Office, 2020). Hare et al. (2013) and Levia et al. (2017) argued that the effects of depression on cardiovascular health were coupled with sedentary behaviors. The combination of decreased social interaction and physical exercise brought on by COVID-19 puts the older adults at a much higher risk of overall health (Goethals et al., 2020). While many researchers have documented devastating impacts of the COVID-19 pandemic on older adults' health and well-being, there is a lack of research identifying protective factors at varied levels in order to support older adults in their resilience against various stressors during COVID-19. 
Resilience is defined as a "dyadic interdependence" of individual and environmental factors (Aldwin \& Igarashi, 2012). The ecological model of resilience includes individual (e.g., individual characteristics), contextual (e.g., family and friends), and sociocultural (e.g., institutions or community) resources to understand how well equipped an individual is to cope with novel stress (Aldwin \& Igarashi, 2012). According to this model, individual resilience involves not only individual coping strategies, but also the individual's environment, which may enable or impede individuals' ability to apply those coping skills. For example, individuals with poor health, limited social networks, or low socioeconomic status tend to lack the opportunity to utilize individual coping skills, not necessarily due to limited capability of individuals but rather due to their environment (Aldwin \& Igarashi, 2012).

Technology has been perceived as a resource to help individuals cope with many of the challenges associated with the COVID-19 pandemic (Morrow-Howell et al., 2020). Older adults' use of technology on a daily basis has been linked to higher rates of self-efficacy and coping strategies for stress (Yagil et al., 2016). However, older adults who have difficulty with technology or those who do not have smartphones disproportionately experience isolation (Seifert et al., 2021). Morrow-Howell et al. (2020) describe the pandemic as a "sink or swim moment" for older adults' relationship with technology, suggesting the importance of focusing on vulnerable older adults who were unable to utilize technology for information, socialization, and remote appointments.

In addition, Morrow-Howell et al. (2020) argued that family can play an important role in increasing the health and well-being of older adults during COVID-19, particularly for older adults with physical and functional limitations who have high dependence on outside help. Furthermore, the relationship between poor built environments and high COVID-19 death rates appeared to be positive (Hu et al., 2021). Impoverishment of one's neighborhood (e.g., poverty or crowded homes) results in poor built environments, which makes low-income individuals who predominantly live in these neighborhoods highly vulnerable to COVID-19 outcomes (Emeruwa et al., 2020).

Most available data focuses on capturing changes in physical activity and social behaviors, but fails to explore subjective experiences of older adults from marginalized backgrounds regarding their day-to-day lives during the pandemic (Woods, et al., 2020; Berg-Weger \& Morely, 2020). As much as marginalized populations were disproportionately affected by the COVID-19 pandemic (Kantamneni, 2020), it is critical to present primary data showing some challenges that they are experiencing.

In particular, Whitehead and Torossian (2020) highlighted older adults' coping behaviors in response to COVID-19-related stressors. By categorizing factors that older adults might have found joyful and comforting in the midst of COVID-19, Whitehead and Torossian indicated coping resources such as family, faith, and self-care. However, this study lacked in-depth information from voices of older adults and addressed the needs of identifying various levels of protective factors in place among marginalized older adults to combat various challenges associated with COVID-19. This study fills the gap in the current state of knowledge by conducting in-depth interviews to explore daily 
activities of marginalized older adults during the COVID-19 pandemic when there was statewide quarantine enforcement to understand how they cope with various challenges. Using a general inductive approach, we identified protective individual, social, and environmental factors that support marginalized older adults from such adversity.

\subsection{LITERATURE REVIEW ON MODELING STRATEGIES}

\subsubsection{Behavioral Modeling}

Individuals' beliefs and attitudes significantly contribute to their transportation choices. However, such abstract measures are difficult to recognize and isolate from other observable features. In transportation decision-making, people who do not have routine trip behaviors are more likely to be open to information about new options. In contrast, strong habitual behaviors keep people from seeking new knowledge because they are heavily driven by their own habitual choices (Verplanken et al., 1997). The constraints of time, past behaviors, and a lack of alternatives are significant attitudinal determinants of mode choice (Burian et al., 2018). Attitudinal features, such as comfort, convenience, safety, and cost, play more important roles in mode choice behaviors than demographic and network variables (Dobson \& Tischer, 1977).

Modeling techniques, such as a regression, multinomial logit, or nested choice models, were used to quantify the impact of attitudinal attributes on travel mode or route choice behaviors. Many researchers used a latent variable in a statistical model to understand the role of abstract factors in transportation behaviors (Rahimi et al., 2020). Ben-Akiva et al. (1999) used a latent variable in a mode choice model linked with utility and extracted unobservable features, such as degree of satisfaction, preference for a choice, and motivation. Paulssen et al. (2014) used a variable capturing value and attitude in a multinomial discrete choice model. They analyzed the influence of values, such as power, hedonism, and security, and extracted travelers' attitudes towards flexibility, comfort, convenience, and ownership. Kroesen et al. (2017) addressed the importance of direction of causation between attitudes and travel behaviors to understand if behaviors change one's attitude or vice versa. Their findings indicated that a person's attitude is maintained and bounded to their physical and economic conditions.

\subsubsection{Personas}

The concept of personas originated in the field of interaction design as essential building blocks of software product development. In his seminal book Inmates Are Running the Asylum, Cooper (2004) defines personas as "hypothetical archetypes of actual users." According to Pruitt and Adlin (2006), personas are "fictitious, specific, concrete representations of target users." The role of personas is to address the need to represent users' personalities, perspectives, attributes, and goals (Cooper, Reimann, Cronin \& Noessel, 2014). In human-centered design, personas eliminate the "elastic 
user" phenomena, which is the tendency of designers to incorporate their own (often mistaken) perceptions of users into the product (Cooper, 2004). For this reason, personas support system design decisions in many different fields. For example, Sim and Brouse (2014) integrated personas into requirements engineering for an improved understanding of user needs, behaviors, tasks, goals, and requirements in a web applications domain. Miaskiewicz and Kozar (2011) conducted a Delphi study with a group of panelists who were experts in personas, which produced an extensive list of the benefits of using personas, including an emphasis on users, a prioritization of service and user requirements, the prevention of self-referential design, and greater empathy for users. Thus, using personas to address the mobility needs of communitydwelling older adults centers the focus on these individuals and their mobility goals, rather than the constraints emerging from transportation policies, budgets, providers, designers, and other stakeholders involved in decision-making. Personas can be used to prioritize the most vulnerable older adults, whose mobility needs require immediate attention to make their basic needs easily accessible and improve social aspects of their lives. In addition, personas can help to determine exact mobility problems of older adults and define the scope of these problems. Furthermore, the use of personas allows established organizational assumptions about older adults' mobility to be challenged. By creating a shared knowledge of older adults, personas can provide intuitive understanding and improved communication among stakeholders while creating awareness of how older adults' mobility needs are different from stakeholders' selfperceived understanding of those needs. Moreover, personas can help to create emotional identification with older adults, which can unify decision-makers in addressing their mobility needs. These benefits emerge from the underlying strength of personas in organizing and presenting raw research data of a diverse population in a way that is the most natural to the human mind.

Reeder, Zaslavksy, Wilamowska, Demiris\& Thompson (2011) utilized personas to gain insights into the capabilities of members of the oldest age group as information technology (IT) users. The study produced a set of design recommendations addressing the needs and obstacles of older adults while accessing care services via IT. Wöckl et al. (2012) created personas representing 12,500 senior adults aged 60 and older from northern, central, and southern regions of Europe in order to create a common understanding of these senior citizens among developers of information and communications technology (ICT) solutions for older adults. The tool developed in this study is a "personas filter" which provides 30 basic personas representing European senior citizens, while allowing developers the capability of customizing according to the needs of persona users. This layered persona approach eliminates persona creation from scratch for each different ICT solution for older adults.

\subsubsection{Agent-Based Modeling}

Agent-based modeling (ABM) is a computational simulation modeling method which consists of heterogenous agents interacting autonomously with each other and their environment, based on their characteristics and independent behaviors in an artificial environment (Axtell \& Epstein, 1994; Macal, 2016). As a result of these interactions, 
agents can acquire new knowledge, change their behaviors, and adapt to the changing population dynamics. Since the agent-based modeling describes a system from the viewpoint of its constituent units, the bottom-up modeling approach is the most important feature of ABM (Bonabeau, 2002). The characteristics, interactions, and dynamic behaviors of these constituent units (agents) may cause unpredictable and counterintuitive global system behaviors, which lack rational explanation from the agentlevel activities, is called emergent phenomena (Bonabeau, 2002a). Therefore, agentbased modeling is suited to study complex adaptive systems and emergent phenomena (Klügl \& Bazzan, 2012).

The number of studies using ABM for older adults' transportation and mobility in urban settings for policy interventions is sparse. Yang et al. (2018) developed a pilot ABM to understand the impact of daily transport activities and neighborhood environment on depression of older adults living in urban areas. Three interventions and the combinations of these interventions are introduced to this model to understand their effects on older adults' depression. The first intervention aims to promote walkability by increasing neighborhood safety. The second intervention reduces bus fares, and the third intervention increases the number of bus lines. Implementing a single intervention did not alleviate older adults' depression as much as the combination of interventions. The most effective scenario in reducing older adults' depression were the combination of improved walkability, reduced fares, and increased bus lines. Zhang et al. (2018) used an exploratory ABM to understand older adults' accessibility to oral health screening and treatment facilities via transportation networks in northern Manhattan, New York City. The purpose of the model is to provide decision support to health planners and policymakers for their endeavors in enabling oral health equity to older adults. The results demonstrate that the proximity of oral health services impacts older adults' decisions to seek oral health services, and the social support in terms of transportation assistance encourages older adults to participate in preventive oral health screenings. 


\subsection{DATA COLLECTION}

\subsection{TRAVEL BEHAVIOR SURVEY}

This study administered a survey to 146 lower-income adults in Dallas, TX, aged 55 and older, between February and June 2020. As affordable public transportation options target senior citizens age 65 and older, this study focused on older adults as aged 65 and over. However, we also recruited adults aged 55 to 64 to distinguish how emerging seniors differently perceive or perform transportation activities compared to current older adults. In a partnership with a local organization providing resources and information for older adults and family caregivers located in Dallas, we used snowball sampling by recruiting participants from Foster Grandparent Program and Senior Companion Program of the AmeriCorps Seniors. In order to become volunteers in these two volunteer programs, volunteers have to be age 55 and older and not exceeding $200 \%$ of the federal poverty guidelines (AmeriCorps, 2020). The research team visited two volunteer trainings and invited potential participants. We also conducted a phone survey for those who were unable to participate in the survey during the in-person training. A total of 146 older adults participated in the survey, with $45.5 \%$ over the phone. All of the participants received a $\$ 5$ Walmart gift card as an incentive. This study was approved by the University of Texas at Arlington Institutional Review Board (\#20200034).

The survey questionnaire asked about overall transportation behaviors, options, and information regarding their mobility, health and well-being, as well as demographics, based on performance metrics identified from literature (Molin et al., 2016; Lee et al., 2019; Kroesen et al., 2017). Transportation behaviors included daily transportation activity (i.e., performed and missed trips for daily activities) and perceived barriers and concerns about existing mobility options, including personal vehicle, public transit, paratransit, ride from family/friends, and walk/bike. Trip frequencies on each mode recorded the average number of weekly trips, and were categorized into four groups more than 10 times, 6 to 10 times, 1 to 5 times, and never. The survey also asked for the likelihood that the participant would adopt a service in the future, and these responses were categorized into four groups - highly likely, likely, neutral, and unlikely. The survey also collected overall attitudes towards different mobility options by asking for participants' perceptions of each option to support their independent living, levels of familiarity, and awareness. We asked whether they obtained transportation information from local (in-person) or web-based resources. 


\subsection{INDIVIDUAL INTERVIEW}

Using a convenient sampling method, older adults with limited income were recruited from urban and suburban communities. We partnered with a local organization that serves older adults and their family members. Directors from federally funded volunteer programs (i.e., Foster Grandparents and Senior Companion Program) promoted this study in their volunteer groups. Inclusion criteria included: (1) being aged 55 and older; (2) having the ability to provide consent for themselves; and (3) being proficient in reading and writing in English. As these programs require older volunteers to have an income of up to $200 \%$ of poverty based on the Department of Health and Human Services poverty guidelines, we did not apply any specific income level as an inclusion criterion. Those who were interested in the study provided us with their name and contact information. Trained, female social work research assistants followed up to reiterate the purpose of the study and conduct the interview over the phone with individuals who agreed to participate in this study from July through August 2020. The participants provided consent at the beginning of the conversation and were asked to find a place where they feel comfortable sharing their lived experiences. As a result, 18 older adults participated in the interviews. During the data analysis, we were able to establish the repetition of responses, thus determining that saturation was reached (Power et al., 2015). Each interview lasted approximately 40-60 minutes and the participants received a $\$ 5$ Walmart gift card along with a copy of the consent form via mail. All of the interviews were conducted over the phone and audio-recorded for transcription. The audio files were transcribed verbatim by a professional company. 


\subsection{METHODOLOGY}

\subsection{OLDER ADULTS BEHAVIORAL MODELING}

\subsubsection{Latent Class Cluster Analysis to Understand Mode Choice Decisions}

A Latent Class Clustering Analysis (LCCA) facilitates latent characteristics in a behavioral choice model by investigating common underlying features that affect the behaviors. Recently, Molin et al. (2016) used LCCA to understand multimodal users' mode choice behaviors and influencing factors. Lee et al. (2019) compared travel behaviors between millennials and Generation X using LCCA, and found that economic factors and land use attributes affected multimodality behaviors of millennials.

Generally, a cluster analysis classifies objects into groups based on their relative similarity and provides memberships into the cluster for individual attributes. Latent Class Cluster in particular categorizes objects to mutually exclusive unmeasured (latent) classes based on exhibiting patterns of categorical and/or continuous indicators that describe their relations to the categories. LCCA extracts a significant association between multiple indicators and allocates each object to an underlying subgroup called a latent class cluster. As a result, statistically independent observations (i.e., individuals' attributes) that share a homogeneous nature belong to the same class. The assumption of independence within a cluster allows the correlations between observations to be explained by latent variables (Vermunit \& Magidson, 2002). Moreover, LCCA produces a parsimonious model using statistical fit criteria like Bayesian information criteria (BIC) and Akaike information criteria (AIC) to ensure the clusters maintain stability in their estimations (Linzer \& Lewis, 2011).

With the assumption of conditional independence of the outcomes, $Y$, the probability density function of each class is given by the weighted sum of individual probabilities as expressed below (Molin et al., 2016; Vermunit \& Magidson, 2002; Linzer \& Lewis, 2011). The model includes two sets of parameters, where $\alpha_{c}$ is the prior probability to class $c$ and $\hat{P}\left(c_{n} \mid Y_{n p r}\right)$ denotes class conditional probability such that a subject in class $c$ gives $r^{\text {th }}$ outcome on $p^{\text {th }}$ manifest variable. Let $Y_{n p r}=1$ if a subject $n$ has a response $r$ to $p^{\text {th }}$ variable and $Y_{n p r}=0$ otherwise. If $\widehat{\alpha_{c}}$ and $\hat{P}\left(c_{n} \mid Y_{n p r}\right)$ are the estimates of $\alpha_{c}$ and $\theta_{c}$, respectively, the posterior probability after observing the responses on manifest variables for each individual belonging to a class $c$ is given by Bayes' formula,

$$
\begin{aligned}
& \hat{P}\left(c_{n} \mid Y_{n}\right)=\frac{\hat{\alpha}_{c} f\left(Y_{n} ; \hat{\theta}_{c}\right)}{\sum_{s=1}^{C} \hat{\alpha}_{s} f\left(Y_{n} ; \hat{\theta}_{s}\right)} \\
& \alpha_{c}=\alpha_{c}\left(X_{n} ; \beta\right)=\frac{e^{X_{n} \beta_{c}}}{\sum_{s=1}^{C} e^{X_{n} \beta_{s}}}
\end{aligned}
$$


Each individual $n$ has a probability of belonging to a particular group or class depending on the characteristics of the individual, which are known as covariates. Let $X_{n}$ represent the active covariates included in the model for individual $n . \beta_{c}$ is the vector of coefficients for $c^{\text {th }}$ latent class. For $M$ number of covariates, the length of coefficients with constants for the vector $\beta_{c}$ will be $M+1$. With the assumption that log-odds of latent class prior probabilities $\alpha_{c n}$ conditional on class $c$ are linear functions of the covariates, we obtain the following equation after simplification. The posterior probability with the estimates $\widehat{\beta_{c}}$ and $\hat{\theta}_{p c r}$ and combining equation (1) and (2) is given by,

$$
\hat{P}\left(c_{n} \mid X_{n} ; Y_{n}\right)=\frac{\alpha_{c}\left(X_{n} ; \hat{\beta}\right) f\left(Y_{n} ; \hat{\theta}_{c}\right)}{\sum_{s}^{C} \alpha_{s}\left(X_{n} ; \hat{\beta}\right) f\left(Y_{n} ; \hat{\theta}_{s}\right)}
$$

This study used a software package poLCA in R programming to categorize the behavioral manifest indicators, representing modality usages and adoptions (see Figure 4.1). The model further incorporates covariates or exogenous variables using a logistic regression framework, as shown in a structural model. The covariates perform comprehensive elaboration of individuals' characteristics belonging to a particular latent class (Linzer \& Lewis, 2011). The model introduces several active covariates, including sociodemographic and barrier-related variables, as well as a few inactive covariates to further characterize the modality choices of older adults.

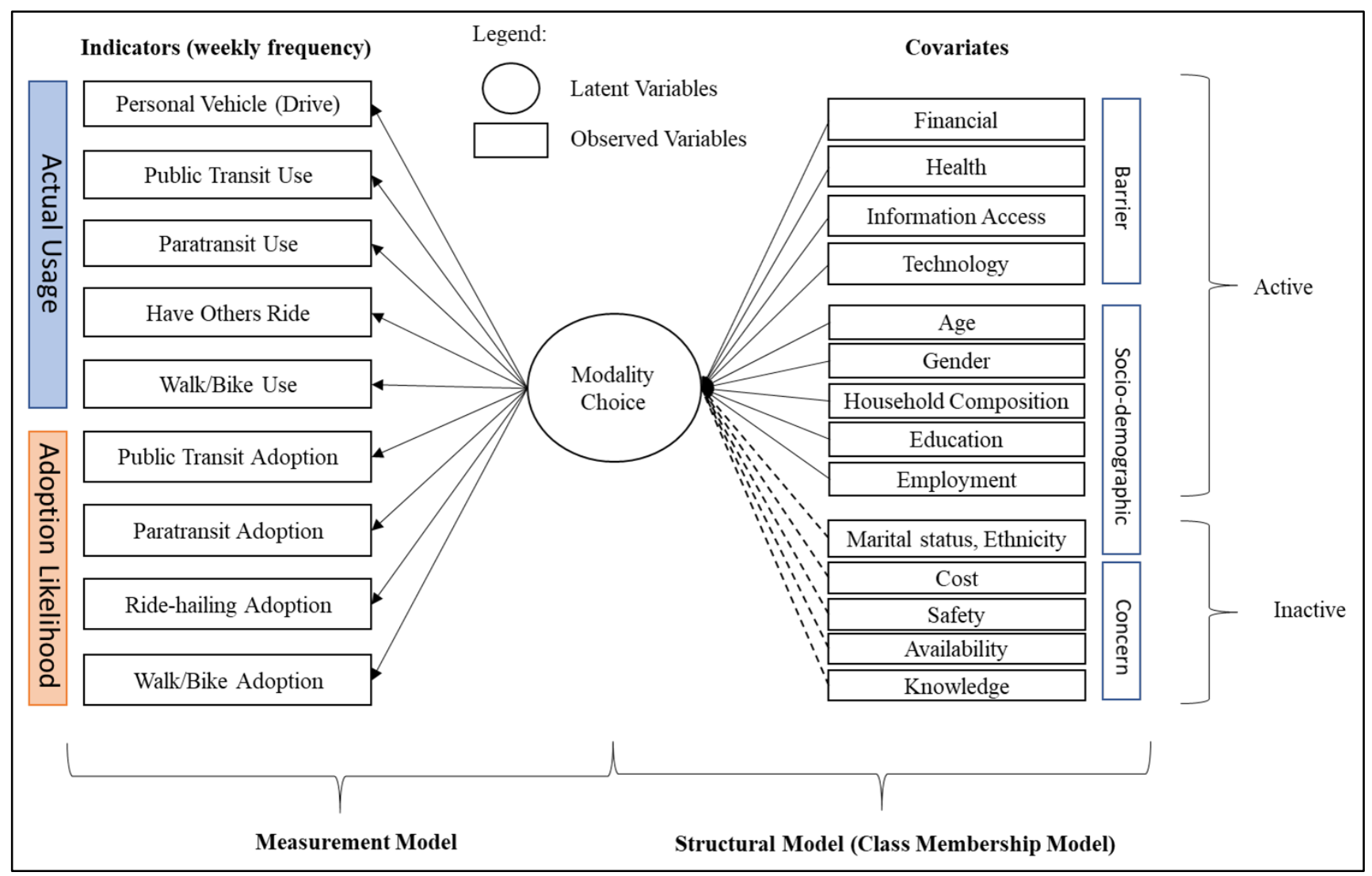

Figure 4.1: A Graphical Framework of LCCA 


\subsection{AGENT-BASED MODEL}

The data collected from the travel behavior survey was used to develop an empirically informed ABM. In this model, each agent represents an individual community-dwelling older adult resident of the city of Dallas. The purpose of the model is to simulate the transportation-related decisions and behaviors of these heterogeneous older adults, subject to their schedules, desired travel destinations, and the availability of different transportation options. By experimentally varying these factors and assessing their impacts on the agents' satisfaction/quality of life over time, we can achieve a better understanding of which mobility-enhancing strategies are most promising, as well as determining the relative impact on older adults with different characteristics and preferences.

To design the agents, data from the survey was used to generate older adult personas, which are highly detailed qualitative representations of real-life older adults. The preferences of the primary personas were then quantified using a multicriteria decision analysis technique known as PAPRIKA (Potentially All Pairwise RanKings of all possible Alternatives). The resulting quantitative preference values were then used to generate utility functions that are embedded within the agents to represent the internal logic necessary for making transportation-related decisions.

\subsubsection{Persona Development}

A separate cluster analysis was performed on the imputed travel behavior survey data to identify naturally occurring groups of the community-dwelling older adults, in which the older adults in the same range of demographic factors with similar transportation needs and behaviors are grouped together. While naturally occurring groups of survey participants can be identified without using advanced statistical tools in small datasets, this task is daunting in large datasets, such as the travel behavior survey described in the previous section. There are several methods for cluster analysis, and the selection of which method to use depends on the characteristics of the collected data and the individual methods. The number and types of input variables, the desired output metrics and features, and requirements on having a pre-determined number of clusters are factors to consider before selecting the appropriate clustering method.

The first step was to develop a clustering method in identifying the naturally occurring groups from the travel behavior survey data. One caveat found in these test runs was the effect of gender on interpretation of the resulting clusters due to non-homogeneity within this factor. To eliminate future confusion in interpretation, the entries for female and male participants were manually separated into two initial clusters prior to applying cluster analysis. 
Next, the male and female groups were exclusively divided into clusters by applying Ward's method of hierarchical clustering with Euclidean distances (Everitt, Landau, Leese \& Stahl, 2011) on age, status of current car possession, education level, marital status, and ethnicity. The parameters for cluster analysis are based on the factors impacting older adults' mobility, transportation behaviors, and needs, as explained in literature. Although older adults rated their health status based on their self-perception regardless of their age, health status was not used as a clustering factor due to the high correlation between increasing age and declining health status. Furthermore, income level was left out of the clustering since it was highly correlated with education level. By contrast, marital status and ethnicity had weak correlations between each other and with the rest of the clustering factors; therefore, both were included in the cluster analysis. It was decided that the number of naturally occurring groups would not be restricted to a predetermined number of clusters to avoid introducing bias to the resulting clusters.

From the resulting clusters, the primary, secondary, and negative persona(s) can be identified. The primary persona(s) is the cluster whose needs and goals cannot be met with a service designed for any other persona (Cooper, 2004). The secondary persona shares some attributes with the primary persona(s), as well as additional specific needs that do not require immediate action, and can be satisfied with the services designed for the primary persona (Cooper et al., 2014). The negative persona (or anti-persona) is a reminder to all stakeholders for whom they should not design the service. Unlike the primary and secondary personas, the negative persona communicates what is not the target of a service (Cooper et al., 2014).

\subsubsection{Agent Logic Development}

To determine the degree to which existing/proposed transportation services meet older adults' needs, the qualitative descriptions of the primary personas' transportation needs must be converted into quantitative measures. In this section, the needs of the primary personas and the attributes of transportation options are translated into 1000minds software to obtain utility functions for understanding the older adults' satisfaction with their transportation options in agent-based modeling.

1000minds software utilizes PAPRIKA method (Potentially All Pairwise RanKings of all possible Alternatives), which is an additive multi-attribute value model with performance categories (Hansen \& Ombler, 2009). A decision-maker using this method performs a pairwise ranking of potentially all undominated pairs of all possible alternatives. An undominated pair is defined as a pair of alternatives from all possible alternatives where one alternative is a higher-ranked category for at least one criterion and a lower-ranked category for at least one other criterion than the other alternative. An undominated pair has only two criteria at a time, and the decision-maker is presented two undominated pairs at a time to make a trade-off between the two undominated pairs. PAPRIKA minimizes the number of pairs a decision-maker has to rank explicitly by identifying the implicitly ranked pairs as the corollaries of the explicitly ranked pairs. Figure 4.2 
demonstrates the sequence of steps in performing the PAPRIKA method in 1000minds software.

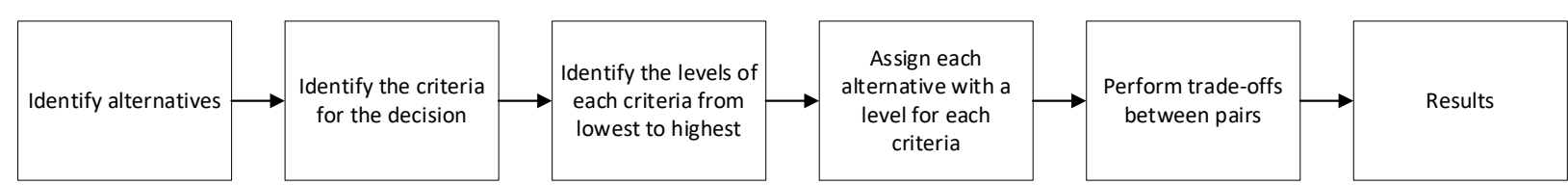

Figure 4.2: The Sequence of Steps in Performing the PAPRIKA Method in 1000minds Software

\subsection{QUALITATIVE ANALYSIS TO EXPLORE FACTORS ENHANCING RESILIENCE DURING THE COVID-19 PANDEMIC}

Qualitative data files were cleaned and entered into ATLAS.ti. The data were analyzed using a general inductive approach (Thomas, 2006). The leading investigator of this study and two trained research assistants separately reviewed the data and created codes. Three researchers discussed initial codes that were frequent across the participants. The coders collaboratively developed and agreed upon key themes. Researchers assessed transcripts to confirm or challenge the initially presented themes. Final themes were identified after reaching consensus from all of the researchers. 


\subsection{RESULTS}

\subsection{QUESTIONNAIRE SURVEY FINDINGS}

A total of 146 older adults participated in the survey, as shown in Table 5.1. The majority of respondents were aged between 65 and 85 (72\%); however, this study included 19 emerging seniors (aged between 55 and 65) to understand how age affects mobility barriers and opportunities. The participants had an average income of less than $\$ 15,000$ per year and did not live with a partner $(79 \%)$. More than half of the respondents were African American (62\%) followed by White (20\%). In general, they maintained good physical and mental health, and only $15 \%$ reported that their health was fair or poor. Survey respondents also have an option not to answer the questions, and these unanswered responses are not used in modeling.

Table 5.1: Socioeconomic Characteristics and Health Profiles of the Survey Respondents

\begin{tabular}{|c|c|c|c|}
\hline Variables & Description & $\mathrm{N}$ & $\%$ \\
\hline \multicolumn{4}{|c|}{ Socioeconomic Characteristics } \\
\hline \multirow{4}{*}{ Age (years) } & $55-65$ & 19 & $11 \%$ \\
\hline & $65-75$ & 67 & $40 \%$ \\
\hline & $75-85$ & 53 & $32 \%$ \\
\hline & Over 85 & 6 & $4 \%$ \\
\hline \multirow{3}{*}{ Income } & less than $\$ 10,000$ & 56 & $34 \%$ \\
\hline & $\$ 10,000-\$ 29,999$ & 55 & $33 \%$ \\
\hline & Over $\$ 30,000$ & 27 & $16 \%$ \\
\hline \multirow{2}{*}{ Marital Status } & Married or living with a partner & 24 & $14 \%$ \\
\hline & Single, Separated, Widowed & 132 & $79 \%$ \\
\hline \multirow{4}{*}{ Other Household Members } & Child/ children under 18 & 8 & $5 \%$ \\
\hline & Child/ children 18 or older & 24 & $14 \%$ \\
\hline & Other adults (e.g., parents, friends etc.) & 21 & $13 \%$ \\
\hline & Living alone & 114 & $68 \%$ \\
\hline \multirow{3}{*}{ Ethnicity } & White or Caucasian & 34 & $20 \%$ \\
\hline & Black or African American & 104 & $62 \%$ \\
\hline & Other & 15 & $9 \%$ \\
\hline \multirow{3}{*}{ Education } & High school diploma or Equivalent & 64 & $38 \%$ \\
\hline & Post-high school education/ training (no degree) & 27 & $16 \%$ \\
\hline & +2 yrs. College degree & 64 & $38 \%$ \\
\hline \multirow{3}{*}{ Employment Status } & Full-time & 9 & $5 \%$ \\
\hline & Part-time & 13 & $8 \%$ \\
\hline & Not employed (e.g., out of work, retired, etc.) & 122 & $73 \%$ \\
\hline \multicolumn{4}{|c|}{ (2) } \\
\hline \multirow{2}{*}{ Mobility } & More than $1 / 4$ mile & 95 & $57 \%$ \\
\hline & Less than $1 / 4$ mile & 44 & $26 \%$ \\
\hline
\end{tabular}




\begin{tabular}{l|l|l|l}
\hline & Difficulty with mobility & 13 & $8 \%$ \\
\hline \multirow{2}{*}{ Physical health Overall } & Excellent/Very Good/Good & 129 & $77 \%$ \\
\cline { 2 - 5 } & Fair/Poor & 26 & $15 \%$ \\
\hline \multirow{2}{*}{ Mental health Overall } & Excellent/Very Good/Good & 129 & $77 \%$ \\
\cline { 2 - 4 } & Fair/Poor & 26 & $15 \%$ \\
\hline
\end{tabular}

The survey first investigated older adults' primary transportation mode choices (Figure 5.1 (left); preferred transportation options (Figure 5.1 (right)); and the frequency of trips using each mode (Figure 5.2). Almost half of the respondents drove their car and made an average of six trips per week, followed by using public transit, walking or biking, or relying on family or friends to get a ride. Only $5 \%$ and $3 \%$ of respondents used paratransit and ride-hailing services such as Uber/ Lyft, respectively, for their daily trips. Figure 5.1 (right) depicts the preferred mode of non-drivers (i.e., $53 \%$ of the respondents of Figure 5.1 (left)) who did not drive but used other modes. Figure 5.1 (right) showed that the majority (43\%) of non-drivers preferred public transportation, followed by paratransit (17\%). Taxi or cab and ride-hailing services showed the lowest proportion ( $4 \%$ each).

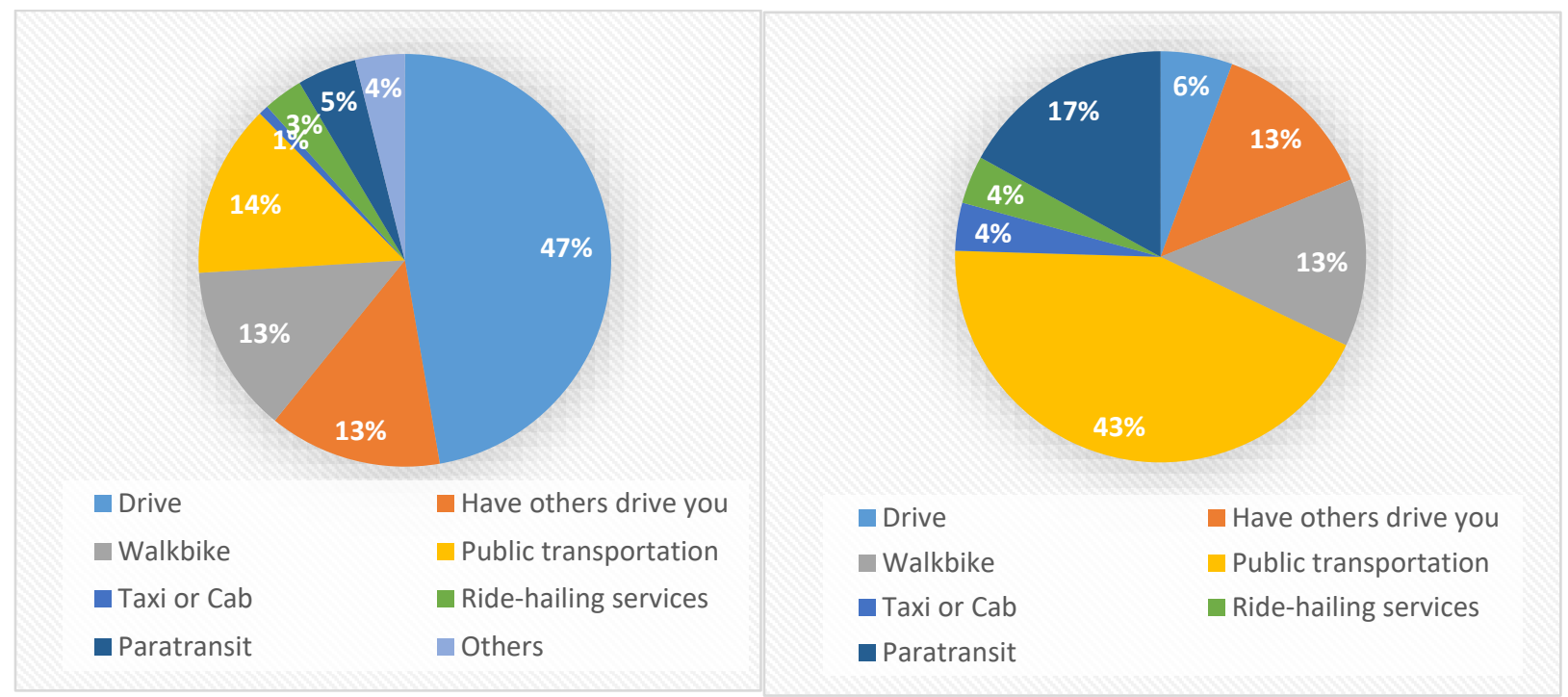

Figure 5.1: Current Mode Users (left) and Preferred Mode Choice for Non-Drivers (right) 


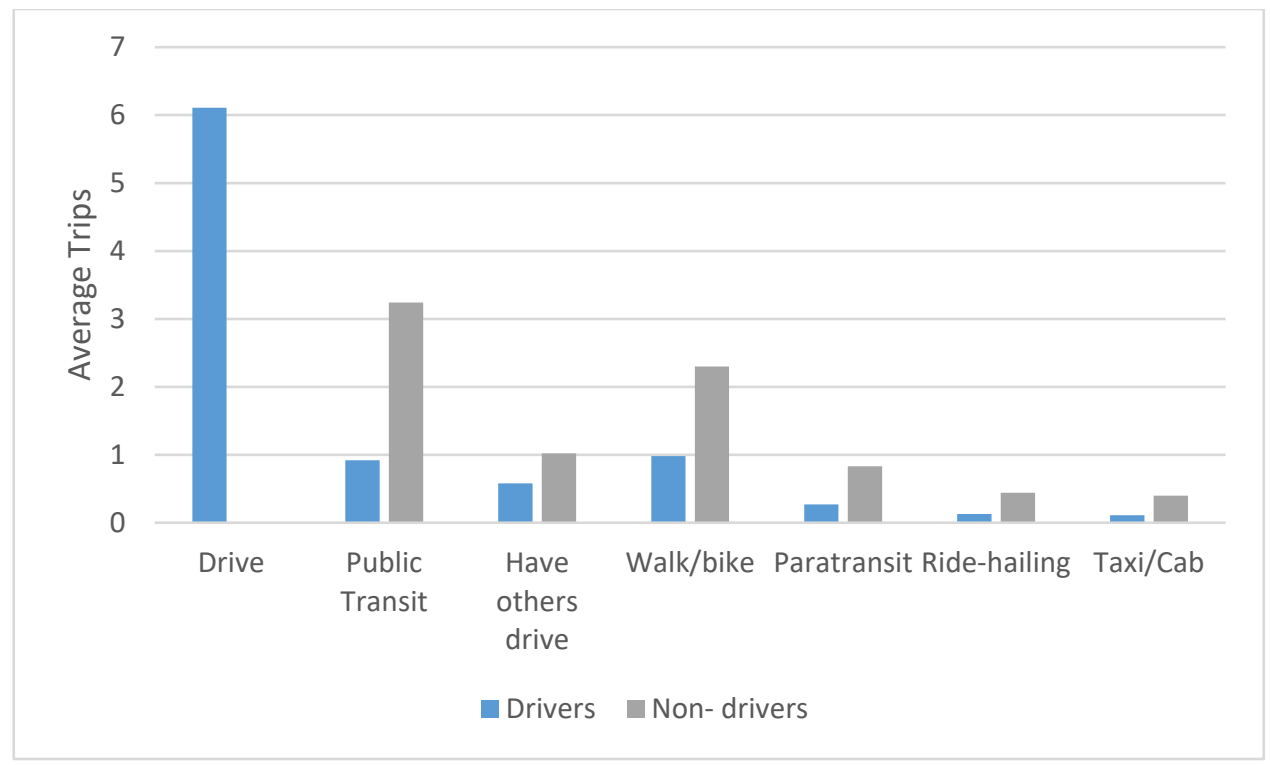

Figure 5.2: Number of Weekly Trips

Figure 5.3 illustrates the level of importance of different transportation options for older adults to live independently. Although only $13 \%$ and $5 \%$ of the respondents used public transit and paratransit, respectively, older adults still reported these services as very important for their independence. The respondents also highlighted the importance of safe and accessible streets, such as well-lit streets and audio/visual aided intersections to enhance walkability. In contrast, the majority of the respondents felt that ride-hailing and taxi/cab were less important for independent living.

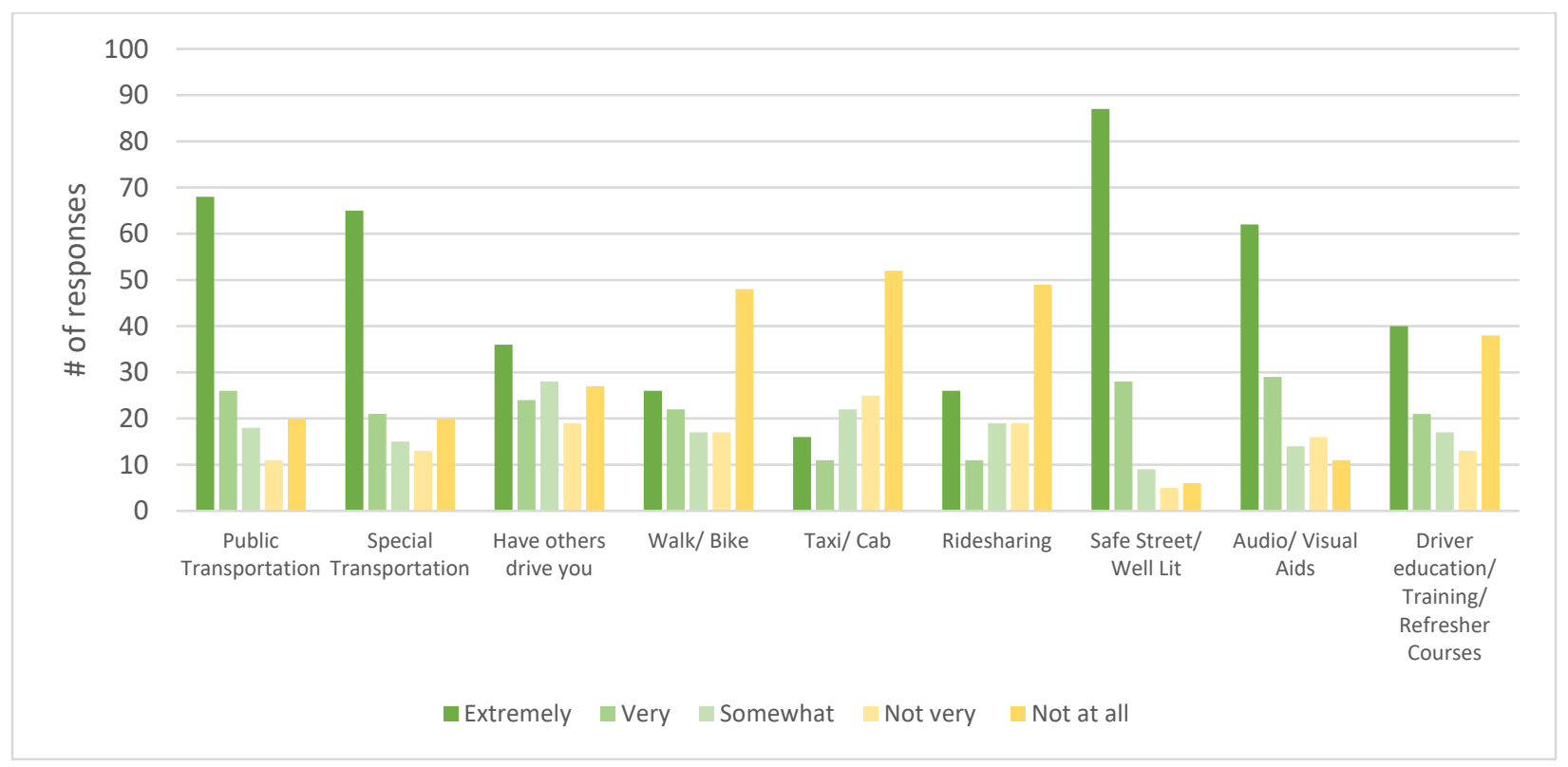

Figure 5.3: Importance of Services for Independent Living 
To understand mobility barriers, participants were asked to indicate concerns, if any, when using transportation modes. Figure 5.4 compares the identified concerns for five modes of transportation with two groups of older adults depending on their main modedrivers and non-drivers. Some of the drivers reported that they had never experienced any other services, and many others indicated that they did not use these modes on a daily basis. Therefore, the drivers' concerns about these modes were based upon their previous experience or indirect experience from others. However, the concerns reported from non-drivers likely reflected their lived experiences with these services.

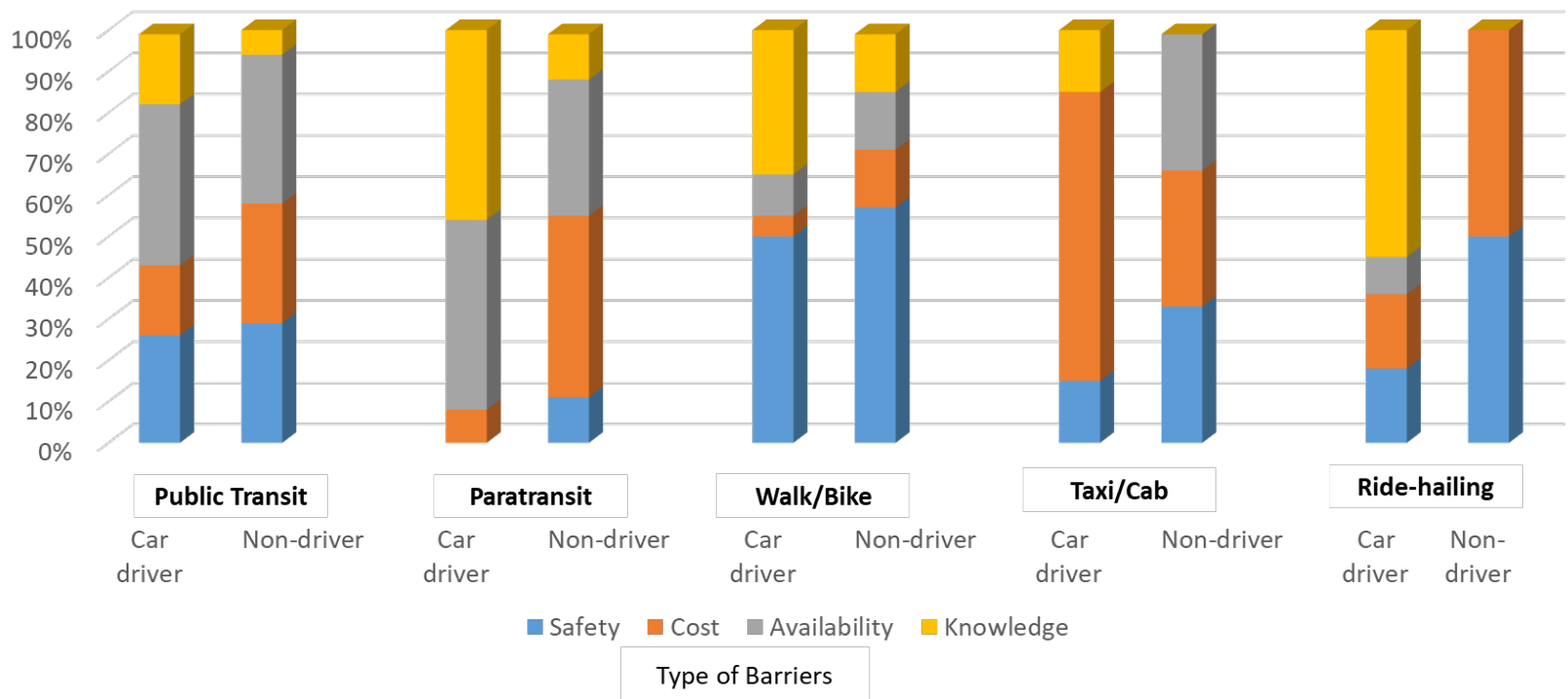

Figure 5.4: Comparisons of Concerns Between Drivers and Non-Drivers

Because a predominant concern regarding paratransit and ride-hailing that drivers had was a lack of knowledge, we looked into how or where drivers obtained transportation information. Figure 5.5 shows that the majority of the respondents (36\%) obtained transportation information through human networks, such as their doctors, family members, neighbors or friends, or local aging or faith-based organizations $(32 \%)$. Surprisingly, more than half of the respondents $(57 \%)$ never used internet services to access transportation information, mostly because they experienced difficulties in accessing internet or using smartphones and computers. Only $6 \%$ of the respondents used internet once every few weeks to gather transportation information. 
(a) Information Resources

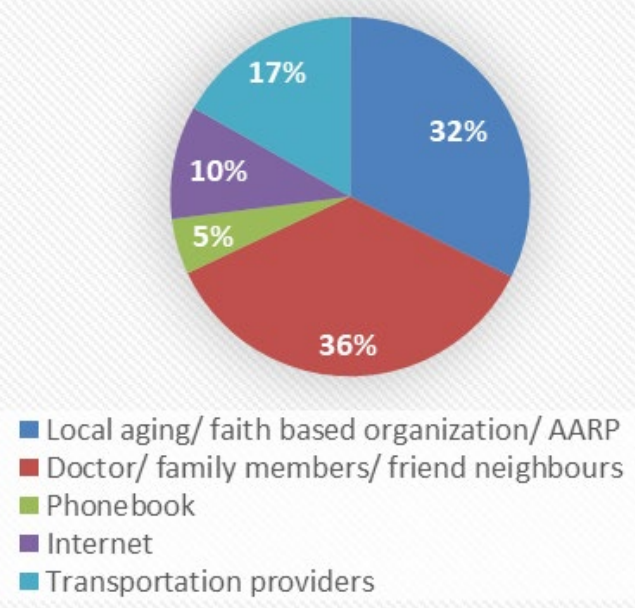

(b) Use of Internet

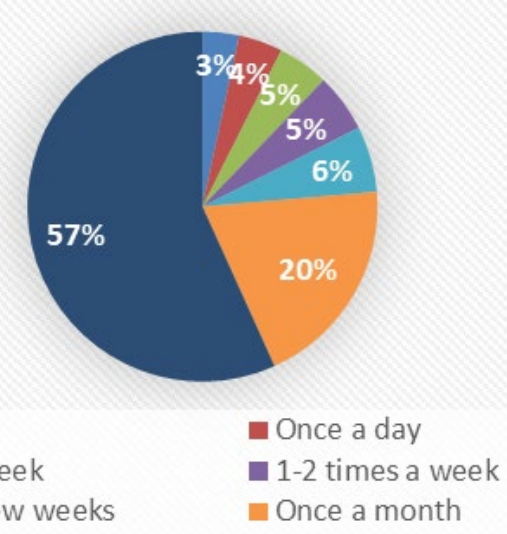

- Several

3-6 times a week

- Once every few weeks

- Never

Figure 5.5: Resources to Obtain Transportation Information

\subsection{LATENT CLASS CLUSTER ANALYSIS TO UNDERSTAND MODE CHOICE DECISIONS}

LCCA characterizes older adults' transportation behaviors based on their mode choices and likelihood of adopting different modes. Typically, the statistical parameters AIC and BIC select the optimal number of clusters in LCCA (Vermunt \& Migidson, 2002). However, several previous studies pointed out that the optimal number is subject to research objectives and data structures since minimum AIC or BIC values do not always provide meaningful clustering outcomes that distinguish unique behavioral patterns (Molin et al., 2016; Lee et al., 2019). This study applied both AIC and empirical insights obtained by the survey analysis and determined three optimal clusters. Although a latent cluster analysis typically requires a large sample size to ensure a stability and statistical power of a model, many studies pointed out that the required sample size depends on the number of classes and power level. The complexity of latent structure and the number of indicators also substantially impact the size of the required sample. Gudicha et al. (2016) reported 131 and 82 samples as required sizes for three-cluster latent analysis when assuming 0.95 , and 0.8 power level, respectively. Park \& Yu (2017) showed that the sample size per cluster could be as small as five when a model has more than 50 clusters while the minimum sample size per cluster increases to 20 when there are 20 clusters in a model. Our study uses 146 samples splitting across three clusters where each cluster includes 63, 33, and 67 individuals. The number of samples appears to be sufficient to represent three clusters, especially characterizing lower-income older adults living in Dallas, TX. 


\section{Three Distinctive Types of Modality Characteristics}

LCCA identified three distinctive older adult groups (clusters) that categorize mode usages and adoptions, as shown in Table 5.3. Overall, $36.3 \%$ of the respondents belong to the first cluster representing car-dependent older adults; the second cluster includes $20.1 \%$ of respondents who mainly use public transit; and the third cluster shows $43.6 \%$ of users who drive and use other transportation modes.

The car dependents made frequent trips using their vehicle. About $62 \%$ of individuals made six to 10 trips a week, and almost $28 \%$ traveled more than 10 times a week using a car. Socioeconomic profiles indicated that most of the respondents were between 65 and 85 years old and retired. The majority of the respondents earned an annual average income over $\$ 10,000$, and around one-half of the group attended higher education. In general, they were well aware of the other transportation services and exhibited less physical or technology barriers. Without any noticeable barriers, this group rarely used or is willing to adopt other modes. About $60 \%$ were unlikely to adopt public transit or ride-hailing services, and over $70 \%$ of the respondents answered that they were also unlikely to adopt paratransit or active transportation modes (walk and bike). These mode adoption behaviors seem natural, especially in suburban area like Dallas where public transit does not serve a broader metropolitan area, while roadway infrastructure for private vehicles connects everywhere faster and more conveniently. However, still, this systematic pattern showing lack of interest using the other modes infers additional hidden psychological or social challenges that lower-income older adults might experience towards public transit or paratransit services.

The transit dependents mostly relied on public transit $(73 \%)$ or paratransit $(21 \%)$ and did not drive their cars. This group features frequent walking/biking trips as well, possibly because of their walk to access transit stops. Only $15 \%$ showed an adoption preference to ride-hailing, mostly because of financial and technology barriers. Over $97 \%$ of this group relied on their social networks to obtain transportation information, and only a few indicated that they did not have adequate knowledge of other transportation services. Most of the individuals earned less than $\$ 10,000$ in annual income, were either retired or unemployed, and were over the age of 65 . A noticeable characteristic of this group is the lower number of trips they are making weekly. Almost half of the participants reported that they traveled less than five times using public transit, which is a significantly lower number of trips compared to the trips that cardependent participants made using their own vehicle. Interestingly, these avid public transit users show little interest in adopting paratransit, and only $21 \%$ reported that they would likely adopt this service in the future. Cost and availability of paratransit, as well as technology barriers, appear to play an important role in using paratransit.

The private mixed-modes users comprised the highest share of respondents $(44 \%)$ and represented those who used a car as a driver or as a passenger. Although $33 \%$ of this group relied on their family members and friends to get a ride at least once a week, most of them were unlikely to adopt ride-hailing services. They reported safety $(8 \%)$ and cost concerns $(12 \%)$, as well as a lack of knowledge $(9 \%)$. Although this group did not 
use public transit or paratransit, over $61 \%$ and $58 \%$, respectively, indicated that they were neutral or likely to adopt those services in the future. However, they highlighted various concerns regarding public transportation, such as cost $(10 \%)$, safety $(13 \%)$, inadequate schedule $(18 \%)$, and a lack of knowledge of the service $(10 \%)$. Their lack of interest in walking or cycling appeared to relate to their safety concern $(18 \%)$ or a lack of knowledge $(16 \%)$. This group indicated that they had less access to information $(30 \%)$ and health problems $(15 \%)$, along with financial $(10 \%)$ and technology-related barriers $(67 \%)$. The majority of this group were non-Whites $(88 \%)$, females $(96 \%)$, car owners $(75 \%)$, and had low education credentials, such as a high school diploma $(69 \%)$.

These three clusters showed how older adults perceive transportation and utilize the existing options. Those who drove their own car, which was almost one-third of the survey respondents, appeared to use their car for daily activities and were not interested in using other transportation modes, except for ride-hailing. The familiarity and convenience of driving may have constrained their option to driving. These drivers did not report any specific barriers or concerns about other modes, yet they are unlikely to adopt them. On the other hand, transit dependents exhibited the opposite behaviors and preferences. They rely on public transit and paratransit mostly because of their financial and technology barriers, although they felt that public transit is not safe. Their safety concerns consistently appeared for ride-hailing and taxi or cab. The last group, mixed-mode users, preferred personal vehicles, whether they drove or rode as a passenger. However, they were not interested in using ride-hailing due to cost and safety concerns. They indicated that they did not have sufficient information on other modes and they experienced technology barriers, all of which created various levels of concerns for ride-hailing, public transit, and even walk/bike.

Table 5.2: Characteristics of Three Clusters

\begin{tabular}{|c|c|c|c|c|c|}
\hline Category & \multicolumn{2}{|c|}{ Indicators/ Covariates } & $\begin{array}{l}\text { Class } 1 \\
\text { Car } \\
\text { dependent } \\
(\%) \\
\end{array}$ & $\begin{array}{l}\text { Class } 2 \\
\text { Transit } \\
\text { dependent } \\
(\%) \\
\end{array}$ & $\begin{array}{l}\text { Class } 3 \\
\text { Private mixed } \\
\text { modes }(\%)\end{array}$ \\
\hline \multicolumn{3}{|l|}{ Class Size $(n)$} & 63 & 33 & 67 \\
\hline \multicolumn{3}{|l|}{ Class Share } & $36.3 \%$ & $20.1 \%$ & $43.6 \%$ \\
\hline \multirow[t]{8}{*}{ Frequency } & \multirow[t]{4}{*}{ Car } & $\begin{array}{l}1-5 \text { times a } \\
\text { week }\end{array}$ & 9.67 & 0.00 & 39.80 \\
\hline & & $\begin{array}{l}6-10 \text { times a } \\
\text { week }\end{array}$ & 62.34 & 0.00 & 32.49 \\
\hline & & $\begin{array}{l}+10 \text { times a } \\
\text { week }\end{array}$ & 27.99 & 0.00 & 14.67 \\
\hline & & No trips & 0.00 & 100.00 & 13.03 \\
\hline & \multirow[t]{3}{*}{\begin{tabular}{|l|} 
Public \\
Transit
\end{tabular}} & $\begin{array}{l}1-5 \text { times a } \\
\text { week }\end{array}$ & 2.21 & 45.73 & 9.46 \\
\hline & & $\begin{array}{l}6-10 \text { times a } \\
\text { week }\end{array}$ & 0.00 & 27.49 & 0.00 \\
\hline & & No trips & 97.79 & 26.78 & 90.54 \\
\hline & Paratransit & $\begin{array}{l}1-5 \text { times a } \\
\text { week }\end{array}$ & 0.00 & 18.20 & 7.10 \\
\hline
\end{tabular}




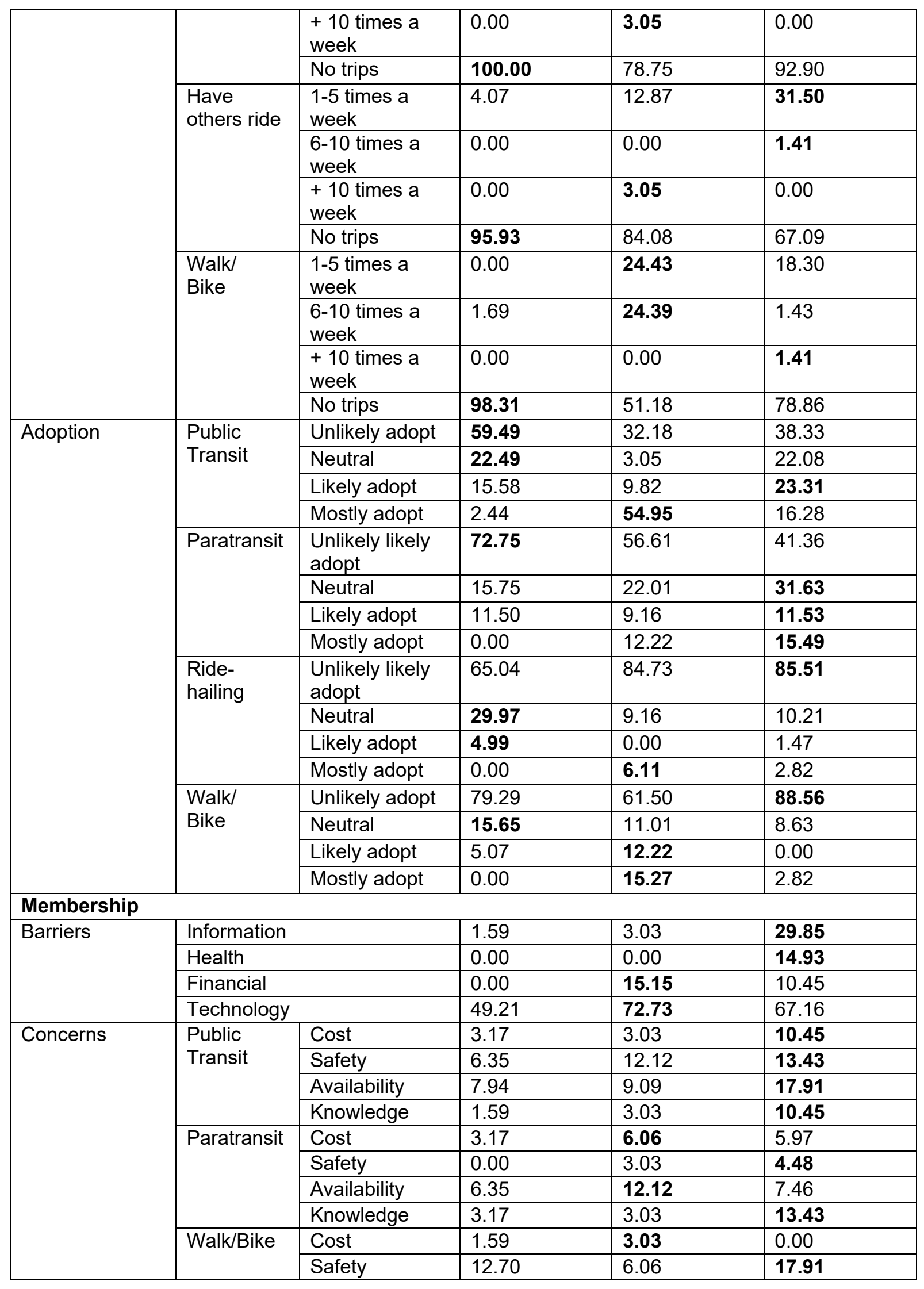




\begin{tabular}{|c|c|c|c|c|c|}
\hline & & Availability & 0.00 & 0.00 & 4.48 \\
\hline & & Knowledge & 3.17 & 3.03 & 16.42 \\
\hline & \multirow[t]{4}{*}{ Taxi/Cab } & Cost & 9.52 & 18.18 & 25.37 \\
\hline & & Safety & 3.17 & 9.09 & 5.97 \\
\hline & & Availability & 0.00 & 3.03 & 2.99 \\
\hline & & Knowledge & 3.17 & 3.03 & 4.48 \\
\hline & \multirow{4}{*}{$\begin{array}{l}\text { Ride- } \\
\text { hailing }\end{array}$} & Cost & 1.59 & 3.03 & 11.94 \\
\hline & & Safety & 0.00 & 12.12 & 8.96 \\
\hline & & Availability & 1.59 & 3.03 & 4.48 \\
\hline & & Knowledge & 7.94 & 6.06 & 8.96 \\
\hline \multirow{16}{*}{$\begin{array}{l}\text { Socioeconomic } \\
\text { Characteristics }\end{array}$} & \multirow[t]{2}{*}{ Race } & White & 30.16 & 21.21 & 11.94 \\
\hline & & Non-White & 69.84 & 78.79 & 88.06 \\
\hline & \multirow[t]{3}{*}{ Age } & $<65$ & 12.70 & 9.09 & 10.45 \\
\hline & & $65-85$ & 87.30 & 81.82 & 85.07 \\
\hline & & over 85 & 0.00 & 9.09 & 4.48 \\
\hline & \multirow[t]{2}{*}{ Gender } & Male & 9.52 & 27.27 & 4.48 \\
\hline & & Female & 90.48 & 72.73 & 95.52 \\
\hline & \multirow{3}{*}{$\begin{array}{l}\text { Other } \\
\text { household } \\
\text { members }\end{array}$} & Child under 18 & 7.94 & 0.00 & 0.04 \\
\hline & & $\begin{array}{l}\text { Child } 18 \text { or } \\
\text { older }\end{array}$ & 19.05 & 3.03 & 16.42 \\
\hline & & Other adults & 12.70 & 12.12 & 13.44 \\
\hline & \multicolumn{2}{|c|}{$\begin{array}{l}\text { Living with a married } \\
\text { partner }\end{array}$} & 19.05 & 21.21 & 5.97 \\
\hline & \multicolumn{2}{|c|}{$\begin{array}{l}\text { Income less than } \\
\$ 10,000\end{array}$} & 17.46 & 51.52 & 40.30 \\
\hline & \multicolumn{2}{|c|}{ Employed } & 12.70 & 9.09 & 16.42 \\
\hline & \multicolumn{2}{|c|}{ Education (+ 2yrs College) } & 50.79 & 33.33 & 31.34 \\
\hline & \multicolumn{2}{|c|}{$\begin{array}{l}\text { Speak other language at } \\
\text { home }\end{array}$} & 12.70 & 9.09 & 4.48 \\
\hline & \multicolumn{2}{|c|}{ Vehicle owned } & 98.41 & 0.00 & 74.63 \\
\hline \multirow[t]{2}{*}{ Health } & \multicolumn{2}{|c|}{ Fair or Good physical health } & 100.00 & 96.97 & 98.51 \\
\hline & \multicolumn{2}{|c|}{ Feel socially isolated } & 4.76 & 0.00 & 2.99 \\
\hline
\end{tabular}

${ }^{*}$ bold indicates a cluster with the highest share for each indicator

\section{Class membership model}

Class membership modeling characterized the public transit and mixed users in comparison to car drivers (reference class) using active covariates including socioeconomic characteristics and perceived barriers (see Table 5.4), as mode choice behaviors are closely related to such variables. Results showed that financial barriers were positively related to non-drivers in clusters 2 or 3 . In other words, individuals who had financial barriers likely utilized public transit (cluster 2) or private mixed modes (cluster 3 ), rather than their own car. Those who had poor health conditions were likely to drive their cars, rather than use public transit. Information and technology barriers more frequently presented among public transit users and mixed-mode users as they were unlikely to adopt ride-hailing services that required a certain level of knowledge of technology. 
Our model reveals that household composition had a strong impact on mode choices. For example, those who lived with children under 18 years of age were likely to drive their cars, while those who lived with adult relatives or friends were likely to use public transit. In addition, male respondents were more likely to use public transit than female counterparts, and those who were unemployed and had a lower education level were more likely to be in a transit-user group.

Table 5.3: Covariates of Class Membership Model

\begin{tabular}{|c|c|c|c|c|}
\hline \multirow[t]{2}{*}{ Covariates } & \multicolumn{2}{|c|}{$\begin{array}{c}\text { Class } 2 \text { Transit Dependent } \\
\text { Older Adults } \\
\text { [Cost share: } 20.1 \%]\end{array}$} & \multicolumn{2}{|c|}{$\begin{array}{c}\text { Class } 3 \text { Private Mixed } \\
\text { Modes Users } \\
\text { [Cost share: } 43.6 \% \text { ] }\end{array}$} \\
\hline & Coefficients & $\begin{array}{l}\text { Standard } \\
\text { errors }\end{array}$ & Coefficients & $\begin{array}{l}\text { Standard } \\
\text { errors }\end{array}$ \\
\hline \multicolumn{5}{|l|}{ Barriers (1: present) } \\
\hline Information Access & $11.535^{\star \star \star}$ & 0.001 & $19.353^{* \star \star}$ & 1.884 \\
\hline Health & $-15.344^{\star \star *}$ & 0.001 & $9.386^{\star \star \star}$ & 0.001 \\
\hline Financial & $6.032^{\star \star \star}$ & 1.208 & $7.183^{\star \star \star}$ & 1.206 \\
\hline Technology & $9.658^{* \star}$ & 3.746 & 0.660 & 0.840 \\
\hline \multicolumn{5}{|l|}{ Socio- demographic variables } \\
\hline \multicolumn{5}{|l|}{ Household composition (1: yes) } \\
\hline Child under 18 & $-4.640^{* \star *}$ & 3.714 & $-10.169^{* * *}$ & 1.884 \\
\hline Child 18 or older & -2.267 & 0.001 & -0.277 & 1.279 \\
\hline Adult relatives 18 or older & $4.334^{* * *}$ & 4.184 & 0.934 & 1.183 \\
\hline $\begin{array}{r}\text { Income (1: income less than } \\
\$ 10,000 ; 2: \text { others) }\end{array}$ & 1.570 & 2.256 & $1.465^{\star}$ & 0.885 \\
\hline Employment (1: employed) & $-13.526^{* \star *}$ & 3.696 & -0.567 & 2.234 \\
\hline Education level (1: higher level) & $-15.958^{* * *}$ & 3.709 & 0.287 & 0.815 \\
\hline Gender (1: male) & $4.577^{\star \star \star}$ & 0.030 & -0.797 & 2.309 \\
\hline Age & 0.155 & 0.216 & 0.041 & 0.058 \\
\hline Owns a car (1: yes) & $-38.917^{\star \star \star}$ & 0.002 & -2.701 & 2.235 \\
\hline
\end{tabular}

Goodness of Fit

AIC (3): 2165.015, BIC (3) :2489.859, Chi-square goodness of fit:30418.16

Note. P-value $\leq{ }^{* \star *} 0.001 ;{ }^{* *} 0.01 ;{ }^{*} 0.05$

\subsection{A STAKEHOLDER-DRIVEN APPROACH TO UNDERSTANDING THE TRANSPORTATION NEEDS}

This study describes and demonstrates a structured stakeholder-driven approach to identifying transportation solutions for community-dwelling older adults. Data from a travel behavior survey conducted with community-dwelling older adults in Dallas, TX, was used to develop personas, or representations, of these older adults. A House of Quality was used to translate qualitative descriptions of these personas' transportation needs into a quantitative assessment of available transportation options. 
Minitab Data Analysis was used to perform the cluster analysis, yielding 13 female and four male clusters, as shown in 5.4. The clusters served as the basis for persona development.

Table 5.4: The Results of Cluster Analysis

\begin{tabular}{|c|c|c|c|c|c|c|}
\hline Cluster & Gender & Age & Car & Education Level & Marital Status & Ethnicity \\
\hline 1 & Female & 75 & No & High School or Equivalent & $\begin{array}{l}\text { Separated or } \\
\text { Divorced }\end{array}$ & $\begin{array}{l}\text { Black or African } \\
\text { American }\end{array}$ \\
\hline 2 & Female & 91 & No & $\begin{array}{l}\text { Post-high school } \\
\text { education/training }\end{array}$ & Widowed & $\begin{array}{l}\text { White or } \\
\text { Caucasian }\end{array}$ \\
\hline 3 & Female & 63 & No & 4-year collage degree & $\begin{array}{l}\text { Single - Never } \\
\text { married }\end{array}$ & $\begin{array}{l}\text { White or } \\
\text { Caucasian }\end{array}$ \\
\hline 4 & Female & 62 & No & High School or Equivalent & $\begin{array}{l}\text { Single - Never } \\
\text { married }\end{array}$ & $\begin{array}{l}\text { Black or African } \\
\text { American }\end{array}$ \\
\hline 5 & Female & 77 & No & High School or Equivalent & $\begin{array}{l}\text { Married or Living } \\
\text { with a partner }\end{array}$ & Asian \\
\hline 6 & Female & 73 & Yes & $\begin{array}{l}\text { Post-high school } \\
\text { education/training }\end{array}$ & $\begin{array}{l}\text { Married or Living } \\
\text { with a partner }\end{array}$ & $\begin{array}{l}\text { Black or African } \\
\text { American }\end{array}$ \\
\hline 7 & Female & 71 & Yes & $\begin{array}{l}\text { Graduate or professional } \\
\text { degrees }\end{array}$ & $\begin{array}{l}\text { Married or Living } \\
\text { with a partner }\end{array}$ & $\begin{array}{l}\text { White or } \\
\text { Caucasian }\end{array}$ \\
\hline 8 & Female & 67 & Yes & $\begin{array}{l}\text { Post-high school } \\
\text { education/training }\end{array}$ & $\begin{array}{l}\text { Separated or } \\
\text { Divorced }\end{array}$ & Other: Hispanic \\
\hline 9 & Female & 69 & Yes & 2-year collage degree & Widowed & $\begin{array}{l}\text { Black or African } \\
\text { American }\end{array}$ \\
\hline 10 & Female & 67 & Yes & High School or Equivalent & $\begin{array}{l}\text { Separated or } \\
\text { Divorced }\end{array}$ & $\begin{array}{l}\text { Black or African } \\
\text { American }\end{array}$ \\
\hline 11 & Female & 78 & Yes & $\mathrm{K}-12$ grade & Widowed & $\begin{array}{l}\text { Black or African } \\
\text { American }\end{array}$ \\
\hline 12 & Female & 68 & Yes & $\begin{array}{l}\text { Graduate or professional } \\
\text { degrees }\end{array}$ & $\begin{array}{l}\text { Separated or } \\
\text { Divorced }\end{array}$ & $\begin{array}{l}\text { Black or African } \\
\text { American }\end{array}$ \\
\hline 13 & Female & 81 & Yes & 2-year collage degree & Widowed & $\begin{array}{l}\text { Black or African } \\
\text { American }\end{array}$ \\
\hline 14 & Male & 78 & No & High School or Equivalent & $\begin{array}{l}\text { Married or Living } \\
\text { with a partner }\end{array}$ & Asian \\
\hline 15 & Male & 70 & Yes & 2-year collage degree & $\begin{array}{l}\text { Separated or } \\
\text { Divorced }\end{array}$ & $\begin{array}{l}\text { Black or African } \\
\text { American }\end{array}$ \\
\hline 16 & Male & 65 & Yes & 4-year collage degree & $\begin{array}{l}\text { Married or Living } \\
\text { with a partner }\end{array}$ & $\begin{array}{l}\text { White or } \\
\text { Caucasian }\end{array}$ \\
\hline 17 & Male & 73 & No & 2-year collage degree & $\begin{array}{l}\text { Single - Never } \\
\text { married }\end{array}$ & $\begin{array}{l}\text { White or } \\
\text { Caucasian }\end{array}$ \\
\hline
\end{tabular}




\subsection{PERSONA DEVELOPMENT FOR THE COMMUNITY-DWELLING OLDER ADULTS}

The primary persona(s) representing older adults will be the most vulnerable in terms of mobility. Clusters 1, 2, and 3 did not own a car, nor could they afford a car. Their health and financial status were limiting factors to use existing transportation options and live independently. In addition, they reported missing trips for basic needs and leisure activities. Cluster 4 did not own a car, but they reported that their main transportation mode and source of mobility was riding with others. Clusters 6 through 13,15, and 16 owned a car that they can afford to maintain and keep in their possession. While these clusters may experience some difficulties with driving due to aging, they are still able to drive everywhere. Clusters 5 and 14 represent older adults who are married and reside in the same household. While both were above 75 years and had low income, they reported their health as excellent compared to other older adults and were able to meet all their needs by using public transportation and walking. Cluster 17 owns a car and considers driving as the only option for transportation without any interest in or knowledge of other transit options.

Based on this analysis, clusters 1,2, and 3 are the most vulnerable, with insufficient transportation options to maintain an independent life without disruptions in their day-today activities. Therefore, these clusters are the primary personas. Clusters 4 through 16 can satisfy their transportation needs with their current arrangements. However, they are aware of the challenges ahead as they age and decline in health. These clusters can benefit from the solutions targeted to the primary personas. Therefore, clusters 4 through 16 make up the secondary personas. Cluster 17 is the negative persona who should not be targeted for designing transportation services for older adults in Dallas. The primary personas are described in detail in Tables 9.1, 9.2, and 9.3 in the appendix. The secondary personas and the negative persona can be found in Tables 9.4 and 9.5, respectively, in the Appendix section.

The three primary personas represent the most vulnerable older adults in terms of transportation and mobility needs. All of the primary personas are female and are living alone on low incomes. This result reflects the literature, which states that female older adults experience a greater decline in mobility compared to their male counterparts. Their ages $(63,75$, and 91$)$ span the low, middle, and high sub-categories of the old age spectrum. This suggests that their poor health status, irrespective of age, is a primary limiting factor on their mobility. However, the primary personas expect to live independently, with safe and affordable transportation options that accommodate their need for comfort and assistance. They would like to go to their destinations directly with the shortest travel times possible, whenever they want. In addition, they would like to live in a crime-free environment that provides safe sidewalks, covered benches for resting at bus stops, and visual and audio aids at intersections. The primary personas emphasize the fact that older adults would like to continue living independently and take trips for their well-being while traveling in comfort and feeling safe - like everyone else. 


\subsection{HOUSE OF QUALITY FOR PRIMARY PERSONAS}

The House of Quality (HOQ) is a tool that can be used to connect the voice of the customer (the customer requirements) to the voice of the development team of a specific product or service by creating a mathematically simple and user-friendly approach (Bahill \& Chapman, 2011; Chan \& Wu, 2002). Figure 5.6 shows the HOQ developed for this study.

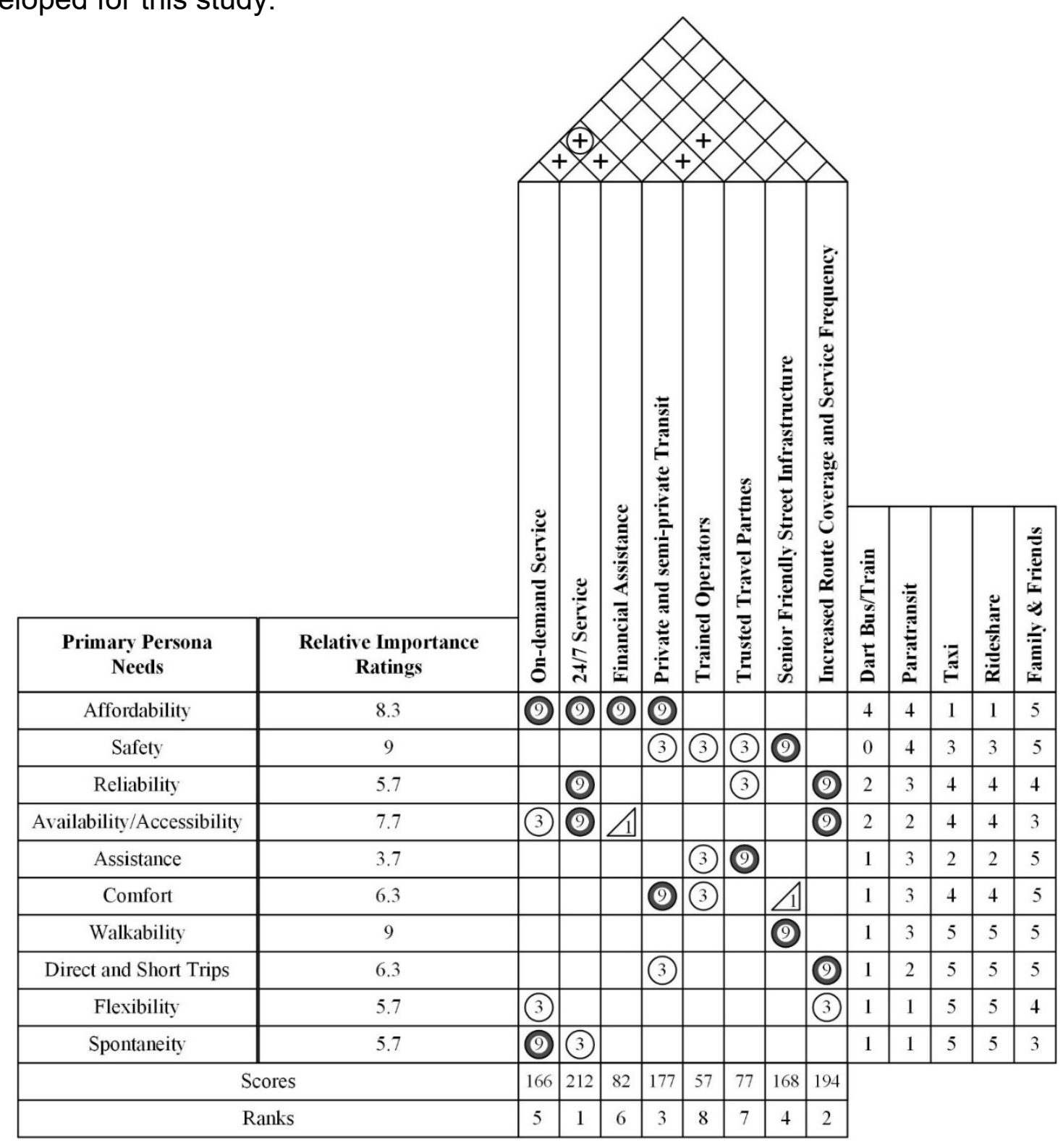

Figure 5.6: House of Quality for Older Adult Transportation

The first step in developing the HOQ is identifying customer/user needs. In an $\mathrm{HOQ}$ analysis, the customers' needs should be described in their own words (Griffin \& 
Hauser, 1993). The descriptions of the primary personas provided in Table 5.5 depicts the transportation needs of the most vulnerable older adults in Dallas. These needs, from the point of view of each persona, are summarized in Table 5.5 and are categorized under umbrella words. Each need is then inserted into the leftmost column of the HOQ (Figure 5.6). While independence is the ultimate transportation need of older adults, it is strongly correlated to all of their other needs. Therefore, independence is not included in further analysis.

\section{Table 5.5: The Transportation Needs of the Primary Personas in Their Own Words}

\begin{tabular}{|c|c|}
\hline The Transportation Needs of the Primary Personas & Umbrella Words \\
\hline $\begin{array}{l}\text { - Beatrice and Cassandra do not want to be dependent and burden on } \\
\text { anyone } \\
\text { - Elizabeth does not want to feel trapped }\end{array}$ & Independence \\
\hline $\begin{array}{l}\text { Beatrice has hard time to walk to bus stops in Texas summers } \\
\text { - Cassandra would like even sidewalks with places to sit down and rest } \\
\text { during her walks } \\
\text { - Elizabeth wishes to have basic amenities close to her house }\end{array}$ & Walkability \\
\hline $\begin{array}{l}\text { - } \quad \text { Beatrice is concerned about riding with strangers } \\
\text { - } \quad \text { Cassandra is afraid of young hoods on streets and in transit } \\
\text { - } \quad \text { Elizabeth does not want to worry about her well-being }\end{array}$ & Safety \\
\hline $\begin{array}{l}\text { - Beatrice misses going to stores or recreational center whenever } \\
\text { she wants } \\
\text { - Elizabeth wants to go out on a whim }\end{array}$ & Spontaneity \\
\hline - Beatrice cannot carry her bags while waking and in transit & Assistance \\
\hline $\begin{array}{l}\text { - Beatrice is unable to stay in balance while in transit } \\
\text { - } \quad \text { Beatrice feels pain when jostled }\end{array}$ & Comfort \\
\hline - Beatrice would like to visit her friends living far from public transit routes & Flexibility \\
\hline $\begin{array}{l}\text { - Elizabeth does not want to depend on the changing schedules and } \\
\text { routes }\end{array}$ & Reliability \\
\hline $\begin{array}{l}\text { - Cassandra would like to be more socially active at different times of the } \\
\text { day } \\
\text { - Elizabeth wants to avoid the hassle of combining modes }\end{array}$ & Availability/Accessibility \\
\hline $\begin{array}{l}\text { - } \quad \text { Beatrice would like to use ride share if it was not costly } \\
\text { - } \quad \text { Cassandra believes that her transportation budget limits her } \\
\text { - } \quad \text { Elizabeth cannot afford ride share although she wants to use it }\end{array}$ & Affordability \\
\hline $\begin{array}{l}\text { Cassandra's travel time to basic needs increases by three times if she } \\
\text { does not have anyone to give a direct ride } \\
\text { - Elizabeth wishes to have direct transit to her destinations to reduce her } \\
\text { travel times }\end{array}$ & $\begin{array}{l}\text { Direct and Shorter } \\
\text { Trips }\end{array}$ \\
\hline
\end{tabular}

After identifying the transportation needs of each persona, the needs are assigned importance ratings (shown in Table 5.6) based on a 5-level qualitative rating system with corresponding quantitative values: 1-very low, 3-low, 5-moderate, 7 high, 9-very high (Chan \& Wu, 2005). These ratings are derived from each persona's needs, goals, and motivations and are then averaged across all three personas to provide a relative importance for each need. The relative importance ratings are inserted into the second column of the $\mathrm{HOQ}$. 
Table 5.6: Importance Ratings of Primary Persona Needs

\begin{tabular}{|c|c|c|c|c|c|c|c|}
\hline \multirow{3}{*}{$\begin{array}{l}\text { Needs } \\
\text { Affordability }\end{array}$} & \multicolumn{6}{|c|}{ Importance Ratings } & \multirow{3}{*}{\begin{tabular}{|l|}
$\begin{array}{l}\text { Relative Importance } \\
\text { Ratings }\end{array}$ \\
8.3 \\
\end{tabular}} \\
\hline & \multicolumn{2}{|c|}{ Beatrice } & \multicolumn{2}{|c|}{ Cassandra } & \multicolumn{2}{|l|}{ Elizabeth } & \\
\hline & High & \begin{tabular}{|l|l}
7 \\
\end{tabular} & Very high & 9 & Very high & 9 & \\
\hline Safety & Very high & 9 & Very high & 9 & Very high & 9 & 9 \\
\hline Reliability & Moderate & 5 & Moderate & 5 & High & 7 & 5.7 \\
\hline Availability/Accessibility & Moderate & 5 & Very high & 9 & Very high & 9 & 7.7 \\
\hline Assistance & Very high & 9 & Very low & 1 & Very low & 1 & 3.7 \\
\hline Comfort & Very high & 9 & Moderate & 5 & Moderate & 5 & 6.3 \\
\hline Walkability & Very high & 9 & Very high & 9 & Very high & 9 & 9 \\
\hline Direct and Short Trips & Moderate & 5 & High & 7 & High & 7 & 6.3 \\
\hline Flexibility & Moderate & 5 & Moderate & 5 & High & 7 & 5.7 \\
\hline Spontaneity & High & 7 & Low & 3 & High & 7 & 5.7 \\
\hline
\end{tabular}

In the second step of the $\mathrm{HOQ}$ analysis, common characteristics of transportation solutions are identified. These characteristics, which were derived from multiple reports and studies on transportation services for older adults, include: on-demand service, $24 / 7$ service, financial assistance, private and semi-private transportation, trained operators, trusted travel partners, senior friendly street infrastructure, route coverage, and frequent service (Cevallos, Skinner, Joslin \& Ivy, 2010; Turner, Adams-Price \& Strawderman, 2017; Chase, 2011; Coughlin, 2009; Borst, Miedema, de Vries, Graham \& van Dongen, 2008; Brown, Bond, Wood \& Suguri, 2015; Rosenbloom, 2010). These eight characteristics are labels on the central matrix of the $\mathrm{HOQ}$, which defines the strength of relationships between the transportation needs of the primary personas and the service characteristics using a 3-level scale: weak (1 in a triangle), medium (3 in a circle), and strong (9 in a donut) (Bahill \& Chapman, 1993). At the bottom of the $\mathrm{HOQ}$, final scores of the service characteristics are achieved by vertically summing the multiplication of the relative importance ratings by each service assessment rating, yielding a priority ranking for the service characteristics. According to the HOQ rankings, $24 / 7$ service has the highest priority, followed by increased route coverage and service frequency as the second, and private and semi-private transit (i.e., cars and vans operated by for-profit and non-profit organizations) as the third, reflecting the top preferences of the most vulnerable community-dwelling older adults in Dallas. However, the characteristics with low scores should not be disregarded based on their rankings since there may be correlations between the low- and high-ranking characteristics.

The "roof" of the HOQ contains the correlations between service characteristics. A strong correlation is indicated by a + sign in a circle, a positive correlation with a + sign, a negative correlation with $a-$ sign, and a strong negative correlation with a - sign in a circle (Bahill \& Chapman, 1993). The roof of the HOQ suggests that positively correlated service characteristics should be implemented jointly. There is a positive correlation between on-demand service and $24 / 7$ service since the premise of ondemand is access at any time. Use of on-demand services are strongly correlated with financial assistance, since they are typically expensive (Saxon, Ebert \& Sobhani, 2019), and the primary personas cannot afford expensive transportation services without assistance. Similarly, the positive correlation between financial assistance and 24/7 
service indicates that traveling during late evening or early morning hours is limited by a lack of affordable transportation options. Private and semi-private transit operations are dependent on and, therefore, positively correlated with the trained operators and the assistance of the travel partners.

The final step of the HOQ analysis is the assessment of existing transportation options against the voice of the personas. The columns of the rightmost matrix of the $\mathrm{HOQ}$ are labeled with five transportation services that are available in the city of Dallas for older adults: Dallas Rapid Area Transit (DART) bus/train, paratransit, taxi, ride share, and family/friends. The values entered in this matrix show the performance of the service with respect to the persona needs (where 1 indicates poor and 5 indicates excellent). Based on the primary persona characteristics, bus, train, paratransit, and riding with family/friends are the most affordable transportation options. However, bus and train receive poor or fair scores on the remaining persona needs. While taxi and ride share are rated at or above very good, fear of riding with a stranger, lack of financial assistance, and the cost of these services are limiting factors for older adults. In addition, riding with family and friends has limitations in regard to the availability of these trusted persons.

The results of the HOQ analysis indicate that public transit options in the city of Dallas meet the affordability requirements of the primary personas, but perform poorly with respect to the remaining persona needs. DART is the main public transit provider in Dallas, and its services include busses, light rail, and commuter rail. DART rail operates from 5 a.m. to midnight daily at every $71 / 2-15$ minutes during rush hours, 20 minutes during the midday and weekends, and 30 minutes late at night. While DART's rail system stretches to distant suburbia, its park-and-ride stations mainly serve commuters trying to reach the city center at high speeds (Martin, Stocker, Cohen, Shaheen \& Brown, 2021). It is common to observe full parking lots at DART stations, where working people living in suburban areas drive to stations and use DART to complete their commutes. In addition, DART is a north-to-south oriented rail system that does not reach vast swaths of Dallas. Operation hours of busses vary by neighborhoods and during holidays, but generally offer limited fixed-route service and infrequent service during midday when older adults travel the most. While DART provides paratransit service for older adults (the primary personas), it is limited to Monday-Friday from 8 a.m. to 5 p.m., necessitating other transportation options for any trip taking place after 5 p.m. on weekdays or weekends. Given that 24/7 service and increased route coverage and service frequency are the most highly ranked transportation service attributes in the $\mathrm{HOQ}$, improving these aspects of the existing bus and train services should be a priority.

Furthermore, long walking distances between bus stops and essential locations are a challenge for the primary personas. Dallas has more than 2.000 miles of sidewalk missing (32\% of total sidewalks) (Macon, 2021), and sidewalks that end abruptly combined with surfaces in disrepair, can put older adults (and any pedestrian) in a dangerous situation. The walkability for older adults living in Dallas is further limited by street/road hybrids where accessibility to essential amenities is disrupted by multilane, 
wide, and high-speed thoroughfares that hinder interactions between people and businesses (Goodyear, 2014; Strong Towns, 2018). Thus, installing and improving sidewalks would help older adults to safely navigate between bus stops; however, in many cases, the distance to transit service is still prohibitive, particularly in the heat of North Texas summers.

In an effort to improve its transit offerings, DART has recently begun offering GoLink, an on-demand point-to-point transit service. This service was initiated as a microtransit system providing noontime transit to corporate employees within the Legacy West zone in Plano (a suburb north of Dallas), and was later expanded to additional areas in North and South Dallas (Martin et al., 2021). While GoLink might initially seem to address the needs of the primary personas, further investigation indicates that this is not the case: DART has received complaints that GoLink serves only suburban and upper-income areas, and DART officials have confirmed that GoLink was not intended for urban and low-income areas as an improvement for fixed-route bus services (Martin et al., 2021).

In contrast to DART services, taxi and ride share offer comfort, spontaneity, and short and direct trips. However, these services are not suitable for the primary personas, due to fear of riding with a stranger, lack of assistance, and the cost. An alternative that performed well in the HOQ analysis is private transit service; for example, Envoy ${ }^{1}$ and SilverRide ${ }^{2}$ are two for-profit companies providing specialized senior transportation for older adults who no longer drive. While SilverRide operates only in the Bay Area, Envoy has operations in the Dallas area. However, these companies charge premium prices for their services, making them out of reach for the low-income primary personas.

To address the affordability requirement of the primary personas, a volunteer-based private transit service could be a good transportation solution. For example, ITNAmerica ${ }^{3}$ is a non-profit providing ride services for older adults by leveraging volunteer drivers and their cars. However, ITNAmerica does not have an affiliate in Dallas, and while its services are more affordable than Envoy and SilverRide, it is not free of cost. Depending on the purpose, duration, and time of the ride, the price of ITNAmerica services can reach as high as the for-profit companies. A more suitable model for non-driving, community-dwelling older adults in Dallas may be borrowed from Drive a Senior ${ }^{4}$, which is a purely volunteer-based driving program offering rides to older adults in the Austin, TX, area with seven affiliates. This program relies on volunteer drivers, legacy givers, online fundraising events, and standard donations from individual citizens to sustain their continuous service to older adults free of charge.

\footnotetext{
${ }^{1}$ https://envoyamerica.com/

2 https://www.silverride.com/

${ }^{3} \mathrm{https}: / /$ www.itnamerica.org/

${ }^{4}$ https://driveasenior.org/
} 


\subsection{APPLICATION OF 1000MINDS}

In the first step of 1000minds execution, the transportation options for the primary personas are identified as follows: DART train, DART bus, DART paratransit, taxi/cab, riding with family/friends, and ride share. Although a volunteer driver program (similar to Drive-a-Senior in Austin, TX) does not exist in the Dallas area, this option is included in the alternatives as a potential service to address the needs of the primary personas. In the second step, the needs of the primary personas are used as the criteria for transportation alternatives. The identified criteria should be mutually exclusive in order to eliminate ambiguity in the trade-off step. Safety as a single criterion is excluded from the criteria since it is embedded in various aspects of transportation and should not be an item to trade-off. However, one aspect of safety (riding with others) is included in further analysis since it frequently appears in literature as a concern for lack of use for ride share. Since flexibility is highly correlated with accessibility and direct and short trips, this criterion is also excluded. In addition, walkability, as the most basic transportation option and a vital element of the built environment, is also a gateway to other transportation options. Therefore, walkability is not included in the trade-off analysis.

In the third step, the levels of each criteria are identified as in Table 5.7, detailing the criteria and the levels of each criterion for the 1000minds trade-offs.

Table 5.7: The Criteria and the Levels of Each Criterion for the 1000minds Trade-offs

\begin{tabular}{|c|c|c|}
\hline Rank & \multicolumn{2}{|r|}{ Affordability } \\
\hline \multirow{5}{*}{ Lowest rank } & \multicolumn{2}{|r|}{$\$ 20+$ (one way) } \\
\hline & \multicolumn{2}{|r|}{ \$10-\$20 (one way) } \\
\hline & \multicolumn{2}{|r|}{$\$ 5-\$ 10$ (one way) } \\
\hline & \multicolumn{2}{|r|}{$\$ 2-\$ 5$ (one way) } \\
\hline & \multicolumn{2}{|r|}{ \$1-\$2 (one way) } \\
\hline Highest rank & \multicolumn{2}{|r|}{ Free } \\
\hline Rank & \multicolumn{2}{|r|}{ Assistance } \\
\hline \multirow[t]{3}{*}{ Lowest rank } & No assistance & - Driver (not trained) does not assist \\
\hline & $\begin{array}{l}\text { Assistance only } \\
\text { with information }\end{array}$ & $\begin{array}{l}\text { - Driver (not trained) may assist only with } \\
\text { information }\end{array}$ \\
\hline & $\begin{array}{l}\text { Assistance with } \\
\text { information and } \\
\text { physical needs }\end{array}$ & $\begin{array}{l}\text { - Driver (trained) assists with information } \\
\text { and physical needs } \\
\text { - Or there is trained staff responsible to } \\
\text { assist older adults other than the driver }\end{array}$ \\
\hline Rank & \multicolumn{2}{|r|}{ Reliability } \\
\hline \multirow[t]{4}{*}{ Lowest rank } & Long wait time & $\begin{array}{l}\text { - Frequent route changes and service } \\
\text { cancellations } \\
-20-40 \text { min. wait time }\end{array}$ \\
\hline & $\begin{array}{l}\text { Somewhat long } \\
\text { wait time }\end{array}$ & $\begin{array}{l}\text { - Limited vehicle availability at the time of } \\
\text { request } \\
\text { - Waiting for in-advance scheduled service, } \\
\text { other passengers, or waiting in traffic } \\
-10-20 \text { min. wait time }\end{array}$ \\
\hline & $\begin{array}{l}\text { Somewhat short } \\
\text { wait time }\end{array}$ & $\begin{array}{l}\text { - Limited vehicle availability } \\
\text { - 5-10 min. wait time }\end{array}$ \\
\hline & Very short wait time & - Reserved vehicle in advance \\
\hline
\end{tabular}




\begin{tabular}{|l|l|l|}
\hline & & $\begin{array}{l}\text { - Vehicle at location on time } \\
- \text { Slight variation due to traffic } \\
-0-5 \text { min. wait time }\end{array}$ \\
\hline Highest rank & \\
\hline
\end{tabular}

\begin{tabular}{|c|c|c|}
\hline Rank & \multicolumn{2}{|r|}{ Spontaneity } \\
\hline \multirow[t]{5}{*}{ Lowest rank } & Not at all spontaneous & - Schedule/plan 2-4 weeks in advance \\
\hline & Slightly spontaneous & - Schedule/plan 1-2 weeks in advance \\
\hline & $\begin{array}{l}\text { Moderately } \\
\text { spontaneous }\end{array}$ & - Schedule/plan 3-7 days in advance \\
\hline & Very spontaneous & - Schedule/plan 1-3 days in advance \\
\hline & Extremely spontaneous & $\begin{array}{l}\text { - Schedule/plan/take the trip within a day } \\
\text { or as soon as needed }\end{array}$ \\
\hline \multicolumn{3}{|l|}{ Highest rank } \\
\hline Rank & \multicolumn{2}{|c|}{ Accessibility to Transit and Stops } \\
\hline \multirow[t]{3}{*}{ Lowest rank } & Not at all accessible & - Access point to transit $1-1.5$ miles away \\
\hline & Slightly accessible & $\begin{array}{l}\text { - Access point to transit } 0.75-1 \text { miles } \\
\text { away }\end{array}$ \\
\hline & Moderately accessible & $\begin{array}{l}\text { - Access point to transit } 0.5-0.75 \text { miles } \\
\text { away }\end{array}$ \\
\hline \multirow[t]{2}{*}{ Highest rank } & Very accessible & $\begin{array}{l}\text { - Access point to transit } 0.25-0.5 \text { miles } \\
\text { away }\end{array}$ \\
\hline & Extremely accessible & $\begin{array}{l}\text { - Access point to transit } 0-0.25 \text { miles } \\
\text { away }\end{array}$ \\
\hline Rank & \multicolumn{2}{|c|}{ Physical Comfort in Vehicle } \\
\hline \multirow[t]{4}{*}{ Lowest Rank } & Not at all comfortable & $\begin{array}{l}\text { - Vehicle is not clean } \\
\text { - No priority seating and no privacy } \\
\text { - Seats are uncomfortable } \\
\text { - Rides are rough and bumpy } \\
\text { - Fast and sudden acceleration and } \\
\text { deceleration }\end{array}$ \\
\hline & Slightly comfortable & $\begin{array}{l}\text { - Occasionally there is trash in vehicle } \\
\text { - Priority seating available without } \\
\text { privacy } \\
\text { - Seats are uncomfortable } \\
\text { - Rides can be rough and } \\
\text { - Occasionally fast and sudden } \\
\text { acceleration and deceleration }\end{array}$ \\
\hline & Moderately comfortable & $\begin{array}{l}\text { - Vehicles are clean } \\
\text { - Priority seating available } \\
\text { - No privacy } \\
\text { - Seats are comfortable } \\
\text { - Rides are rarely rough and bumpy } \\
\text { - Smooth ride }\end{array}$ \\
\hline & Very comfortable & $\begin{array}{l}\text { - Vehicles are clean } \\
\text { - Private seating (vehicle is not shared } \\
\text { with others except the driver) } \\
\text { - Seats are comfortable } \\
\text { - Never bumpy or rough rides } \\
\text { - Smooth ride }\end{array}$ \\
\hline
\end{tabular}




\begin{tabular}{|c|c|c|}
\hline Rank & \multicolumn{2}{|c|}{ Direct and Short Trips } \\
\hline \multirow[t]{3}{*}{ Lowest rank } & Not at all direct and short & $\begin{array}{l}\text { - Driving all around the city to pick } \\
\text { up/drop off others } \\
\text { - Transiting more than } 2 \text { vehicles to get } \\
\text { to destination } \\
\text { - Trip takes all day }\end{array}$ \\
\hline & $\begin{array}{l}\text { Somewhat direct and } \\
\text { short }\end{array}$ & $\begin{array}{l}\text { - Picking up others only at } 2-3-\text { mile } \\
\text { radius } \\
\text { - Transiting } 2 \text { vehicles to get to } \\
\text { destination } \\
\text { - Trip takes half of the day }\end{array}$ \\
\hline & Very direct and short & $\begin{array}{l}\text { - Picking up others only at } 1-2-\text { mile } \\
\text { radius } \\
\text { - No need to transit ( } 1 \text { vehicle) } \\
\text { - Trip takes } 1-2 \text { hours of the day }\end{array}$ \\
\hline Rank & \multicolumn{2}{|c|}{ Riding with Others } \\
\hline \multirow[t]{2}{*}{ Lowest Rank } & $\begin{array}{l}\text { Afraid of riding with } \\
\text { others }\end{array}$ & $\begin{array}{l}\text { - Afraid of riding with stranger(s) } \\
\text { - Able to ride with familiar and trusted } \\
\text { people }\end{array}$ \\
\hline & $\begin{array}{l}\text { Somewhat afraid of } \\
\text { riding with others }\end{array}$ & $\begin{array}{l}\text { - Concerned about riding with strangers } \\
\text { but still rides due to lack of another } \\
\text { option }\end{array}$ \\
\hline Highest Rank & $\begin{array}{l}\text { Not afraid of riding with } \\
\text { others }\end{array}$ & - Not afraid of riding with strangers \\
\hline
\end{tabular}

In the fourth step, each transportation option is assigned a level for each criterion, based on the collective results from the primary and secondary personas. Table 5.8 demonstrates criterion level of each transportation option. 
Table 5.8: Criterion Levels of Each Transportation Option

\begin{tabular}{|c|c|c|c|c|c|c|c|c|}
\hline $\begin{array}{l}\text { Transportatio } \\
\text { n Options }\end{array}$ & $\begin{array}{l}\text { Affordabili } \\
\text { ty }\end{array}$ & Assistance & Reliability & Spontaneity & $\begin{array}{l}\text { Accessibility } \\
\text { to Transit and } \\
\text { Stops }\end{array}$ & $\begin{array}{l}\text { Physical } \\
\text { Comfort in } \\
\text { Vehicle }\end{array}$ & $\begin{array}{l}\text { Direct and Short } \\
\text { Trips }\end{array}$ & $\begin{array}{l}\text { Riding with } \\
\text { Others }\end{array}$ \\
\hline $\begin{array}{l}\text { Volunteer } \\
\text { driver }\end{array}$ & Free & $\begin{array}{l}\text { Assistance } \\
\text { with info. } \\
\text { and physical } \\
\text { needs }\end{array}$ & $\begin{array}{l}\text { Very short } \\
\text { wait time }\end{array}$ & $\begin{array}{l}\text { Moderately } \\
\text { spontaneous }\end{array}$ & $\begin{array}{l}\text { Extremely } \\
\text { accessible }\end{array}$ & Very comfortable & Very direct and short & $\begin{array}{l}\text { Not afraid of riding } \\
\text { with others }\end{array}$ \\
\hline $\begin{array}{l}\text { Riding with } \\
\text { family/friends }\end{array}$ & Free & $\begin{array}{l}\text { Assistance } \\
\text { with info. } \\
\text { and physical } \\
\text { needs }\end{array}$ & $\begin{array}{l}\text { Somewhat } \\
\text { short wait } \\
\text { time }\end{array}$ & $\begin{array}{l}\text { Very } \\
\text { spontaneous }\end{array}$ & $\begin{array}{l}\text { Extremely } \\
\text { accessible }\end{array}$ & Very comfortable & Very direct and short & $\begin{array}{l}\text { Not afraid of riding } \\
\text { with others }\end{array}$ \\
\hline Ride share & $\begin{array}{l}\$ 10-\$ 20 \\
\text { (one way) }\end{array}$ & $\begin{array}{l}\text { Assistance } \\
\text { only with } \\
\text { information }\end{array}$ & $\begin{array}{l}\text { Somewhat } \\
\text { short wait } \\
\text { time }\end{array}$ & $\begin{array}{l}\text { Extremely } \\
\text { spontaneous }\end{array}$ & $\begin{array}{l}\text { Extremely } \\
\text { accessible }\end{array}$ & $\begin{array}{l}\text { Moderately } \\
\text { comfortable }\end{array}$ & Very direct and short & $\begin{array}{l}\text { Somewhat afraid of } \\
\text { riding with others }\end{array}$ \\
\hline $\begin{array}{l}\text { Dart } \\
\text { paratransit }\end{array}$ & $\begin{array}{l}\$ 2-\$ 5 \\
\text { (one way) }\end{array}$ & $\begin{array}{l}\text { Assistance } \\
\text { with info. } \\
\text { and physical } \\
\text { needs }\end{array}$ & $\begin{array}{l}\text { Somewhat } \\
\text { long wait } \\
\text { time }\end{array}$ & $\begin{array}{l}\text { Not at all } \\
\text { spontaneous }\end{array}$ & $\begin{array}{l}\text { Extremely } \\
\text { accessible }\end{array}$ & $\begin{array}{l}\text { Moderately } \\
\text { comfortable }\end{array}$ & $\begin{array}{l}\text { Somewhat direct } \\
\text { and short }\end{array}$ & $\begin{array}{l}\text { Not afraid of riding } \\
\text { with others }\end{array}$ \\
\hline Taxi/cab & $\begin{array}{l}\$ 20+ \\
\text { (one way) }\end{array}$ & $\begin{array}{l}\text { Assistance } \\
\text { only with } \\
\text { information }\end{array}$ & $\begin{array}{l}\text { Somewhat } \\
\text { long wait } \\
\text { time }\end{array}$ & $\begin{array}{l}\text { Very } \\
\text { spontaneous }\end{array}$ & $\begin{array}{l}\text { Extremely } \\
\text { accessible }\end{array}$ & $\begin{array}{l}\text { Moderately } \\
\text { comfortable }\end{array}$ & Very direct and short & $\begin{array}{l}\text { Somewhat afraid of } \\
\text { riding with others }\end{array}$ \\
\hline Dart Bus & $\begin{array}{l}\$ 1-\$ 2 \\
\text { (one way) }\end{array}$ & $\begin{array}{l}\text { No } \\
\text { assistance }\end{array}$ & $\begin{array}{l}\text { Long wait } \\
\text { time }\end{array}$ & $\begin{array}{l}\text { Moderately } \\
\text { spontaneous }\end{array}$ & $\begin{array}{l}\text { Slightly } \\
\text { accessible }\end{array}$ & $\begin{array}{l}\text { Slightly } \\
\text { comfortable }\end{array}$ & $\begin{array}{l}\text { Not at all direct and } \\
\text { short }\end{array}$ & $\begin{array}{l}\text { Afraid of riding with } \\
\text { others }\end{array}$ \\
\hline Dart Train & $\begin{array}{l}\$ 1-\$ 2 \\
\text { (one way) }\end{array}$ & $\begin{array}{l}\text { No } \\
\text { assistance }\end{array}$ & $\begin{array}{l}\text { Long wait } \\
\text { time }\end{array}$ & $\begin{array}{l}\text { Moderately } \\
\text { spontaneous }\end{array}$ & $\begin{array}{l}\text { Not at all } \\
\text { accessible }\end{array}$ & $\begin{array}{l}\text { Slightly } \\
\text { comfortable }\end{array}$ & $\begin{array}{l}\text { Not at all direct and } \\
\text { short }\end{array}$ & $\begin{array}{l}\text { Afraid of riding with } \\
\text { others }\end{array}$ \\
\hline
\end{tabular}


In the fifth step, separate rounds of trade-offs are performed for each primary persona. Figure 5.7 demonstrates an example of a trade-off performed by a decision-maker from the perspective of the persona.
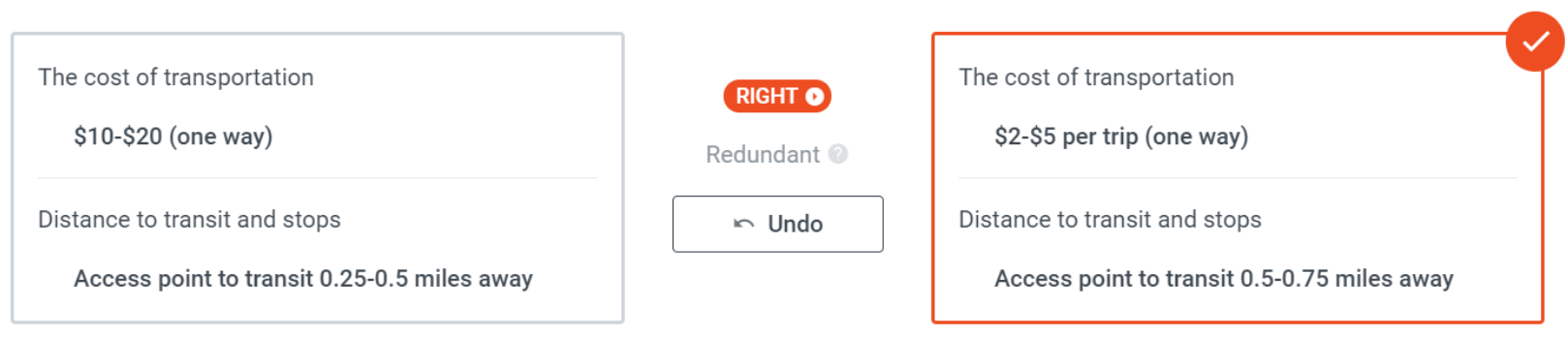

Figure 5.7: Example of a Trade-off in 1000minds

After completing a series of pairwise trade-offs as shown in Figure 5.7,1000minds calculates an accuracy level as a measure of confidence of the results. If this accuracy level is greater than $90 \%$, the utilities of criteria and the ranked alternatives obtained from the trade-offs can be confidently used in further decisions. The accuracy levels of trade-offs for Elizabeth, Cassandra and Beatrice are 99\%, 98\%, and 92\%, respectively. The utilities of criteria are presented in Table 5.9 for each primary persona. Sequence of criteria for each persona is given in descending order of criteria weights. 
Table 5.9: Criteria Weights and Utilities for Elizabeth

\begin{tabular}{|c|c|c|c|c|}
\hline Criteria & Criterion Levels & $\begin{array}{l}\text { Criterion Weight } \\
(\text { sum }=1)\end{array}$ & $\begin{array}{l}\text { Score }(0- \\
100)\end{array}$ & $\begin{array}{l}\text { Utility } \\
(\%)\end{array}$ \\
\hline \multirow{5}{*}{$\begin{array}{l}\text { Accessibility to Transit } \\
\text { and Stops }\end{array}$} & Not at all accessible & \multirow{5}{*}{0.269} & 0 & 0 \\
\hline & Slightly accessible & & 19.7 & 5.3 \\
\hline & Moderately accessible & & 39.3 & 10.6 \\
\hline & Very accessible & & 74.6 & 20.1 \\
\hline & Extremely accessible & & 100 & 26.9 \\
\hline \multirow{6}{*}{ Affordability } & $\$ 20+$ (one way) & \multirow{6}{*}{0.217} & 0 & 0 \\
\hline & $\$ 10-\$ 20$ (one way) & & 35.3 & 7.6 \\
\hline & $\$ 5-\$ 10$ (one way) & & 68.3 & 14.8 \\
\hline & $\$ 2-\$ 5$ (one way) & & 84.2 & 18.2 \\
\hline & $\$ 1-\$ 2$ (one way) & & 92.8 & 20.1 \\
\hline & Free & & 100 & 21.7 \\
\hline \multirow{5}{*}{ Spontaneity } & Not al all spontaneous & \multirow{5}{*}{0.153} & 0 & 0 \\
\hline & Slightly spontaneous & & 10.2 & 1.6 \\
\hline & Moderately spontaneous & & 50 & 7.6 \\
\hline & Very spontaneous & & 60.2 & 9.2 \\
\hline & Extremely spontaneous & & 100 & 15.3 \\
\hline \multirow{3}{*}{ Direct and Short Trips } & Not at all direct and short & \multirow{3}{*}{0.14} & 0 & 0 \\
\hline & Somewhat direct and short & & 75.6 & 10.6 \\
\hline & Very direct and short & & 100 & 14 \\
\hline \multirow{4}{*}{ Reliability } & Long wait time & \multirow{4}{*}{0.125} & 0 & 0 \\
\hline & Somewhat long wait time & & 15 & 1.9 \\
\hline & Somewhat short wait time & & 76.2 & 9.5 \\
\hline & Very short wait time & & 100 & 12.5 \\
\hline \multirow{4}{*}{$\begin{array}{l}\text { Physical Comfort in } \\
\text { Vehicle }\end{array}$} & Not at all comfortable & \multirow{4}{*}{0.037} & 0 & 0 \\
\hline & Slightly comfortable & & 25 & 0.9 \\
\hline & Moderately comfortable & & 83.3 & 3.1 \\
\hline & Very comfortable & & 100 & 3.7 \\
\hline \multirow{3}{*}{ Riding with Others } & Afraid of riding with strangers & \multirow{3}{*}{0.034} & 0 & 0 \\
\hline & $\begin{array}{l}\text { Somewhat afraid of riding with } \\
\text { strangers }\end{array}$ & & 45.5 & 1.6 \\
\hline & Not afraid of riding with strangers & & 100 & 3.4 \\
\hline \multirow{3}{*}{ Assistance } & No help or assistance & \multirow{3}{*}{0.025} & 0 & 0 \\
\hline & $\begin{array}{l}\text { Help or assistance only } \\
\text { information }\end{array}$ & & 75 & 1.9 \\
\hline & $\begin{array}{l}\text { Help or assistance with } \\
\text { information and physical needs }\end{array}$ & & 100 & 2.5 \\
\hline
\end{tabular}


Table 5.10: Criteria Weights and Utilities for Cassandra

\begin{tabular}{|c|c|c|c|c|}
\hline Criteria & Criterion Levels & $\begin{array}{l}\text { Criterion Weight } \\
\text { (sum = 1) }\end{array}$ & $\begin{array}{l}\text { Score } \\
(0-100)\end{array}$ & $\begin{array}{l}\text { Utility } \\
(\%)\end{array}$ \\
\hline \multirow{6}{*}{ Affordability } & $\$ 20+$ (one way) & \multirow{6}{*}{0.42} & 0 & 0 \\
\hline & $\$ 10-\$ 20$ (one way) & & 30.4 & 12.8 \\
\hline & $\$ 5-\$ 10$ (one way) & & 47.8 & 20.1 \\
\hline & $\$ 2-\$ 5$ (one way) & & 65.2 & 27.4 \\
\hline & $\$ 1-\$ 2$ (one way) & & 92.5 & 38.9 \\
\hline & Free & & 100 & 42 \\
\hline \multirow{5}{*}{$\begin{array}{l}\text { Accessibility to } \\
\text { Transit and Stops }\end{array}$} & Not at all accessible & \multirow{5}{*}{0.175} & 0 & 0 \\
\hline & Slightly accessible & & 32.8 & 5.7 \\
\hline & Moderately accessible & & 67.2 & 11.7 \\
\hline & Very accessible & & 83.6 & 14.6 \\
\hline & Extremely accessible & & 100 & 17.5 \\
\hline \multirow{3}{*}{ Direct and Short Trips } & Not at all direct and short & \multirow{3}{*}{0.146} & 0 & 0 \\
\hline & Somewhat direct and short & & 39.3 & 5.7 \\
\hline & Very direct and short & & 100 & 14.6 \\
\hline \multirow{4}{*}{ Reliability } & Long wait time & \multirow{4}{*}{0.128} & 0 & 0 \\
\hline & Somewhat long wait time & & 57.1 & 7.3 \\
\hline & Somewhat short wait time & & 91.8 & 11.7 \\
\hline & Very short wait time & & 100 & 12.8 \\
\hline \multirow{3}{*}{ Riding with Others } & Afraid of riding with strangers & \multirow{3}{*}{0.063} & 0 & 0 \\
\hline & $\begin{array}{l}\text { Somewhat afraid of riding with } \\
\text { strangers }\end{array}$ & & 95.8 & 6 \\
\hline & Not afraid of riding with strangers & & 100 & 6.3 \\
\hline \multirow{5}{*}{ Spontaneity } & Not al all spontaneous & \multirow{5}{*}{0.026} & 0 & 0 \\
\hline & Slightly spontaneous & & 20 & 0.5 \\
\hline & Moderately spontaneous & & 40 & 1 \\
\hline & Very spontaneous & & 80 & 2.1 \\
\hline & Extremely spontaneous & & 100 & 2.6 \\
\hline \multirow{3}{*}{ Assistance } & No help or assistance & \multirow{3}{*}{0.021} & 0 & 0 \\
\hline & Help or assistance only information & & 25 & 0.5 \\
\hline & $\begin{array}{l}\text { Help or assistance with information } \\
\text { and physical needs }\end{array}$ & & 100 & 2.1 \\
\hline \multirow{4}{*}{$\begin{array}{l}\text { Physical Comfort in } \\
\text { Vehicle }\end{array}$} & Not at all comfortable & \multirow{4}{*}{0.021} & 0 & 0 \\
\hline & Slightly comfortable & & 25 & 0.5 \\
\hline & Moderately comfortable & & 50 & 1 \\
\hline & Very comfortable & & 100 & 2.1 \\
\hline
\end{tabular}


Table 5.11: Criteria Weights and Utilities for Beatrice

\begin{tabular}{|c|c|c|c|c|}
\hline Criteria & Criterion Levels & $\begin{array}{l}\text { Criterion Weight } \\
\text { (sum = 1) }\end{array}$ & $\begin{array}{l}\text { Score } \\
(0-100)\end{array}$ & $\begin{array}{l}\text { Utility } \\
(\%)\end{array}$ \\
\hline \multirow{3}{*}{ Assistance } & No help or assistance & \multirow{3}{*}{0.252} & 0 & 0 \\
\hline & Help or assistance only information & & 49.6 & 12.5 \\
\hline & $\begin{array}{l}\text { Help or assistance with information } \\
\text { and physical needs }\end{array}$ & & 100 & 25.2 \\
\hline \multirow{5}{*}{$\begin{array}{l}\text { Accessibility to } \\
\text { Transit and Stops }\end{array}$} & Not at all accessible & \multirow{5}{*}{0.229} & 0 & 0 \\
\hline & Slightly accessible & & 12.5 & 2.9 \\
\hline & Moderately accessible & & 17.9 & 4.1 \\
\hline & Very accessible & & 67 & 15.3 \\
\hline & Extremely accessible & & 100 & 22.9 \\
\hline \multirow{4}{*}{ Reliability } & Long wait time & \multirow{4}{*}{0.145} & 0 & 0 \\
\hline & Somewhat long wait time & & 77.5 & 11.2 \\
\hline & Somewhat short wait time & & 85.9 & 12.5 \\
\hline & Very short wait time & & 100 & 14.5 \\
\hline \multirow{3}{*}{ Direct and Short Trips } & Not at all direct and short & \multirow{3}{*}{0.125} & 0 & 0 \\
\hline & Somewhat direct and short & & 73.8 & 9.2 \\
\hline & Very direct and short & & 100 & 12.5 \\
\hline \multirow{4}{*}{$\begin{array}{l}\text { Physical Comfort in } \\
\text { Vehicle }\end{array}$} & Not at all comfortable & \multirow{4}{*}{0.125} & 0 & 0 \\
\hline & Slightly comfortable & & 9.8 & 1.2 \\
\hline & Moderately comfortable & & 83.6 & 10.4 \\
\hline & Very comfortable & & 100 & 12.5 \\
\hline \multirow{6}{*}{ Affordability } & $\$ 20+$ (one way) & \multirow{6}{*}{0.09} & 0 & 0 \\
\hline & $\$ 10-\$ 20$ (one way) & & 36.4 & 3.3 \\
\hline & $\$ 5-\$ 10$ (one way) & & 61.4 & 5.5 \\
\hline & $\$ 2-\$ 5$ (one way) & & 68.2 & 6.1 \\
\hline & $\$ 1-\$ 2$ (one way) & & 81.8 & 7.4 \\
\hline & Free & & 100 & 9 \\
\hline \multirow{5}{*}{ Spontaneity } & Not al all spontaneous & \multirow{5}{*}{0.031} & 0 & 0 \\
\hline & Slightly spontaneous & & 40 & 1.2 \\
\hline & Moderately spontaneous & & 60 & 1.8 \\
\hline & Very spontaneous & & 80 & 2.5 \\
\hline & Extremely spontaneous & & 100 & 3.1 \\
\hline \multirow{3}{*}{ Riding with Others } & Afraid of riding with strangers & \multirow{3}{*}{0.004} & 0 & 0 \\
\hline & $\begin{array}{l}\text { Somewhat afraid of riding with } \\
\text { strangers }\end{array}$ & & 50 & 0.2 \\
\hline & Not afraid of riding with strangers & & 100 & 0.4 \\
\hline
\end{tabular}




\section{Ranked Transportation Options for Elizabeth}

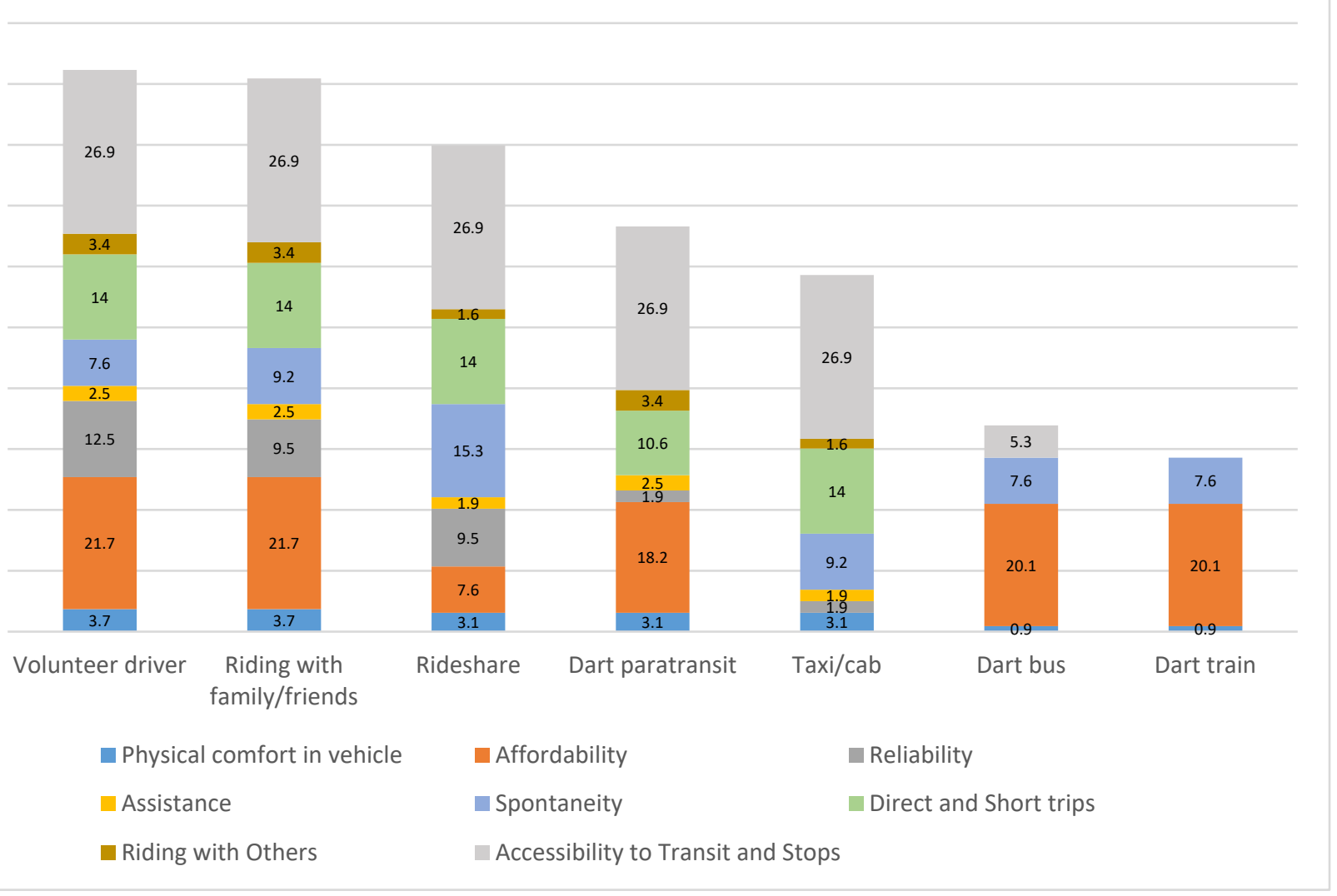

Figure 5.8: Ranked Transportation Options for Elizabeth 


\section{Ranked Transportation Options for Cassandra}

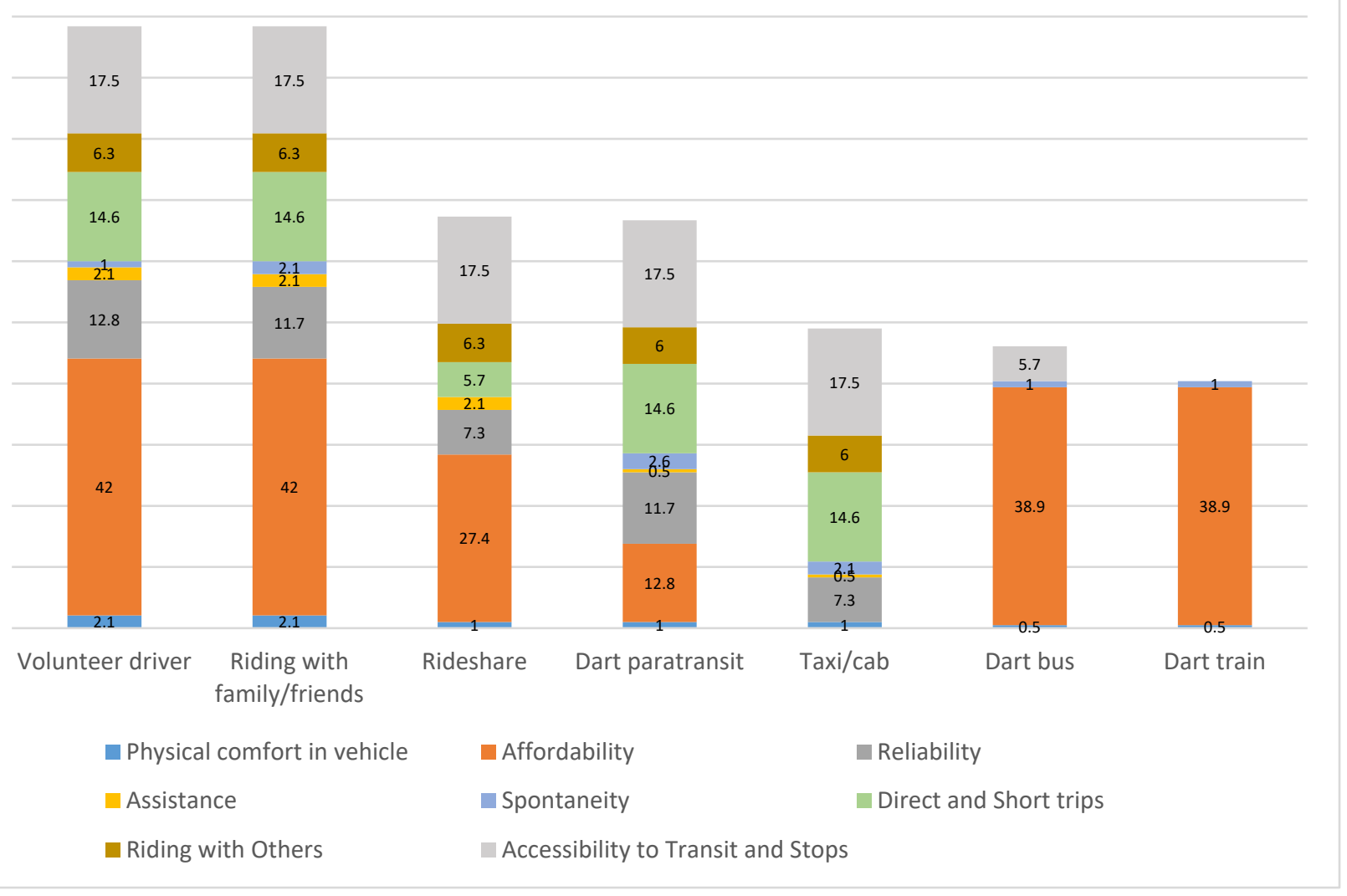

Figure 5.9: Ranked Transportation Options for Cassandra 


\section{Ranked Transportation Options for Beatrice}

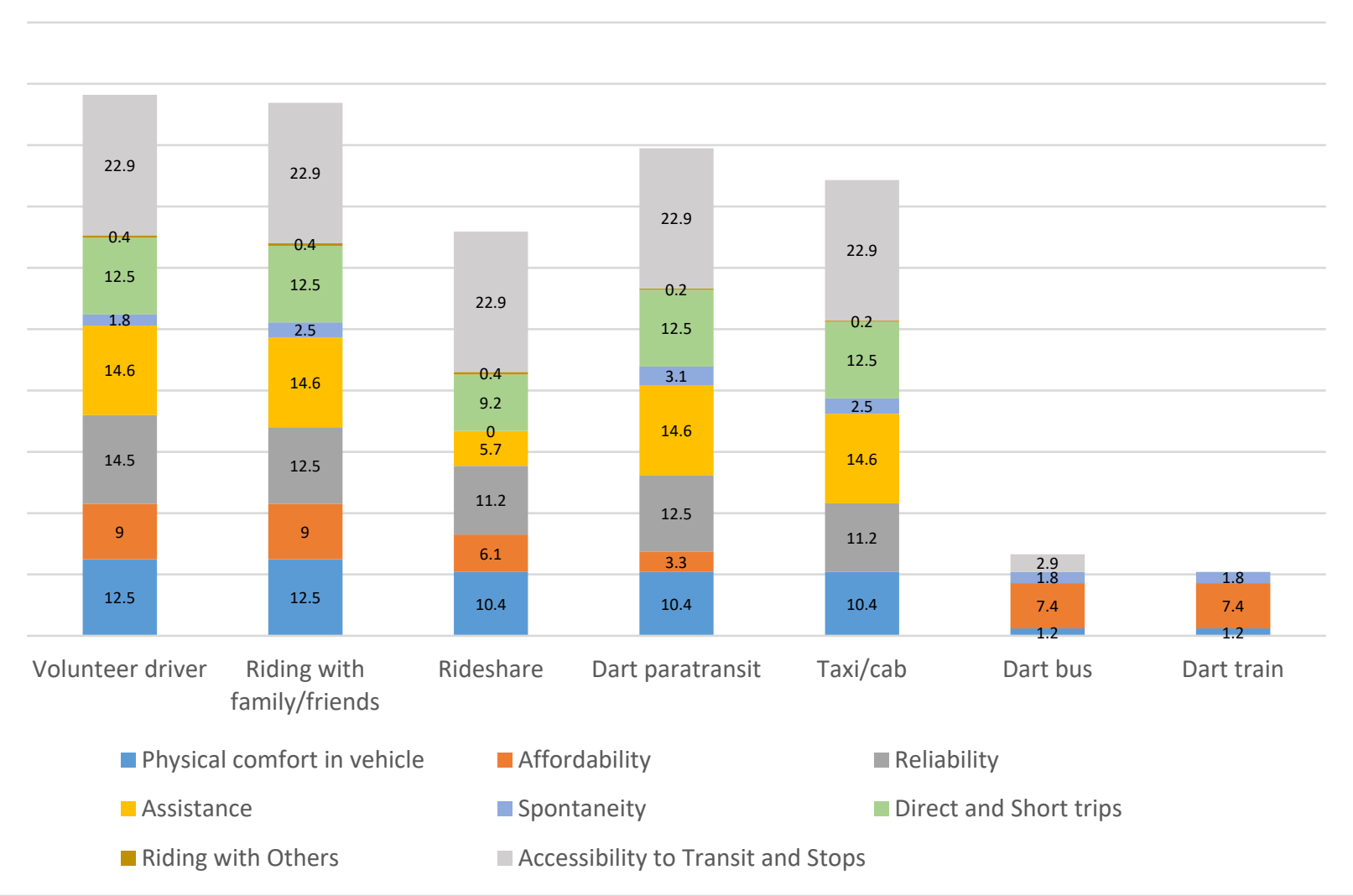

Figure 5.10: Ranked Transportation Options for Beatrice

Volunteer driver option is the highest ranked for all primary personas. Riding with family/friends closely follows the volunteer driver option. While the ride share option is in the fifth place for Beatrice, it is the third preferred option for Elizabeth and Cassandra. DART bus and train are the lowest-ranked alternatives for all primary personas. The volunteer driver option is ranked in the first place due to different reasons for each primary persona. Accessibility, assistance, and comfort are the main reasons for Elizabeth to prefer a volunteer driver. Cassandra's preference for the volunteer driver option is heavily impacted by its affordability. Elizabeth prefers a volunteer driver for its affordability and ease of access.

\subsection{USING 1000MINDS RESULTS FOR AGENT-BASED MODELING}

The criteria weights and scores identified for the primary personas in the previous section are used to create utility functions as a measure of personas' satisfaction with three transportation modes: volunteer drivers, ride share service, and DART bus. Each agent's utility function is a weighted sum of the scaled satisfaction scores $S_{i, t, c}$, where $i$ indicates the persona, $t$ represents the transportation mode, and $c$ is the characteristic 
of the mode. The parameter $c$ takes on the following values: physical comfort in vehicle is represented by $p h$, affordability by $a f$, reliability by $r e$, assistance by $a s$, spontaneity by $s p$, direct and short trips by $d s$, riding with others $r o$, and accessibility by $a c$. The values of the satisfaction scores are derived from the PAPRIKA outputs in Tables 5.9, 5.10 , and 5.11. The parameters $\beta_{i, c}$ are the relative weights on each score for each persona $i$ and transportation mode characteristic $c$. The values assigned to each $\beta_{i, c}$ are obtained from PAPRIKA results given in Tables 5.9, 5.10, and 5.11. An agent's satisfaction depends on the ratio of the number of trips taken with each transportation mode $t\left(n_{t}\right)$ to the total number of trips attempted $\left(n_{\text {total }}\right)$, based on the assumption that its satisfaction is a cumulative result of its experiences with a given mode. The utility $U_{i, t}$ of each agent having persona type $i$ for transportation mode $t$ is given in Equation 1:

$$
\begin{aligned}
U_{i, t}=\beta_{i, p h}( & \left.S_{i, t, p h} * \frac{n_{t}}{n_{\text {total }}}\right)+\beta_{i, a f}\left(S_{i, t, a f} * \frac{n_{t}}{n_{\text {total }}}\right)+\beta_{i, r e}\left(S_{i, t, r e} * \frac{n_{t}}{n_{\text {total }}}\right) \\
& +\beta_{i, a s}\left(S_{i, t, a s} * \frac{n_{t}}{n_{\text {total }}}\right)+\beta_{i, s p}\left(S_{i, t, s p} * \frac{n_{t}}{n_{\text {total }}}\right)+\beta_{i, d s}\left(S_{i, t, d s} * \frac{n_{t}}{n_{\text {total }}}\right) \\
& +\beta_{i, r o}\left(S_{i, t, r o} * \frac{n_{t}}{n_{\text {total }}}\right)+\beta_{i, a c}\left(S_{i, t, a c} * \frac{n_{t}}{n_{\text {total }}}\right)
\end{aligned}
$$

\subsection{AGENT-BASED MODEL (ABM)}

Next, the utility functions are embedded within three agents in a conceptual agentbased model (implemented in NetLogo). Each of the three agents represents a primary persona. The origin point of ABM environment represents downtown Dallas, and the agents' homes are located in accordance with the persona narratives: five miles northeast, 10 miles south, and 16 miles north of downtown.

Furthermore, a grocery store location is created for each primary persona, based on the assumption that older adults tend to go to the same grocery store. The locations of the grocery stores are randomly assigned at a proportional distance based on the fact that the average household primarily shops at a store 3.79 miles from home (Mentzer \& Mancino, 2015). The agents' grocery store trips are scheduled on a monthly basis, and the agents are assumed to make these trips on the same day each month. Each month is assumed to have 30 days, and the model is run for 12 months. Table 5.12 details the monthly schedules of the agents.

Table 5.12: Agents' Monthly Grocery Trip Schedules

\begin{tabular}{l|l}
\hline Agents & Monthly Schedule \\
\hline Elizabeth & $1^{\text {st }}, 8^{\text {th }}, 15^{\text {th }}$, and $22^{\text {nd }}$ of each month \\
\hline Cassandra & $2^{\text {nd }}, 9^{\text {th }}, 16^{\text {th }}$, and $23^{\text {rd }}$ of each month \\
\hline Beatrice & $3^{\text {rd }}, 10^{\text {th }}, 17^{\text {th }}$, and $24^{\text {th }}$ of each month \\
\hline
\end{tabular}

Each time-step corresponds to one day. Since grocery trips are essential, it is assumed that the agents will go to grocery stores consistently, according to their schedules; however, a $10 \%$ allowance is assigned to account for potential trip cancellations due to 
events such as health issues and hazardous weather conditions. After each simulated trip, each agent will calculate the utility it gained from the trip and will then store this value in its "memory."

\section{Experiments}

In the first set of experiments, each agent is allowed to use a single transportation option for its grocery trips over 12 simulated months Their overall utility levels at the end of each simulation run are provided in Figure 5.11.

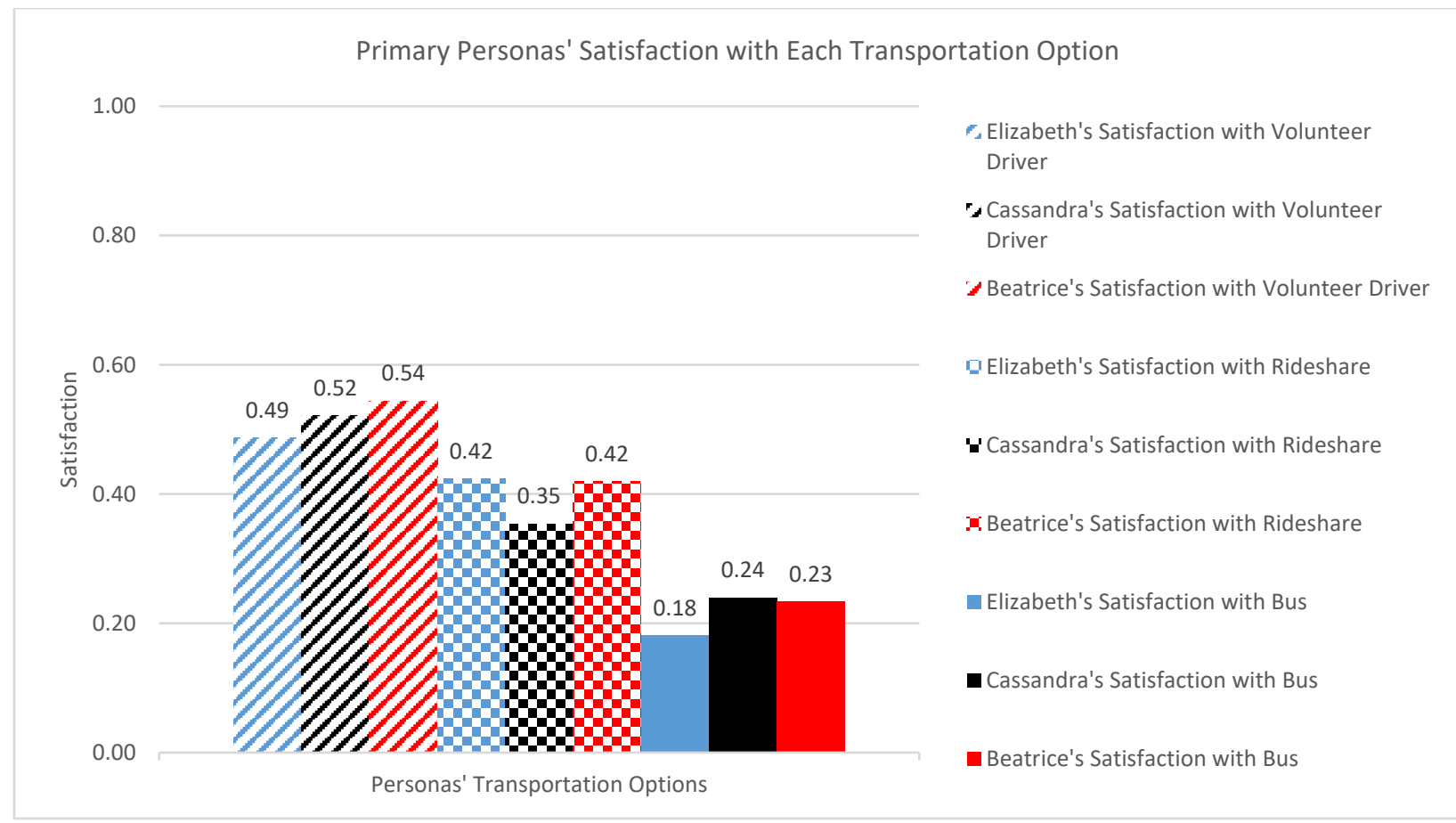

Figure 5.11: Primary Personas' Satisfaction with Each Transportation Option

In the second set of experiments, the change in agents' satisfaction levels is observed when improvements to ride share and bus services are introduced. A potential partnership with ride share companies is introduced to provide a $50 \%$ discount for older adults and trained drivers to help provide information and assist riders with physical needs. Furthermore, new bus routes were added with more frequent bus stops, such that wait times for bus services are reduced from 20-40 minutes to 5-10 minutes. Figure 5.14 shows agents' satisfaction levels for their transportation options after these improvements. 


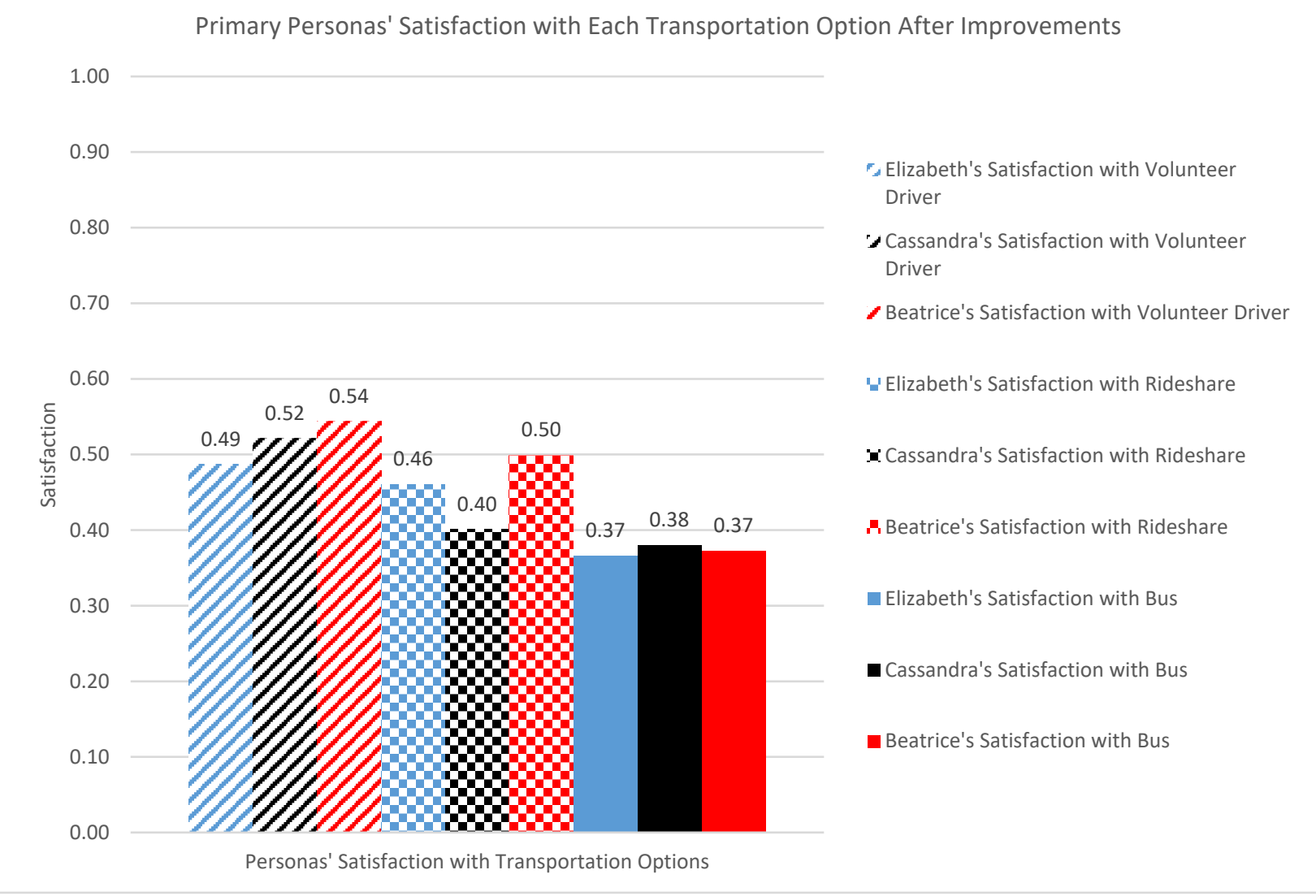

Figure 5.12: Primary Personas' Satisfaction with Each Transportation Option After Improvements

\subsection{QUALITATIVE ANALYSIS TO EXPLORE FACTORS ENHANCING RESILIENCE DURING THE COVID-19 PANDEMIC}

Two themes emerged from the data: (1) sedentary behaviors and (2) the negative impact on mental health and social well-being that reflected major challenges that our participants experienced during the COVID-19 pandemic. To respond to such challenges, we were able to identify various coping strategies addressed across the participants and developed four major themes based on the individual, social, and built environments: (1) individual environment: use of technology; (2) social environment: informal support from family and neighbors; (3) social environment: formal support from community organizations for older adults; and (4) built environment: walkable neighborhoods. To increase trustworthiness in our study, we conducted peer debriefings and stakeholder checks (Janesick, 2007; Thomas, 2006). Our results were also reported to an advocacy group for elders at our partner agency. We use pseudonyms when presenting our findings. 


\section{Sedentary Behaviors}

Many participants said restrictions against congregating, gatherings, and group exercise at senior centers affected their overall physical health. One participant, Mary, claimed that she used to be active in spite of her limited mobility and participated in an exercise program offered by a local hospital.

"Although I do have my limitation as far as my mobility with walking, the biggest challenge is that I'm not able to get out as often, not even go to the hospital. Hospital, you could go there and walk around, and do the mile walk. Because of COVID-19, I don't have access to do that. Before, I went there three to four days a week for at least an hour or 45 minutes to get my walking in. When I say my walking, of course, l'm using my rollator." (Mary)

Mary expressed her concerns about the loss of muscle strength and balance that she had experienced during the COVID-19 outbreak. She tried to walk as often as she used to in her house, but noticed a loss of balance since she was not able to maintain the same level of activity at home.

"When you walk, you're strengthening your muscles. You're strengthening, especially your leg muscles. But when you're not doing that, and it's like, they're doing more resting than they are doing any type of activity, it could be a hindrance. Sometimes, even in my household, if I haven't been walking as often as I used to, I lose more balance." (Mary)

Other participants discussed insufficient physical activities and reduced levels of physical fitness which, in turn, negatively affected their health. Consequently, they suffered ailments such as aching knees, feelings of tiredness, and a lack of energy. Additionally, those with existing health conditions, such as arthritis, found that the lack of physical activity worsened their symptoms.

"I can't volunteer anymore. That was something to do every day. COVID-19 is scary. I am not able to move around like I used to do. I am walking less. Oh, I might get a little stiff from sitting. I have arthritis, so sitting don't help that much. Sometimes I just get up and walk from the front to the back [of the house]." (Lynn)

"The biggest challenge during this time is staying at home because we can't participate in senior activities. I used to go to water aerobics on Monday through Thursday. I would go over to the recreation centers on Fridays. Now we're not having any of that. I exercise less. My knees are aching, my legs are aching, and I'm just tired, because I sleep a lot. And that's because I don't have to get up and go anywhere. I can tell the difference." (Janet) 


\section{The Negative Impact on Mental and Social Well-Being}

COVID-19 influenced not only physical health but also the mental health of older adults. Although many participants stayed in touch with their family and friends, they mentioned that they felt lonely because of the limited physical contact with others.

"Lonely... You can't go uncovered, but [family members] they're trying to stay safe as well. And I only have one son here. My kids call and check often, but it's not like looking in their face and getting a hug and all that." (Barb)

"I feel socially isolated, but I'm not at home by myself, I've got my husband luckily. Mostly, we communicate with other family over the phone. But I have that yearning of going to see them and actually socializing with them physically. It does get lonely." (Heather)

Additionally, a lot of older adults felt vulnerable during the pandemic, namely people like Mary who had mobility limitations, and therefore expressed extra concerns as they often require assistance from others to meet their daily needs.

"It's a little depressing. For the agency, it's just hard for them to find someone that really wants to come and go into someone else's house with all this going on, even if they are exercising precautions. So that puts me at a disadvantage because I am in need of help, because of my mobility issues." (Mary)

However, the study participants showed resilience to adversity to some extent. First, technology served as an individual-level protective factor against this novel disease. Second, their social environment, including both informal support from family members and neighbors and formal support from community organizations, created a buffer against loneliness and social isolation. Lastly, living in a walkable built environment was identified as a protective factor to keep older adults active and healthy.

\section{Individual Environment: Use of Technology}

An individual resource that has been reportedly vital among the participants was technology. A few participants demonstrated prior competence with technology, while many others mentioned that they learned internet and teleconferencing skills during the pandemic.

"I did not use the internet a lot before COVID-19. Now, I do use it more to shop than going into the stores, even for household items... I started with computers and worked in a business in 80's... I'm not afraid of computers. I was able to load Zoom on my phone, on my iPad, and on my laptop without any problems. That was surprising to me." (Ashley) 
"This is my first time I just started. You can do the Zoom on computer or you can do it on the phone. Church has a livestream. I'm doing Zoom now as far as we have Bible study." (Janet)

Being able to join worship services and communicating with family members and friends were good motivators for many older adults to learn and utilize teleconferencing. Moreover, many older adults familiarized themselves with virtual platforms as medical clinics incorporated telehealth services. In particular, some participants described the benefits of telehealth services that made healthcare more accessible than ever, with some detailing how they prefer these new options over in-person visits.

"I do telemedicine... It's better if they look you over eye-to-eye, but what are you going to do? I'm sure it's going to be a big to-do going forward, long after COVID-19covid-19. I think the issue of people getting primary care face-to-face is going to be limited." (Donna)

"It's much easier... I need a hip replacement. It's already broken, and it hurts to try to get up and go. Usually the office is pretty long walk. If I go, I would have to use valet parking. You gotta pay for that. That's extra." (Tammy)

In addition, many older adults used the internet (e.g., YouTube) to stay active and physically and mentally engaged.

"I have to exercise, and [there is] YouTube for the seniors to exercise with. I checked that out yesterday. I surely did. I do the leg exercise, like stand up on the panel. And I'll walk around sometime in the apartment without the walker stick." (Amy)

"I live by myself. When I feel a little bit lonely, I go on my patio, read, and go on YouTube. I love YouTube, I get a lot of information. The last year and a half I really came into YouTube and I'm enjoying it. Love some information and learning." (Cindy)

While technology served as the most critical protective factor for our participants, some shared challenges utilizing the internet or teleconferencing. A few mentioned not having access to the internet or having poor internet connectivity.

"The hospital was where I could just go in because they had different activities for the seniors. They still have a program online, but I don't have access to that [the internet]." (Mary)

"I try to use Zoom every Sunday, but everybody else is on the internet so it's hard to get it in the mornings because I don't have the best internet service. But yes, I do. I try to watch something as far as I can go, as long as my internet is working." (Ashley)

When technology was challenging, some older adults used the telephone to interact with others and continue religious activities. 
"It's all about computers. I don't even have a computer. They [family and friends] make phone calls to talk and check in and see how I'm doing. I have a cousin that's a pastor in Houston and he's doing live screening. So I call him on the line every Sunday morning. So that helps with me not being able to go to church." (Lynn)

\section{Social Environment: Informal Support from Family and Neighbors}

Many participants reported that their social networks were a vital resource to meet their daily needs during the pandemic. As Donna, who lives alone, said, "with COVID, you are putting on an extra layer of need, either their family or neighbors or somebody," family members played an important role to support older adults, particularly those who do not drive, during this difficult time.

"My son used to take me to go food shopping... So instead of doing that, he does the food shopping, or his wife does it. And l've had deliveries and they've also set up deliveries for me to do the stuff. I have family that can actually help me out." (Donna)

Some of the participants reported that their grandchildren were an important source to combat emotional and social challenges during the pandemic. They reported that their grandchildren visited often, taught them how to use a smartphone, and provided fun games.

"I use that [Facetime] whenever my grandkids call. Nobody has been able to teach me how to use it. They walked me through it. You call that number and then their face pops up. My granddaughter told me that. That's all you gotta do Grandma, it's not that hard." (Barb)

While most of our participants relied on their family members for help, some participants exhibited strong social networks that included neighbors. Not only did these older adults receive help from their neighbors, they also helped their neighbors and shared resources.

"There's nobody but me. Sometimes I have a very nice friend next door who tell me always "Please call me if you need any help." She tried to bring me flowers. She'd even come up and water them after she gave them to me." (Tammy)

"I have friends, neighbors, who don't go out at all because they do have worries... they've got a medical condition. But I try to do the times when I go to the store, I call and ask them, "Do you need something?" And I usually get it for them." (Heather)

\section{Social Environment: Formal Support from Community Organizations for Older Adults}

Our participants praised changes that some organizations made to accommodate social distancing guidelines to support older adults during the pandemic. The participants said 
that some organizations switched congregate meals to home-delivered meals and provided virtual support groups and community workshops. In addition, local organizations helped these older adults stay informed via newsletters and flyers, sent them care packages, and often called to check on them.

"Well, they keep us informed of where there are free resources. The director made personal contacts with all and left a care package. Which was remarkable. Because we're not doing anything, but they are keeping in touch with us. My church has, the local aging organization has, and senior centers have... So those are places that l've had people who call me to check on me." (Ashley).

"We all seniors learn to listen and pay attention to the newsletters. Yes, and they mail them out to us. Birthdays, events, what's going on, what's coming up. It's a lot of different things. They never forget an individual. It's wonderful." (Barb)

\section{Built Environment: Walkable Neighborhoods}

Many participants voiced that they wanted to remain physically active, with several stating that they started walking around their neighborhood more often than before. This demonstrated the importance of the built environment, including safe streets and wellmaintained sidewalks for older adults.

"I can still go walking, but I don't feel safe enough to go the gym... I used to go the gym. I try to do more [walking now]. Walking has helped a lot... Oh I have got a bike to ride around." (Christine)

"I've been walking around my apartment because I don't have to come in contact with nobody. With exercising, it gets good. I like to move around. It's good for you, and it's good at a certain age anyway, for anybody. I love it. It makes my life better." (Cindy)

However, some older adults complained about their neighborhood environments due to off-leash dogs or individuals who were not wearing masks. A few participants indicated their fear of walking around their neighborhood, where they would see people gathered in groups or not wearing masks.

"It's terrible over here. I'm afraid to get out and go walk, even with a stick or whatever because dogs were so bad loose. I don't try to walk far no more." (Sue)

"I hate to go to these parks because these young people, they don't regard this as something that is tragic. All these people are dying, they still don't get it. And they're not going to wear a mask and different stuff, you know? Well, this can't happen to me." (Nancy) 


\subsection{DISCUSSION}

\subsection{MOBILITY POLICY AND STRATEGY RECOMMENDATIONS}

Based on the survey and modeling findings, this study makes recommendations to promote safe, affordable, and efficient mobility for low-income older adults. This section focuses on three significant areas to enhance older adults' mobility.

\subsubsection{Understanding Older Adults' Mobility Needs and Gaps in a Socioeconomic Context}

According to Coughlin (2001), individuals perceive a car as synonymous with transportation. Therefore, older adults who lose their ability to drive are unlikely to continue productive social engagement and out-of-home activity, experience a greater dependency on others, and are more likely to develop depression and psychological symptoms (Chihuri et al., 2016; Hwang and Hong, 2018). These civic, social, and economic impacts of driving cessation have stressed the importance for city planners and policymakers to promote and design transportation alternatives for older adults so that they are able to maintain their level of independence and health even after they are unable to drive themselves (Chihuri et al., 2016).

Car-dependent groups have a high dependence on driving and had little to no interest in using other mobility options. Such high dependence likely results in a mobility gap when they no longer drive. No exposure and little experience to alternative mobility options might create psychological or social barriers towards public transit and paratransit, which could easily be their alternatives when they stop driving. Our results from the class membership modeling also showed that household compositions (having a child) and employment status (being employed) were negatively associated with public transit usage among lower-income older adults. Driving a car when they have a job or children give them more convenient accessibility as the model indicated; however, this sole option limits their chance to learn about new and emerging transportation systems. Therefore, policy strategies informing older adults about transportation in their employment or child-care systems might be important to expand their knowledge and reduce social barriers even if they do not need to use other modes. Developing person-centered strategies would also serve different needs and gaps among older adults since financial and technological barriers may vary between individuals (Jeong et al., 2017). Transportation planners, policymakers, and social workers need to collaborate to capture the diverse perspectives of disadvantaged older adults regarding new and existing mobility options to reduce any social and personal barriers (Fields et al., 2020).

\subsubsection{Transportation Education and Technology Training}


Among the eight age-friendly community domains that AARP identified, older adults in Dallas rated transportation as the most important domain for independent living (AARP, 2016). However, our findings showed that lower-income older adults' knowledge of available transportation resources remained low, and the survey highlighted that most of the participants did not use technology or internet resources to obtain transportation information. Overreliance on their human networks may limit an older adult's ability to obtain information on emerging transportation services. While researchers reported that technology has made positive impacts on older adults' lifestyles (Hakobyan et al., 2016), it is critical to provide low-income older adults with more accessible transportation resources using mails and telephone-based services.

Providing education and training sessions through public assistance programs for lowincome seniors (e.g., Senior Companions Program, Foster Grandparent Program, or Senior Community Service Employment Program) can be another way to help them broaden their knowledge of transportation options and local resources. Transportation training and education sessions have already yielded many positive outcomes. Although the majority of these training sessions focus on educating older adults on safe driving skills (Alsnih \& Hensher, 2003), a few initiatives started to focus on helping older adults improve access to different transportation options. For example, national (e.g., National Rural Transit Assistance Program) and local (e.g., Dallas Area Rapid Transit) organizations provide formal travel training services that offer comprehensive one-onone instruction for individuals who are unable to drive and are in need of alternative transportation services even though their audience is limited to their transit users. The goal of these training services is to give older adults the confidence needed to utilize services, such as public buses or paratransit vehicles. We highlight the need for training based on unique needs of low-income older adults, especially those who heavily depend on their vehicle. We also suggest providing transportation resources in resources-scarce neighborhoods for the success of low-income, older, adult learners. The training should be also more accessible and less technology-driven to include those who have limited access to internet or electronic devices, such as lower-income groups.

\subsubsection{Practical Age-Friendly Guidelines and Implementation}

Despite the infrastructure and policy in place, older adults, especially those who drive, still seem hesitant to adopt mobility alternatives. As our findings showed, even public transit users perceive buses and trains as unsafe and inconvenient. Along with infrastructure enhancements, such as more transit stops for shorter walking distance, affordable fares, and handicapped-friendly services, cities should work on practical improvements (e.g., well-lit streets) to encourage older adults to adopt public transit services and walking. Expanding affordable door-to-door mobility options, such as community-driven ride-hailing and vanpooling, would also provide direct benefits for low-income older adults and those with physical and mental disabilities. For-profit transit companies have partnered with major healthcare organizations to address transit needs of older adults, and actively arrange mobility to medical appointments. Lyft showed its successful implementation by reducing wait times by $30 \%$ and per-ride cost by $32 \%$ through a partnership with healthcare agencies (e.g., Medicare Advantage and 
Medicaid). These services are very accessible to older adults regardless of their knowledge or familiarity with technology (internet or smartphone) since hospital staff are able to schedule the ride for their clients (Powers et al., 2016).

\subsection{FINDINGS FROM ABM}

In the first set of experiments, the agents were given access to only one of the transportation options over the course of a simulated year. At the end of one year, as expected, the agents were most satisfied with the volunteer driver option, followed by ride share and bus. Elizabeth's utility values from ride share and bus service were $14 \%$ and $63 \%$ less than her utility with volunteer drivers. Cassandra's utility values from ride share and bus service were $32 \%$ and $53 \%$ less than her utility with volunteer drivers. Beatrice's utility values from ride share and bus service were $20 \%$ and $57 \%$ less than her satisfaction with volunteer drivers. The results suggest that riding with familiar people from the community via a volunteer driver program may provide the social connection older adults seek. Therefore, starting a volunteer driver program in Dallas may add tremendous value to the lives and well-being of older adults.

In a second set of experiments, improvements to ride share and bus services are introduced. In a partnership with the City of Dallas, ride share services included a fleet with trained drivers for assisting older adults, and a $50 \%$ discount is given to the older adults. In addition, more frequent services and bus stops and increased area coverage with additional bus lines are introduced to improve bus services. After these improvements, Elizabeth's, Cassandra's, and Beatrice's satisfaction with ride share improved by $10 \%, 14 \%$, and $19 \%$, respectively, compared with the results of the first experiment. Their satisfaction with bus service improved by $105 \%, 58 \%$, and $61 \%$, respectively.

The results of the experiments demonstrate that each primary persona's utility is different for each transportation option due to their heterogenous characteristics, expectations, motivations, and goals. The degree of change in their satisfaction levels with the service improvements reflects how much these improvements address their expectations from transportation services. In particular, the improvements in ride share resulted in a greater increase in Cassandra's and Beatrice's satisfaction levels, compared with Elizabeth. Since Elizabeth does not seek assistance from ride share drivers and she knows how to use ride share services, her satisfaction level only improved because of the discount. On the other hand, Cassandra and Beatrice are more satisfied with ride share since the trained drivers are able to accommodate their physical and information needs. While the improvements in bus service resulted in a greater than $50 \%$ increase in each of the primary personas' satisfaction levels, Elizabeth benefited more than Cassandra and Beatrice. Adding bus stops and lines resulted in shorter walking distances to access points, which is important for Elizabeth since she is not able to walk more than 0.25 miles at once. 


\subsection{CONCLUSION}

This study provides practical recommendations to enhance disadvantaged older adults' mobility and accessibility. This study highlighted person-centered strategies to serve varying mobility needs and gaps for older adults depending on their socioeconomic characteristics, current knowledge of transportation options, and familiarity with technology. Our suggestions will be informative for community organizations that serve older adults from diverse backgrounds (e.g., low-income older adults, socially isolated older adults, and older adults with physical disabilities) and those who frequently find that transportation is a major obstacle for maintaining quality of life. Findings from our study further address social equity concerns about low-income older adults' mobility and assist with creating more efficient, safer, and socially equitable transportation services. By understanding how individual socioeconomic demographics and personal barriers affect mobility choice and how older adults perceive new and conventional mobility options, we can better advocate the mobility needs and gaps for older adults to transportation planners and decision-makers. Our finding suggests that developing more person-centered institutional assistance and educational programs is a priority to increase individuals' accessibility to various mobility options. Future researchers will be able to use these pilot data to support development of new approaches that enhance equitable and sustainable mobility across disadvantaged senior communities.

The HOQ approach of this study demonstrates the potential of empirically derived personas to clearly portray the transportation needs and preferences of the most mobility-vulnerable older adults. Personas incorporate the goals, motivations, and other lifestyle choices of older adults, which provides an advantage over market segmentation approaches that focus on grouping older adults solely by demographic factors. The primary personas identified in this study provide a common ground for decision-making by transportation system stakeholders, including government officials, policymakers, funding agencies, land use planners, transportation providers, and designers. Using the primary personas and $\mathrm{HOQ}$ enables a systematic design process to identify holistic transportation solutions without car dependency that not only serves non-driver older adults but also can help older adults who drive to make easier decisions on driving cessation, as well as addressing the transportation challenges of other vulnerable populations.

One limitation of this study is the relatively limited diversity of the survey participants, who are mostly from low-income Black communities. The COVID-19 pandemic prevented the administration of additional survey sessions, but as pandemic restrictions continue to relax, there is the possibility of holding focus groups with a more diverse set of older adult participants to validate the primary persona attributes. Additionally, focus groups with older adults who are identified based on the characteristics of the primary personas can provide greater detail on the transportation needs and expectations of the 
older adults, as well as validating the personas. Other future work includes a more extensive exploration of existing transportation alternatives in Dallas, according to the needs of the primary personas, as well as an assessment of the feasibility of initiating a volunteer-based transportation service that is tailored to the primary personas' needs.

The qualitative analysis to understand resilience among marginalized older adults during the COVID-19 pandemic revealed that many older adults have been able to leverage protective factors at individual, social, and built-environment levels to demonstrate resiliency to pandemic stressors. While technology is unable to replace the emotional satisfaction received from person-to-person contact, it has provided older adults with access to vast resources for learning, entertainment, and physical activity. Additionally, support from community organizations has proved to be vital, keeping older adults informed with resources and services tailored for their needs. Fear of physical injury and personal safety in neighborhoods emerged as a critical factor that can impede older adults' physical activity and worsen their social isolation. These results suggest that improving the resilience of older adults requires a holistic approach to improve individual, social, and built environments to enhance individuals' resilience from an unprecedented event. 


\subsection{REFERENCES}

AARP. (2016). Livability for all in Dallas: An age-friendly community survey of AARP members age 50-plus. Retrieved from https://www.aarp.org/content/dam/aarp/research/surveys_statistics/livcom/2016/2016-afc-dallas-report-rc-liv-com.pdf

AARP. (2019) Age-Friendly Community Survey, https://www.aarp.org/content/dam/aarp/livable-communities/livabledocuments/2020/2020\%20AARP\%20AgeFriendly\%20Community\%20Survey\%20Paper\%20Pencil\%20Version\%20Final.pdf

AARP. (2020) The 8 Domains of Livability: An Introduction, https://www.aarp.org/livablecommunities/network-age-friendly-communities/info-2016/8-domains-of-livabilityintroduction.html

Aldwin, C. \& Igarashi, H. (2012). An ecological model of resilience in late life. Annual Review of Gerontology and Geriatrics, 32(1), 115-130. Retrieved from https://login.ezproxy.uta.edu/login?url=https://www-proquestcom.ezproxy.uta.edu/scholarly-journals/ecological-model-resilience-latelife/docview/922382227/se-2?accountid=7117.

Alsnih, R., \& Hensher, D. A. (2003). The mobility and accessibility expectations of seniors in an aging population. Transportation Research, Part A 37, 903-916.

AmeriCorps, 2020, https://www.nationalservice.gov/programs/senior-corps

Anderson, M. (2016). Pew Research Center. Who relies on public transit in the U.S. Retrieved from https://www. pewresearch.org/fact-tank/2016/04/07/who-relies-onpublic-transit-in-the-u-s/

Anstey, K. J., Windsor, T. D., Luszcz, M. A., \& Andrews, G. R. (2006). Predicting driving cessation over 5 years in older adults: Psychological well-being and cognitive competence are stronger predictors than physical health. Journal of the American Geriatrics Society, 54(1), 121-126.

Ben-Akiva, M., McFadden, D., Garling, T., Gopinath, D., Walker, J., Bolduc, D., . . Rao, V. (1999). Extended Framework for Modeling Choice Behavior. Marketing Letters 10:3, 187-203. 
Berg-Weger, M. \& Morley, J. E. (2020). Loneliness and social isolation in older adults during the COID-19 pandemic: Implications for gerontological social work. The Journal of Nutrition, Health \& Aging, 24; 456-458. https://doi.org/10.1007/s12603-020-1366-8.

Bryanton, O., Weeks, L. E., \& Lees, J. M. (2010). Supporting older women in the transition to driving cessation. Activities, Adaptation \& Aging, 34(3), 181-195.

Burian, J., Zajickova, L., Ivan, I., \& Macku, K. (2018). Attitudes and motivation to use public or individual transport: A case Study of two middle-sized cities. Social Sciences, $1-25$.

Central Statistics Office. (2020). Social impact of COVID-19 survey April 2020.

Retrieved from https://www.cso.ie/en/releasesandpublications/ep/psic19/socialimpactofcovid-19surveyapril2020/changesinconsumption/.

Chihuri, S., Mielenz, T. J., DiMaggio, C. J., Betz, M. E., DiGuiseppi, C., Jones, V. C., \& $\mathrm{Li}, \mathrm{G}$. (2016). Driving cessation and health outcomes in older Adults. The Journal of the American Geriatrics Society, 64, 332-341.

City of Dallas, 2020, Strategic Mobility Plan, https://dallascityhall.com/departments/transportation/Pages/Strategic-MobilityPlan.aspx

Coughlin, J. (2001). Transportation and Older Persons: Perceptions and Preferences. Washington, DC: Public Policy Institute, AARP.

Dobson, R., \& Tischer, M. L. (1977). Comparative Analysis of Determinants of Modal Choices by Central Business District Workers. Federal Highway Administration, U.S. Department of Transportation, 7-14.

Emeruwa, U. N., Ona, S., Shaman, J. L., Turitz, A., Wright, J. D., Gyamfi-Bannerman, C., \& Melamed, A. (2020). Associations between built environment, neighborhood socioeconomic status, and SARS-CoV-2 infection among pregnant women in New York City. Jama, 324(4), 390-392. https://doi,org/ 10.1001/jama.2020.11370.

Fields, N.L., Miller, V.J., Cronley, C., Hyun, K., Mattingly, S.P., Khademi, S., Nargesi, S.R.R. and Williams, J. (2020). Interprofessional collaboration to promote transportation equity for environmental justice populations: A mixed methods study of civil engineers, transportation planners, and social workers' perspectives.

Transportation Research Interdisciplinary Perspectives, 5, 100-110. 
Goethals, L., Barth, N.,Guyot, J., Hupin, D., Celarier, T., \& Bongue, B. (2020). Impact of home quarantine on physical activity among older adults living at home during the COVID-19 Pandemic: Qualitative interview study. Journal of Medical Internet Research Aging, 3(1), e19007. https://doi.org/10.2196/19007

Greenfield, E. A., Oberlink, M., Scharlach, A. E., Neal, M. B., \& Stafford, P. B. (2015). Age-friendly community initiatives: Conceptual issues and key questions. The Gerontologist, 55(2), 191-198.

Gudicha, D.W., Tekle, F.B. and Vermunt, J.K. (2016). Power and sample size computation for Wald tests in latent class models. Journal of Classification, 33(1), pp.30-51.

Hakobyan, L., Lumsden, J., Shaw, R., \& O'Sullivan, D. (2016, September). A longitudinal evaluation of the acceptability and impact of a diet diary app for older adults with age-related macular degeneration. In Proceedings of the 18th International Conference on Human-Computer Interaction with Mobile Devices and Services (pp. 124-134).

Hare, D. L., Toukhsati, S. R., Johansson, P., \& Jaarsma, T. (2013). Depression and cardiovascular disease: A clinical review. European Heart Journal, 35(21), 13651372. https://doi.org/10.1093/eurheartj/eht462.

Hess, D. B. (2009). Access to public transit and its influence on ridership for older adults in two U.S. cities. Journal of Transport and Land use, 2(1), 3-27. doi:10.5198/jtlu.v2i1.11

Hjorthol, R. (2013). Transport resources, mobility and unmet transport needs in old age. Ageing and Society, 33, 1190-1211.

Hu, M., Roberts, J. D., Azevedo, G. P., \& Milner, D. (2021). The role of built and social environmental factors in COVID-19 transmission: A look at America's capital city. Sustainable Cities and Society, 65, 102580. https://doi.org/10.1016/j.scs.2020.102580.

Hwang, Y. and Hong, G.R.S. (2018). Predictors of driving cessation in communitydwelling older adults: A 3-year longitudinal study. Transportation research part F: traffic psychology and behaviour, 52, pp.202-209.

Janesick, V. J. (2007). Peer debriefing. The Blackwell Encyclopedia of Sociology, G. Ritzer (Ed.). https://doi.org/10.1002/9781405165518.wbeosp014.pub2. 
Jeong, K., Hyun, K., and Ritchie, S.G. (2017). Influence of personal concerns about travel on travel behavior, Proceedings of the Annual Meeting of the Transportation Research Board, Washington, D.C.

Kantamneni, N. (2020). The impact of the COVID-19 pandemic on marginalized populations in the United States: A research agenda. Journal of Vocational Behavior, 119. https://doi.org/10.1016/j.jvb.2020.103439.

Kiuchi, S., Aida, J., Kusama, T., Yamamoto, T., Hoshi, M., Yamamoto, T., Osaka, K. (2020). Does public transportation reduce inequalities in access to dental care among older adults? japan gerontological evaluation study. Community Dentistry and Oral Epidemiology, 48(2),

Kroesen, M., Handy, S., \& Chorus, C. (2017). Do attitudes cause behavior or vice versa? An alternative conceptualization of the attitude-behavior relationship in travel behavior modeling. Transportation Research Part A, 101, 190-202.

Lee, Y., Circella, G., Mokhtarian, P. L., \& Guhathakurta, S. (2019). Are millennials more multimodal? A latent-class cluster analysis with attitudes and preferences among millennial and Generation X commuters in California. Transportation (2019).

Lian, J.W. \& Yen, D.C. (2014). Online shopping drivers and barriers for older adults: Age and gender Differences. Computers in Human Behavior, 37, 133-143.

Linzer, D. A., \& Lewis, J. b. (2011). poLCA: An R Package for Polytomous variable Latent Class Analysis. Journal of Statistical Software, Volume 42, Issue 10, 1-20.

Maggi, E., \& Vallino, E. (2016). Understanding urban mobility and the impact of public policies: The role of the agent-based models. Research in Transportation Economics, $55,50-59$.

Marx, J., Davis, C., Miftari, C., Salamone, A. \& Weise, W. (2010). Developing brokered community transportation for seniors and people with disabilities. Journal of Gerontological Social Work, 53(5), 449-466.

Miah, M., Naz, F., Hyun, K., Mattingly, S., Cronley, C., Fields, N (2020) Barriers and Opportunities for Paratransit Users to Adopt On-Demand Micro Transit, Proceedings of the Annual Meeting of the Transportation Research Board, TRB 2020 
Molin, E., Mokhtarian, P., \& Kroesen, M. (2016). Multimodal travel groups and attitudes: A latent class cluster analysis of Dutch travelers. Transportation Research Part A 83, 14-29.

Morrow-Howell, N., Galucia, N., \& Swinford, E. (2020). Recovering from the COVID-19 pandemic: A focus on older adults. Journal of Aging \& Social Policy, 32(4-5); 526-535. https://doi.org/10.1080/08959420.2020.1759758.

National Aging and Disability Transportation Center (2019). Transportation options for older adults. Retrieved from https://www.n4a.org/files/TransportationOptions.pdf

Nicholson, N. R. (2012). A review of social isolation: An important but underassessed condition in older adults. The Journal of Primary Prevention, 33(2-3); 137-152. https://doi.org/10.1007/s10935-012-0271-2.

Park, J. and Yu, H.T. (2018). Recommendations on the sample sizes for multilevel latent class models. Educational and Psychological Measurement, 78(5), pp.737-761.

Paulssen, M., Temme, D., Vij, A., \& Walker, J. L. (2014). Values, attitudes and travel behavior: A hierarchical latent variable mixed logit model of travel mode choice. Transportation, Vol 41, 873-888.

Power, T., Jackson, D., Carter, B., \& Weaver, R. (2015). Misunderstood as mothers: Women's stories of being hospitalized for illness in the postpartum period. Journal of Advanced Nursing, 71(2), 370-380. https://doi.org/10.1111/jan.12515.

Powers, B. W., Rinefort, S., \& Jain, S. H. (2016). Nonemergency medical transportation: Delivering care in the era of lyft and uber. JAMA: The Journal of the American Medical Association, 316(9), 921-922.

Rahimi, A., Azimi, G. and Jin, X. (2020). Examining human attitudes toward shared mobility options and autonomous vehicles. Transportation Research Part F: Traffic Psychology and Behaviour, 72, 133-154.

Robinson, S. Cronley, C., Hyun, K., Naz, F., (2020) Examining the feasibility of shared mobility programs for reducing transportation inequities: Perspectives from the frontline, Proceedings of the Annual Meeting of the Transportation Research Board, TRB

Seifert, A., Cotten, S. R., \& Xie, B. (2021). A double burden of exclusion? Digital and 
social exclusion of older adults in times of COVID-19. The Journals of Gerontology: Series B, 76(3), 99-103. https://doi.org/10.1093/geronb/gbaa098.

Shahid, Z., Kalayanamitra, R., McClafferty, B., Kepko, D., Ramgobin, D., Patel, R., Aggarwal, C. S. Vunnam, R., Sahu, N., Bhatt, D., Jones, K., Golamari, R., \& Jain, R. (2020). COVID-19 and older adults: What we know. Journal of the American Geriatrics Society, 68(5), 926-929. https://doi.org/10.1111/jgs.16472.

Shiftan, Y., Kheifits, L., \& Sorani, M. (2015). Travel and emissions analysis of sustainable transportation policies with activity-based modeling. Transportation Research Record, 2531(1), 93-102.

Spinney, J.E., Scott, D.M. \& Newbold, K.B. (2009). Transport mobility benefits and quality of life: A Time-use Perspective of Elderly Canadians. Transport policy, 16(1), 111.

Thomas, D. R. (2006). A general inductive approach for analyzing qualitative evaluation data. American Journal of Evaluation, 27(2), 237-246. https://doi.org/10.1177/1098214005283748.

Vermunt, J., \& Magidson, J. (2002). Latent class cluster analysis. Applied latent class analysis, 89-106.

Vernooij-Dassen, M., Verhey, F., \& Lapid, M. (2020). The risks of social distancing for older adults: A call to balance. International Psychogeriatrics, 32(10); 1235-1237. https://doi.org/10.1017/S1041610220001350.

Verplanken, B., Aarts, H., \& Knippenberg, A. V. (1997). Habit, information acquisition, and the process of making travel mode choices. European Journal of Social Psychology, Vol. 27, 539-590.

Vivoda, J.M., Harmon, A.C., Babulal, G.M. and Zikmund-Fisher, B.J. (2018). E-hail (ride share) knowledge, use, reliance, and future expectations among older adults. Transportation research part F: traffic psychology and behaviour, 55, 426-434.

Whitehead, B. R. \& Torossian, E. (2020). Older adults' experience of the COVID-19 Pandemic: A mixed-methods analysis of stresses and joys. The Gerontologist, 61(1), 36-47. https://doi.org/10.1093/geront/gnaa126. 
Woods, J. A., Hutchinson, N. T., Powers, S. K., Roberts, W. O., Gomez-Cabrera, M. C., Radak, Z., Berkesa, I., Boros, A., Boldogh, I., Leeuwenburgh, C., Coelho-Júnior, H. J., Marzetti, E., Cheng, Y., Liu, J., Durstine, J. L., Sun, J., \& Ji, L. L. (2020). The COVID19 pandemic and physical activity. Sports Medicine and Health Science, 2(2); 55-64. https://doi.org/10.1016/j.smhs.2020.05.006.

Yagil, D., Cohen, M., \& Beer, J. D. (2016). Older adults' coping with the stress involved in the use of everyday technologies. Journal of Applied Gerontology, 35(2), 131-149. https://doi.org/10.1177/0733464813515089

Yang, Y., Langellier, B. A., Stankov, I., Purtle, J., Nelson, K. L., \& Diez Roux, A. V. (2019). Examining the possible impact of daily transport on depression among older adults using an agent-based model. Aging \& mental health, 23(6), 743-751.

Kim, S. (2011). Transportation alternatives of the elderly after driving cessation. Transportation research record, 2265(1), 170-176.

Cevallos, F., Skinner, J., Joslin, A., \& Ivy, T. (2010). Attracting senior drivers to public transportation: Issues and concerns (No. FTA-FL-04-7104-2010.02).

Rosenbloom, S. (2005). The mobility needs of older Americans: Implications for transportation reauthorization. Accessed: Nov. 29, 2020. [Online]. Available: brookings.edu/wp-content/uploads/2016/06/20030807_Rosenbloom.pdf.

Turner, J. J., Adams-Price, C. E., \& Strawderman, L. (2017). Formal alternative transportation options for older adults: An assessment of need. Journal of gerontological social work, 60(8), 619-646.

Coughlin, J. (2001). Transportation and older persons: Perceptions and preferences. A report on focus groups. Accessed: Nov. 27, 2020. [Online]. Available: https://assets.aarp.org/rgcenter/il/2001_05_transport.pdf.

Chase, H. H. E. (2011). Transportation planning options for elderly mobility (Doctoral dissertation, Massachusetts Institute of Technology).

Alsnih, R., \& Hensher, D. A. (2003). The mobility and accessibility expectations of seniors in an aging population. Transportation research part a: policy and practice, 37(10), 903-916. 
R. Hjorthol (2013). Transport resources, mobility and unmet transport needs in old age. Ageing Soc., vol. 33, no. 7, 1190-1211, 2013, doi: 10.1017/S0144686X12000517.

Cooper, A., Reimann, R., Cronin, D., \& Noessel, C. (2014). About face: the essentials of interaction design. John Wiley \& Sons.

Pruitt, J., \& Adlin, T. (2010). The persona lifecycle: keeping people in mind throughout product design. Elsevier.

Cooper, A. (1999). The inmates are running the asylum. In Software-Ergonomie'99 (pp. 17-17). Vieweg+ Teubner Verlag, Wiesbaden.

Sim, W. W., \& Brouse, P. S. (2014). Empowering requirements engineering activities with personas. Procedia Computer Science, 28, 237-246.

Miaskiewicz, T., \& Kozar, K. A. (2011). Personas and user-centered design: How can personas benefit product design processes?. Design studies, 32(5), 417-430.

Reeder, B., Zaslavksy, O., Wilamowska, K. M., Demiris, G., \& Thompson, H. J. (2011). Modeling the oldest old: personas to design technology-based solutions for older adults. In AMIA Annual Symposium Proceedings (Vol. 2011, p. 1166). American Medical Informatics Association.

Wöckl, B., Yildizoglu, U., Buber, I., Aparicio Diaz, B., Kruijff, E., \& Tscheligi, M. (2012, October). Basic senior personas: a representative design tool covering the spectrum of European older adults. In Proceedings of the 14th international ACM SIGACCESS conference on Computers and accessibility (pp. 25-32).

Kim, S. (2011). Assessing mobility in an aging society: Personal and built environment factors associated with older people's subjective transportation deficiency in the US. Transportation research part F: traffic psychology and behaviour, 14(5), 422-429.

Rimmö, P. A., \& Hakamies-Blomqvist, L. (2002). Older drivers' aberrant driving behaviour, impaired activity, and health as reasons for self-imposed driving limitations. Transportation Research Part F: Traffic Psychology and Behaviour, 5(1), 47-62.

Coughlin, J. F. (2009). Longevity, lifestyle, and anticipating the new demands of aging on the transportation system. Public Works Management \& Policy, 13(4), 301-311. 
Adler, G., \& Rottunda, S. (2006). Older adults' perspectives on driving cessation. Journal of Aging studies, 20(3), 227-235.

Kim, S., \& Ulfarsson, G. F. (2004). Travel mode choice of the elderly: effects of personal, household, neighborhood, and trip characteristics. Transportation Research Record, 1894(1), 117-126.

Rosenbloom, S., \& Waldorf, B. (2001). Older travelers: does place or race make a difference?. Transportation research circular, (E-C026), 103-120.

Kim, S. (2003). Analysis of elderly mobility by structural equation modeling. Transportation research record, 1854(1), 81-89.

Rosenbloom, S., \& Winsten-Bartlett, C. (2002). Asking the right question: Understanding the travel needs of older women who do not drive. Transportation Research Record, 1818(1), 78-82.

Bauer, M. J., Adler, G., Kuskowski, M. A., \& Rottunda, S. (2003). The influence of age and gender on the driving patterns of older adults. Journal of Women \& Aging, 15(4), 3-16.

Freund, B., \& Szinovacz, M. (2002). Effects of cognition on driving involvement among the oldest old: Variations by gender and alternative transportation opportunities. The Gerontologist, 42(5), 621-633.

Edwards, J. D., Bart, E., O'Connor, M. L., \& Cissell, G. (2010). Ten years down the road: predictors of driving cessation. The Gerontologist, 50(3), 393-399.

Marin-Lamellet, C., \& Haustein, S. (2015). Managing the safe mobility of older road users: How to cope with their diversity?. Journal of Transport \& Health, 2(1), 22-31.

Dupuis, J., Weiss, D. R., \& Wolfson, C. (2007). Gender and transportation access among community-dwelling seniors. Canadian Journal on Aging/La Revue Canadienne Du Vieillissement, 26(2), 149-158.

Ramsay, D. (2009). Adapting to the changing transportation needs of older adults: coordinating transportation services in Victoria BC. 
Rosenbloom, S. (1988). The mobility needs of the elderly. Transportation in and Aging Society, Improving Mobility and Safety for Older Persons, 2, 21-71.

Anstey, K. J., Windsor, T. D., Luszcz, M. A., \& Andrews, G. R. (2006). Predicting driving cessation over 5 years in older adults: Psychological well-being and cognitive competence are stronger predictors than physical health. Journal of the American Geriatrics Society, 54(1), 121-126.

Everitt, B. S., Landau, S., Leese, M., \& Stahl, D. (2011). Cluster analysis 5th ed.

Bahill, A. T., \& Chapman, W. L. (1993). A tutorial on quality function deployment. Engineering Management Journal, 5(3), 24-35.

Chan, L. K., \& Wu, M. L. (2002). Quality function deployment: a comprehensive review of its concepts and methods. Quality engineering, 15(1), 23-35.

Griffin, A., \& Hauser, J. R. (1993). The voice of the customer. Marketing science, 12(1), $1-27$.

Chan, L. K., \& Wu, M. L. (2005). A systematic approach to quality function deployment with a full illustrative example. Omega, 33(2), 119-139.

Borst, H. C., Miedema, H. M., de Vries, S. I., Graham, J. M., \& van Dongen, J. E. (2008). Relationships between street characteristics and perceived attractiveness for walking reported by elderly people. Journal of environmental psychology, 28(4), 353361.

Brown, J., Bond, M., Wood, J., \& Suguri, V. (2015). Older Adult Public Transportation Services in Rural and Small Communities in the United States: An Examination of Service Types, Provision, and Use.

Rosenbloom, S. (2010). How adult children in the UK and the US view the driving cessation of their parents: Is a policy window opening?. Journal of Transport Geography, 18(5), 634-641.

Saxon, L., Ebert, R., \& Sobhani, M. (2019). Health impacts of unlimited access to networked transportation in older adults. Journal of mHealth. 
What's a STROAD and Why Does It Matter? Strong Towns (2018). https://www.strongtowns.org/journal/2018/3/1/whats-a-stroad-and-why-does-it-matter (accessed Aug. 19, 2021).

Macon, A. (2021). Dallas Is Missing More Than 2,000 Miles of Sidewalk. D Magazine, Dallas.

DART. How to Ride. https://www.dart.org/riding/riding.asp (accessed Aug. 19, 2021).

Martin, E., Stocker, A., Cohen, A., Shaheen, S., \& Brown, L. (2021). Mobility on Demand (MOD) Sandbox Demonstration: Dallas Area Rapid Transit (DART) First and Last Mile Solution Evaluation Report (No. FTA Report No. 0195). United States. Department of Transportation. Federal Transit Administration. Accessed: Aug. 19, 2021. [Online]. Available: https://www.transit.dot.gov/about/research-innovation.

Goodyear, S. (2014). Defining the Worst Type of Street Design. Bloomberg. https://www.bloomberg.com/news/articles/2014-01-07/defining-the-worst-type-ofstreet-design (accessed Aug. 19, 2021). 


\subsection{APPENDIX}

Table 9.1: Primary Persona - Beatrice

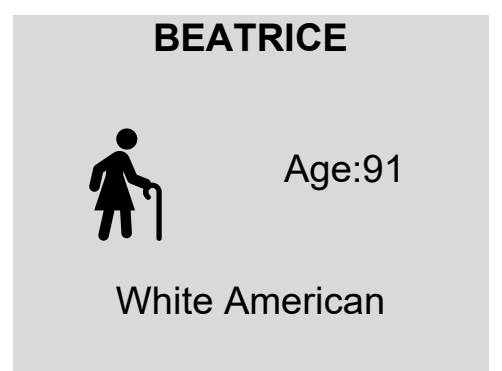

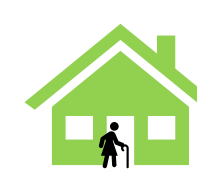

Home

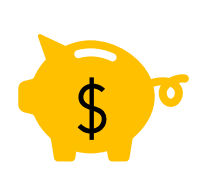

Income Social Connections

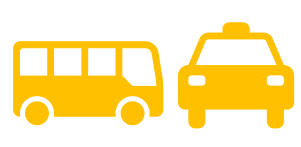

Transportation

Health: Mobility:

Transportation Options:

\section{About}

Beatrice has a high school degree and training in a trade school. Beatrice lives alone in a house she owns located 16 miles north of Downtown Dallas. Beatrice's annual income is $\$ 43,000$.

\section{Health Background}

As a stay-at-home mother, she was careful with her and her family's diet. She was always physically active inside and outside of the house.

\section{Social Connections}

Beatrice talks to her children everyday who live out-of-state. Beatrice likes spending time by herself with gardening, crochet, and word puzzles.

\section{Transportation Options}

Beatrice gave up driving willingly at the age of 85. She uses special transportation for grocery trips and public transportation to go to doctor appointments and bank. She would like to use ride-hailing services, but she is concerned about riding with strangers and the cost.

\section{Health Status}

- Expected deterioration due to aging

- Able to walk 0.25 miles in 20 minutes

- Self-perceived physical health rating is good

\section{Social Status}

- Rarely feels lonely and socially isolated

\section{Mobility Status}

- Rarely misses grocery store trip or doctor appointments

- Difficulty in reaching to bus stops in Texas summers

- Using public transit and walking between stops and locations while carrying bags gets harder

- Unable to stay in balance while in transit

- May depend on other drivers for basic needs 
- Feels pain when jostled by others, rapid accelerations, and decelerations.

Transportation Information

Beatrice schedules her trips on her laptop once in every few weeks.

\section{Accessing Transportation Information}

- DART's website and printed schedules

\section{Goals and Motivation}

Beatrice wants to live without being burden on other people. However, she sometimes wishes to have help from people she trusts whom understands her needs. While Beatrice likes spending time in her home, she sometimes would like to visit her friends, but her transportation options limit her reach to her friends' houses. Beatrice misses going to stores or recreational center whenever she wants.

\section{Satisfied: (-) Not Satisfied:}

\section{Table 9.2: Primary Persona - Cassandra}

\section{CASSANDRA}

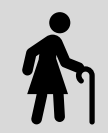

Age:75

Black American

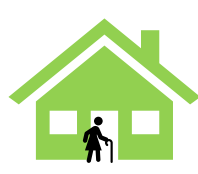

Home

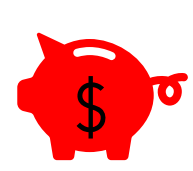

Income Social Connections
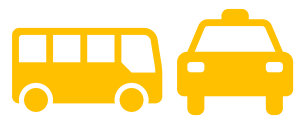

Transportation

Health:

Mobility:

Transportation Options:

\section{About}

Cassandra has a high school degree. She worked in retail industry since high school.

Cassandra lives alone in a house she owns located 10 miles south of Downtown Dallas.

Cassandra's annual income is $\$ 14,000$.

\section{Health Background}

Cassandra had an unhealthy lifestyle due to her work and being a single mother. She did not have time to exercise and take care of

\section{Health Status}

- Type-2 diabetes

- Vision impairment

- Able to walk 0.25 miles in 10 minutes 
herself. She reached for fast food as an easy meal option.

\section{Social Connections}

Cassandra does not like to depend on other people. Her closest child visits her every three weeks to help with her needs. While she has some friends and neighbors she reaches out, she lacks strong connections.

\section{Transportation Options}

Cassandra uses public and special transportation for her monthly doctor appointment, visiting her friends and volunteering. She mostly depends on her daughter and neighbor for grocery shopping. Otherwise, her travel time increases by three times due to transfers between vehicles, long riding time in current routes, or waiting for others on special transportation.

\section{Transportation Information}

Cassandra reads AARP bulletin and bimonthly magazine, and news on local newspaper for transportation information.
- Self-perceived physical health rating is good

\section{Social Status}

- Occasionally feels lonely and socially isolated

\section{Mobility Status}

- Occasionally misses grocery trip, doctor appointment, or a volunteering session

- Afraid of young hoods on streets and in transit, especially at nights

- May depend on other drivers for basic needs

\section{Accessing Transportation Information}

- Mail-in printed schedules and routes from DART

- Printed schedules from the Internet with others' help

- Phonebook to call for information

- Friends and family

\section{Goals and Motivation}

Cassandra wishes to have easier access to her basic needs. She wants to avoid falling down due to uneven sidewalks and sit down and rest during her walks. Cassandra wishes to participate in more voluntary activities and increase her social connections. She wants to be more aware of her transportation options and take additional entertainment trips at around midday and evenings without depleting her budget.

\footnotetext{
Satisfied: $\because$ Not Satisfied: 0 Disappointed: $\because$
} 
Table 9.3: Primary Persona - Elizabeth
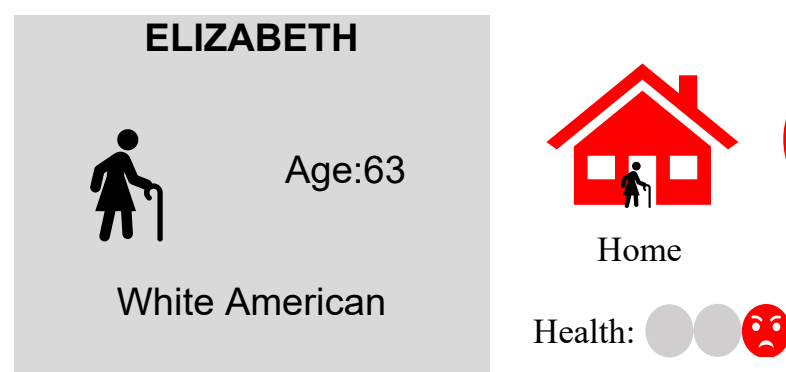

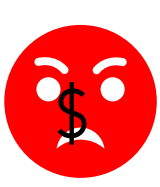

Income Social Connections

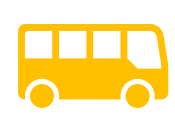

Transportation

Health:

Mobility:

Transportation Options:

\section{About}

Elizabeth has 4-year college degree, and she worked as teacher for 30 years. Elizabeth lives alone in a rental apartment located 5 miles northeast of Downtown Dallas. Elizabeth's annual income is $\$ 16,000$.

\section{Health Background}

Elizabeth had a major traffic accident 10 years ago and was hospitalized for 3 months.

After the accident, she did not fully recover physically and financially, and she had to stop teaching.

\section{Social Connections}

Elizabeth has some friends who regularly visits her. She likes to keep herself occupied with reading and researching. Elizabeth feels fulfilled with volunteering activities. She likes to go to recreational centers and parks with her friends.

\section{Transportation Options}

Elizabeth stopped driving due to her health and limited finances. She accesses her basic needs and attends her social activities by combining different modes of transportation.

\section{Transportation Information}

Elizabeth goes online at least once a day to check updates on time schedules, routes, and pricing.

\section{Health Status}

- Deterioration due to aging and the accident

- Able to walk less than 0.25 miles at once

- Self-perceived physical health rating is fair

\section{Social Status}

- Rarely feels lonely and socially isolated

- Feels depressed when not able to go outdoors

\section{Mobility Status}

- Rarely misses grocery store trip or doctor appointments

- May depend on other drivers for leisure activities

\section{Accessing Transportation Information}

- DART's website and printed schedules

- Ride-hailing apps 


\section{Goals and Motivation}

Elizabeth does not want to feel trapped. She wishes to go out whenever she wants for any reason without worrying for her well-being. Although she uses ride share services, she cannot afford it frequently. She does not want to be limited by the changing transit schedules and routes. She prefers to have a direct transit to her destination to reduce her travel times and avoid the hassle of combining modes. Elizabeth wishes to have basic amenities close to her house.

Satisfied: $\because$ Not Satisfied: 0 Disappointed: 20

Table 9.4: Negative Personas

MICHAEL

i

Age:65

\section{White American}

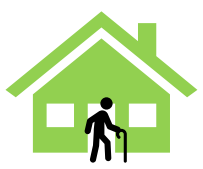

Home

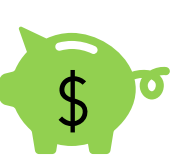

Income Social Connections

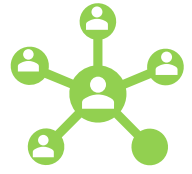

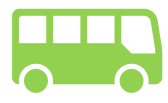

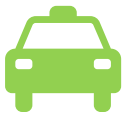

Transportation
Health:

Mobility:

\section{About}

Michael has a mechanical engineering degree from Rice University. He lives with his wife in a house they own that is 15 miles northwest of Downtown Dallas. Michael has two children. He expects to retire in the next 2 years. Michael's current annual household income is $\$ 100,000$.

\section{Health Background}

Michael maintained a healthy lifestyle with his wife. He walks 5 to 7 miles every other day and plays tennis with his wife on the weekends. He did not have major health issues all his life, except couple of sports related injuries.

\section{Social Connections}

Since Michael still works as an engineer, he is connected with co-workers. He attends company events with his wife. Their children live and work in Dallas/Fort Worth area and they go to brunches after their church service on Sundays. As recent empty-nesters, Michael and his wife enjoy their company.

\section{Transportation Options}

For Michael, driving his personal car is the only transportation option since he got his driver's license at 16 . He commutes to work every day, and one-way trip is 40 minutes. While he is aware that there is public and special transportation in his area, he foresees that he will be able to drive for a long time and will not need to use any of these transportation options.

\section{Health Status}

- Able to walk 0.25 miles fast

- Self-perceived physical health rating is excellent

\section{Social Status}

- Never feels lonely and socially isolated

\section{Mobility Status}

- Never misses any trips, appointments, or events

- Able to travel wherever he wants at anytime

- No need for trip planning rather than accessing driving durations 


\section{Transportation Information}

Since Michael was born in Dallas, he has a

detailed knowledge of the roads.

\section{Accessing Transportation Information}

- Navigation apps for directions, road closures

and traffic status

\section{Goals and Motivation}

Michael would like to drive as long as he is able to. In the case of losing his ability to drive, he thinks that he can combine walking and public transportation to go to the nearby shopping center where he can find everything he needs for himself and his wife. For other trips, he would probably use ride share or special transportation and acquire scheduling information from the providers' websites. However, Michael is very confident that he will not need any other transportation for a long time. He expects improvements on street and outdoor recreational areas for safer walking and biking experience.

Satisfied: $(-)$ Not Satisfied: -0 Disappointed:

Table 9.5: Secondary Personas

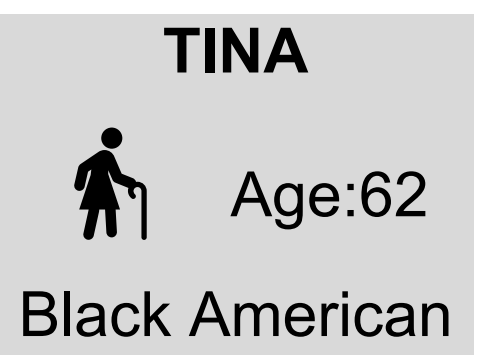

\section{About}

Tina has a high school degree. She worked as a receptionist for 33 years. Tina currently lives alone in an affordable senior housing that is 4.5 miles northeast of Downtown Dallas. Tina's current annual household income is $\$ 15,500$.

\section{Health Background}

Tina struggled with her weight all her life due to emotional eating, caused by being single and living alone after leaving her parents' house at a young age.

\section{Social Connections}

Although Tina does not have close family relationships, she has a good network of friends from the offices she worked at and her current senior housing complex.

\section{Transportation Options}

Tina ceased driving since she thinks driving is not necessary for her anymore. She rides in her friends' cars to go to grocery store, doctor appointments and other errands. While Tina can benefit from special transportation, she is not qualified for it and she finds it pricey as well. She wants to use public transportation, but the closest bus stop is 1.5 miles away. Also, she despises the condition of busses.

\section{Transportation Information}

Tina depends on printed transit schedules. She never goes online for transportation information.

\section{Health Status}

- Unable to walk less than 0.25 miles at once

- Self-perceived physical health rating is good

\section{Social Status}

- Rarely feels lonely and socially isolated

\section{Mobility Status}

- Prefers to walk with a companion

- Missed trips for activities due to not finding transportation

- Dislikes undermaintained condition of public transportation: trash, wet seats

\section{Accessing Transportation Information}

- Local aging and faith-based organizations

- Doctor and health care offices

- Friends/Neighbors 


\section{Goals and Motivation}

Tina is aware of the fact that she will not have the option of riding with her friends since her friends may also have difficulties with driving in the near future. Public transportation will be more essential for her trips when she cannot ride with others. Therefore, she wishes to have easier access to public transportation to take all her trips around the city.

\section{Satisfied: $(-)$ Not Satisfied: Disappointed:-0}

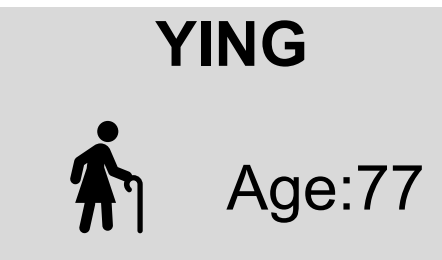

\section{Asian American}

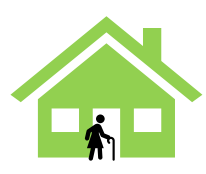

Home

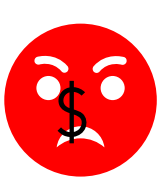

Income

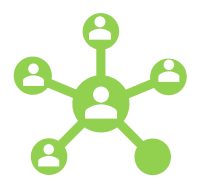

Social Connections
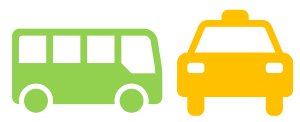

Transportation

\section{About}

Ying has a high school degree. She worked together with her husband, Wei, at their tailoring and shoe repair shop for 45 years. Ying currently lives with her husband in an affordable residential apartment complex for seniors that is 11 miles northeast of Downtown Dallas. Ying's current annual household income is $\$ 9,500$.

\section{Health Background}

Ying had a healthy and active life. Walking, homecooked food, and work life kept her active mentally and physically.

\section{Social Connections}

Ying spends most of her time with her husband. She has a few friends in the same apartment complex with whom she goes to bible study and gathers for tea to chat in Mandarin.

\section{Transportation Options}

Ying never had a car before. Therefore, she is used to navigate with the available transportation options. She may find single item grocery needs from a close by neighborhood market. For the rest of her needs, she mostly uses public transportation and sometimes rides with others living in the same complex.

\section{Transportation Information}

Ying depends on printed transit schedules. She does not use online services for transportation information due to difficulty of reading and understanding English.

\section{Goals and Motivation}

Ying had close calls to tipping over on sidewalks and lost her balance a few times due to driver's behaviors while crossing the streets. Therefore, she wants to avoid these situations that can injure her. While she still anticipates using public transportation, she acknowledges the fact that she may depend more on riding with others as she gets older. Regardless, she wishes to continue maintaining and managing her trips by herself or with her husband as she gets older.

\section{Health Status}

- Easily able to walk more than 0.25 miles

- Self-perceived physical health rating is very good

\section{Social Status}

- Never feels lonely and socially isolated

\section{Mobility Status}

- Walks 30 minutes 5 days a week

- Uses public transportation 4 to 5 times a week

\section{Satisfied: -2 Not Satisfied: 2 Disappointed:}




\section{DERICIA \\ in \\ Age:73 \\ Black American}

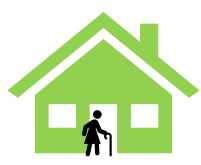

Home

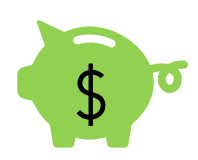

Income Social Connections
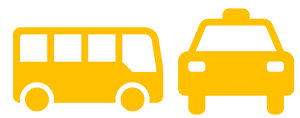

Transportation
Health:

Mobility:

Transportation Options:

\section{About}

Dericia has a high school degree. She was a stay-at-home mother. Dericia took jobs on and off to help her husband make the ends meet. Dericia currently lives with her husband and an adult child in a house they own that is 8 miles south of Downtown Dallas. Dericia's current annual household income is $\$ 42,500$.

\section{Health Background}

Dericia had a healthy life without major health issues. She experiences expected decline in her health due to increasing age.

\section{Social Connections}

Dericia feels lucky to have her adult daughter and husband around. She has people to talk and ask for help without hesitation. She has couple of good friends with whom she gets together for card and board games once in every few weeks.

\section{Transportation Options}

Dericia stopped driving but she still rides with her husband and daughter. She goes out couple of times a week and her rides take about 45 minutes. She used special transportation once, but she did not like the experience of waiting more than an hour. Dericia has never used taxi and ride share services. Also, she does not prefer to walk as a means of transportation.

\section{Transportation Information}

Dericia depends on her family's transportation knowledge and hears about available services with word of mouth

\section{Goals and Motivation}

Dericia is aware of the fact that she may not have the option of riding with her husband and daughter since her husband may also have difficulties with driving in the near future and her adult daughter may leave the house after finding a job. Public transportation will be more essential for her trips when she cannot ride with others. However, she despises that there is no public transit provided in her area.

- Never feels lonely and socially isolated

\section{Health Status}

- Able to walk more than 0.25 miles

- Self-perceived physical health rating is very good

\section{Social Status}

\section{Mobility Status}

- Rides with others

- Missed a memorial service when no one was able to give a ride

- Concerned about neighborhood safety and uneven sidewalks which lacks senior friendly facilities

\section{Accessing Transportation Information}

- Family and friends/neighbors

- Doctor and health care offices

- Phonebook

\section{Satisfied: $\because$ Not Satisfied: $*$ Disappointed: 0}

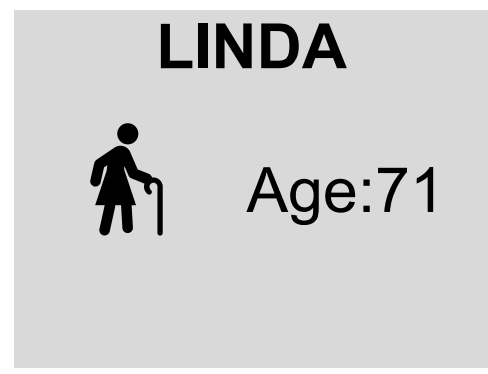

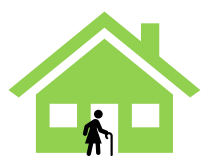

Home

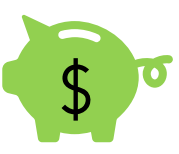

Income

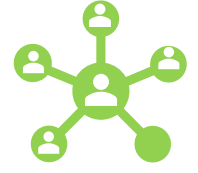

Social Connections
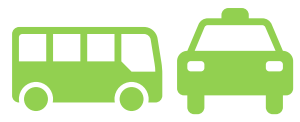

Transportation 


\section{White American}

\section{About}

Linda has a master's degree in Education. She worked as standardized test developer and retired 5 years ago. Linda currently lives with her husband and an adult child in a house they own that is 20 miles north of Downtown Dallas. Linda's current annual household income is $\$ 100,000$.

\section{Health Background}

Linda had a healthy life without major health issues. She experiences expected decline in her health due to increasing age.

\section{Social Connections}

Linda feels lucky to have her adult son and husband around. She has people to talk all the time. She goes to a book club and meets with her friends regularly. Also, she likes to go to libraries to read and browse for material to learn new hobbies. She makes effort to attend aerobics classes in recreational center where she has couple of work out friends.

\section{Transportation Options}

Linda's current transportation is driving her personal car. Occasionally, she rides with her husband and son. She drives her car approximately 10 times a week with 20 minutes average trip durations. She would like to take more walks around the neighborhood, but it is not convenient due to lack of sidewalks. She does not use public transportation and special transportation for now. Although Linda does not use ride share services actively, her son accompanied her to book and use ride share.

\section{Transportation Information}

Linda knows her way around the city. If she needs to go somewhere that she is not sure how to get there, she looks up directions on online maps. In addition, her son helps her if she needs more assistance. Linda is subscribed to AARP magazine and she grabs public transit schedules at doctor offices and church to increase her awareness and knowledge of other transportation options.

\section{Goals and Motivation}

Linda is aware of the fact that she may have to give up driving in the future and not have the option of riding with her husband and son since her husband may also have difficulties with driving in the near future and her adult son may leave the house. She would like to have senior friendly sidewalks and repairs on the existing ones. Although she is not an active user of public transportation for now, she hears from her friends that reaching to public transit stops and long wait times are challenging. Therefore, she is worried for her mobility in the future while expecting to keep her activities.

\section{Health Status}

- Able to walk more than 0.25 miles

- Self-perceived physical health rating is very good

\section{Social Status}

- Never feels lonely and socially isolated

- Active in self-learning and socializing

\section{Mobility Status}

- Occasionally rides with others

- Never misses event or appointments

- Lack of sidewalks preventing leisure walks around the neighborhood

\section{Accessing Transportation Information}

- Family and friends/neighbors

- Online map resources 1-2 times a week

- Healthcare offices and church for transportation knowledge after driving cessation 


\section{CARMEN}

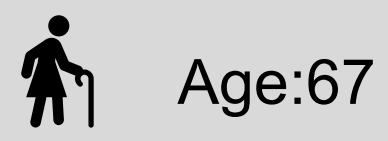

Hispanic American

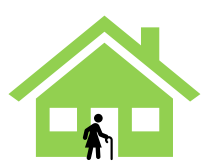

Home

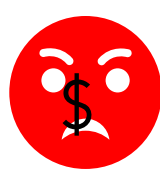

Income

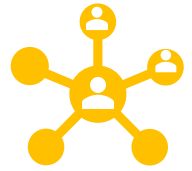

Social Connections
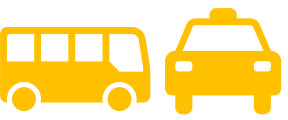

Transportation

Health: Mobility: Transportation Options:

\section{About}

Carmen has a high school degree. She worked at a university cafeteria. She has been separated from her husband for 30 years. Carmen currently lives with her 91 -year-old mother in a house they own that is 3.7 miles east of Downtown Dallas. Linda's current annual household income is $\$ 19,000$.

\section{Health Background}

Carmen had a healthy life without major health issues. She experiences expected decline in her health due to increasing age and responsibilities of taking care of her mother.

\section{Social Connections}

Carmen has an older son who lives in Dallas area, as well. Her son tries to stay in touch and help

Carmen as much as he can. However, as a primary care giver to her mother, Carmen cannot participate in any type of social activities and feels trapped.

\section{Transportation Options}

Carmen's current transportation is driving her personal car. She drives up to 12 times a week with an average 25 minutes of driving time. Her old car breaks up occasionally, but she has to keep it up since it is the only way to provide transit for her mother. She tries to walk to places when she can to save from gas and prevent being stranded by the side of the road if the car breaks up. Carmen cannot walk long distances as she used to before and worries about her safety. She despises the condition of sidewalks.

\section{Transportation Information}

Carmen's son gave his old smart phone to Carmen and tried to teach how to use the internet. Carmen rarely uses online map sources. She relies on her own knowledge of directions.

\section{Goals and Motivation}

Carmen is aware of the fact that she may have to give up driving in the future and she may still have to take care of her mother. She would like to have assistance for older adults who take care of their parent(s), like herself, so that she can care for herself and maybe have a chance to do other activities.

\section{Health Status}

- Able to walk more than 0.25 miles

- Self-perceived physical health rating is good

\section{Social Status}

- Sometimes feels lonely and socially isolated

\section{Mobility Status}

- Missed couple of doctor appointments to take care of her mother

- Unable to walk due to uneven sidewalks and lack of safety

\section{Accessing Transportation Information}

- Online map resources once a month or less
- Her son

\section{Satisfied: $\because$ Not Satisfied: $\because$ Disappointed:}




\section{SHANDRA \\ i⿱宀 \\ Age:69 \\ Black American}

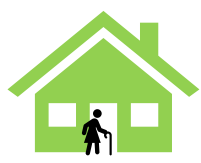

Home

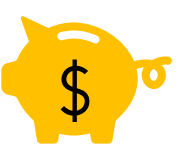

Income Social Connections
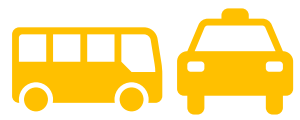

Transportation

Health:

Mobility:

Transportation Options:

\section{About}

Shandra has an associate degree in Accounting. She worked as a payroll clerk in a pharmaceutical company. Shandra retired a year ago. She currently lives alone in a house she owns that is 10 miles southeast of Downtown Dallas. Shandra's current annual household income is $\$ 20,000$.

\section{Health Background}

Shandra had a healthy life without major health issues. She experiences expected decline in her health due to increasing age.

\section{Social Connections}

Although Shandra's husband passed away two years ago, she was able to cope with the help of her daughter and granddaughter.

\section{Transportation Options}

Shandra still drives her personal car. She drives approximately 8 times a week with an average of 34 minutes per trip. She tried to use public transportation to test how to manage her life without a car. However, she finds the public transportation too expensive for the span of service provided. Also, she does not like to walk because dog problems in her area.

\section{Transportation Information}

Shandra relies on her own knowledge of directions while driving. If she encounters problems, she will reach out to her daughter and granddaughter. She does not use internet for information or to secure transportation since she does not have a credit card and access to internet.

\section{Goals and Motivation}

Shandra is aware of the fact that she may not have the option of driving herself all the time later in her life. She wishes to have public transportation going directly into neighborhoods with more affordable prices. She had a chance to experience ride share with her daughter. While she thinks that she may not afford the ride share frequently, she would like to learn how to secure this transit option online in case she needs it for special events and activities.

\section{Accessing Transportation Information \\ - Family}

- Able to walk more than 0.25 miles

\section{Social Status}

- Rarely feels lonely and socially isolated
- Concerned about her safety when walking due to stray dogs
Mobility Status

Health Status \\ Satisfied Not Satisfied: \\ Disappointed:}




\section{RONNELL \\ is \\ Age:67 \\ Black American}

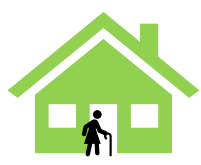

Home

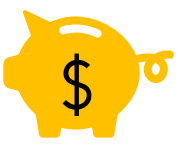

Income Social Connections
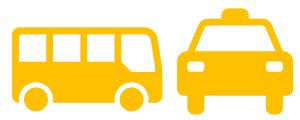

Transportation

Health:

Mobility:

Transportation Options:

\section{About}

Ronnell has a high school degree. She was a stay-at-home mother to her two children. She currently lives alone in a house she owns that is 10 miles south of Downtown Dallas. Ronnell's current annual household income is $\$ 18,500$.

\section{Health Background}

Ronnell had a healthy life without major health issues. She experiences expected decline in her health due to increasing age.

\section{Social Connections}

Ronnell's husband passed away five years ago.

She was able to cope with the help of her daughter and cousins.

\section{Transportation Options}

Ronnell still drives her personal car. She drives approximately 8 times a week with an average of 15 minutes per trip. She is aware of the transit services in her area, and she finds the services insufficient in terms of frequency. She feels anxious while driving because other drivers drive fast. She knows about ride share and taxi via her daughter, but she is afraid of riding with strangers and finds these services expensive.

\section{Transportation Information}

Ronnell relies on her own knowledge of directions while driving. She does not use internet for information or to secure transportation since she does not have access to internet. She finds technology too difficult. Therefore, she does not go online for any reason.

\section{Goals and Motivation}

Ronnell is aware of the fact that she may not have the option of driving herself all the time later in her life. She wishes to have more frequent public transportation with a larger service area so that she can reach to her basic needs when she can no longer drive.

\section{Health Status}

- Able to walk more than 0.25 miles

- Self-perceived physical health rating is good

\section{Social Status}

- Never feels lonely and socially isolated

\section{Mobility Status}

- Panics while driving in high-speed streets and roads due to other driver's behaviors

\section{Accessing Transportation Information \\ - Family when necessary}

\section{Satisfied: $:$ Not Satisfied: $\quad$ Disappointed:}




\section{QUISHA \\ i⿱宀 \\ Age:77 \\ Black American}

\section{About}

Quisha has $\mathrm{K}-12^{\text {th }}$ grade without a diploma. She was a stay-at-home mother to her two children. She currently lives alone in a house she owns that is 16 miles south of Downtown Dallas. Quisha's current annual household income is $\$ 9,000$.

\section{Health Background}

Quisha has back problems impacting her ability to walk

\section{Social Connections}

Quisha's husband passed away ten years ago.

She was able to cope with the help of her children. She gained the ability to be sufficient to herself with time.

\section{Transportation Options}

Quisha still drives her personal car. She drives approximately 10 times a week with an average of 35 minutes per trip. She has never used public transportation and other transit options. Driving at nights can be challenging.

\section{Transportation Information}

Quisha relies on her own knowledge of directions while driving. She does not use internet for information or to secure transportation since she does not have access to internet. She finds technology too difficult. Therefore, she does not go online for any reason.

\section{Goals and Motivation}

Quisha anticipates that she will be able to drive for at least next ten years. She expects gas cards as a financial support. Quisha would like to drive on safer roads with less traffic that are well lit at night.

\section{Mobility Status}

- Dislikes walking

- Hard to drive at night

\section{Accessing Transportation Information}

- Family when necessary

\section{Satisfied: $\because$ Not Satisfied: $\because$ Disappointed: 20}

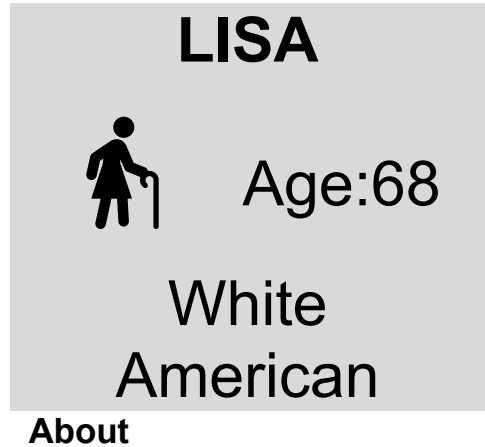

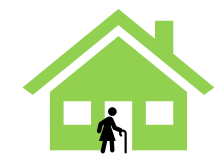

Home

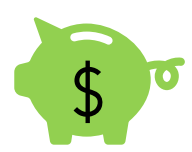

Income Social Connections
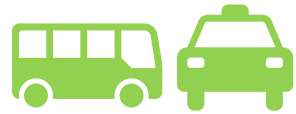

Transportation

Health:

Mobility: Transportation Options: 
Lisa has MBA. She worked at several non-profits and retired 3 years ago. Lisa currently lives alone in a house she owns that is 3 miles southwest of Downtown Dallas. Lisa's current annual household income is $\$ 70,000$.

\section{Health Background}

Lisa had a healthy life without major health issues.

She experiences expected decline in her health due to increasing age.

\section{Social Connections}

Lisa separated from her husband 20 years ago.

She has close relationship with her two adult children who also live in Dallas area. Lisa is still involved in fund raising activities with multiple non-profits. She likes to go to exhibitions and concerts with her friends. She tries to exercise regularly at recreation center and plays racket ball with her friends. Lisa tries to participate in seniors' events to learn about resources available to her.

\section{Transportation Options}

Lisa's current transportation is driving her personal car. Occasionally, she rides with her children. She drives her car approximately 12 times a week with 30 minutes average trip durations. She would like to take more walks around the neighborhood, but it is not convenient due to lack of sidewalks. She uses Uber when she does not feel like driving.

\section{Transportation Information}

Lisa knows her way around the city. If she needs to go somewhere that she is not sure how to get there, she looks up directions on online maps or navigation on her smartphone. In addition, her children help her if she needs more assistance.

Lisa is subscribed to AARP magazine.

\section{Goals and Motivation}

Lisa expects to drive for a long time. She would like better lit streets for easier driving at night and wellmaintained sidewalks. Although she is not an active user of public transportation for now, she knows that bus stops are too far away for her. She wishes improvements with public transportation for all older adults. She wishes free medical transportation for older adults with medical conditions. Lisa expects better communication of transit options from providers with a detailed directory.

\section{Health Status}

- Able to walk more than 0.25 miles

- Self-perceived physical health rating is very good

\section{Social Status}

- Never feels lonely and socially isolated

- Active in self-improvement and socializing

\section{Accessing Transportation Information}

- Family and friends/neighbors

- Online resources3-6 times a week

Satisfied: Not Satisfied

\section{Disappointed:}

\section{TYRELL}

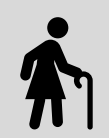

Age:81

\section{Black American}

\section{About}

Tyrell has an associate of art in Business. She worked at various banks. She currently lives alone in a senior living facility that is 15 miles northwest of Downtown Dallas. Tyrell's current annual household income is $\$ 25,000$. 


\section{Health Background}

Tyrell experiences decline in her health due to her age. Walking gets harder for her.

\section{Social Connections}

Tyrell's husband passed away six years ago. She has a son living out of state and she talks to him multiple times in a week. Tyrell has good circle of friends in the senior living center with whom she enjoys social activities.

\section{Transportation Options}

Tyrell still drives her personal car. She drives approximately 6 times a week with an average of 20 minutes per trip. She tried using special transportation, but she does not like that there are too many pick ups and long rides. She does not use public transportation because bus stops are too far for her. Sometimes she rides in the vans of senior facility.

\section{Transportation Information}

Tyrell relies on her own knowledge of directions while driving. She does not use internet for information or to secure transportation. She sometimes asks associates in senior living for help or calls her son.

\section{Goals and Motivation}

Tyrell does not see any other transportation option she likes but driving her own car. Since she does not like riding with strangers; therefore, ride share is not an option for her. Her goal is to take care of herself as much as she can to continue driving.

\section{Health Status}

- Have some difficulty with mobility

- Able to walk less than 0.25 miles at once

- Self-perceived physical health rating is good

\section{Social Status}

- Never feels lonely and socially isolated

\section{Mobility Status}

- Never walks outside on the ground

- Unable to walk to bus stops

- Dislikes long rides in special transportation

\section{Satisfied: $\because$ Not Satisfied: 2 Disappointed: 2}

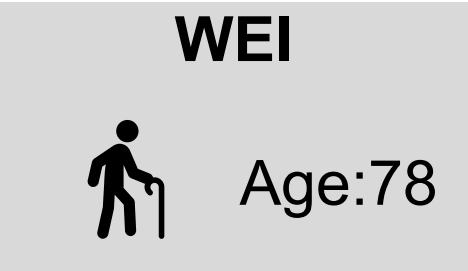

Asian American

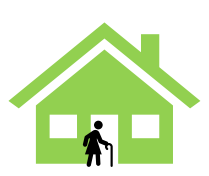

Home

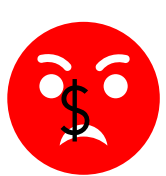

Income

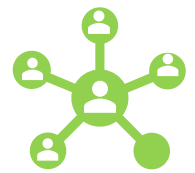

Social Connections
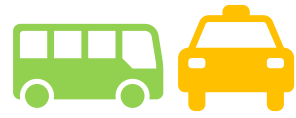

Transportation

\section{About}

Health: Mobility:

Transportation Options:

Wei has a high school degree. He worked together with his wife, Ying, at their tailoring and shoe repair shop for 45 years. Wei currently lives with his wife in an affordable residential apartment complex for seniors that is 11 miles northeast of Downtown Dallas. Wei's current annual household income is $\$ 9,500$.

\section{Health Background}

Wei had a healthy and active life. Walking, homecooked food, and work life kept him active mentally and physically. Due to straining his eyes for his job, he does not see well and needs prescribed eyeglasses.

\section{Social Connections}

\section{Health Status}

- Easily able to walk more than 0.25 miles

- Self-perceived physical health rating is good

- Issues with vision

\section{Social Status}


Wei spends most of his time with his wife. He has a few friends in the same apartment complex with whom he goes to bible study and gathers for tea and board games, and chats in Mandarin.

\section{Transportation Options}

Wei never had a car before. Therefore, he is used to navigate with the available transportation options. He goes everywhere with his wife Ying. He mostly uses public transportation and sometimes rides with others living in the same complex.

\section{Transportation Information}

Wei depends on printed transit schedules with his wife's assistance. He does not use online services for transportation information due to difficulty of reading and understanding English.

\section{Goals and Motivation}

Wei had close calls to tipping over on sidewalks with his wife. He may navigate better with audio aid at intersections. While he still anticipates using public transportation, he acknowledges the fact that he may depend more on riding with others as he gets older. Regardless, he wishes to continue maintaining and managing his trips by his wife as he gets older.

\section{Satisfied: $\because$ Not Satisfied: -0 Disappointed:}

\section{ISAIAH \\ î \\ Age:71 \\ Black American}

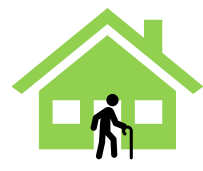

Home

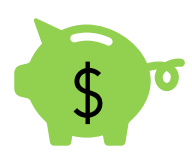

Income Social Connections

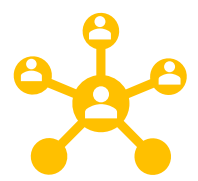

Transportation Options:

\section{About}

Isaiah has an associate of science degree in Industrial Engineering. He retired six years ago from a manufacturing company. He lives alone in a house he owns that is 5.5 miles southwest of Downtown Dallas. Isaiah has one child. Isaiah's current annual household income is $\$ 53,000$.

\section{Health Background}

Isaiah had a healthy life. He did not have major health issues. He manages his high blood pressure with a prescribed beta blocker.

\section{Social Connections}

Isaiah's wife passed away two years ago. He still grieves but also tries to connect with other seniors at local aging organizations. He has a son who lives out-of-state. He talks to his son couple of times in a week but does not see him frequently.

\section{Transportation Options}

Isaiah drives everywhere with his personal car. While he is aware that there is public and special transportation in his area, he foresees that he will be able to drive for some time and will not need to use any of these transportation options in the near future.

\section{Health Status}

- Able to walk more than 0.25 miles at once

- Self-perceived physical health rating is very good

\section{Social Status}

- Sometimes feels lonely and socially isolated

\section{Mobility Status}

- Never misses any trips, appointments, or events

- Able to travel wherever he wants at anytime 


\section{Transportation Information}

Isaiah has detailed knowledge of roads in Dallas area. If needs to go to a location he has never been to, he will check online map resources

before planning his trip.

\section{Goals and Motivation}

Isaiah will continue driving until he is not able to. He grabs and reads printed transportation information available in healthcare offices, church, and local aging organizations to get more familiar with his options when he can no longer drive. Isaiah wishes to increase his circle of friends by participating more events with local aging organizations and recreational centers.

\section{Satisfied: $\because$ Not Satisfied: 2 Disappointed: 20}

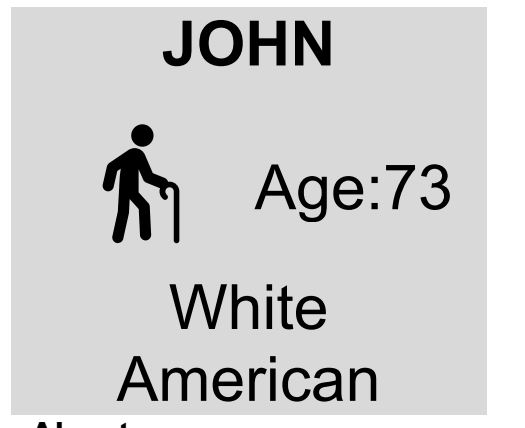

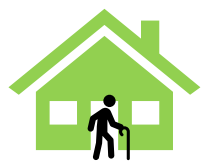

Home

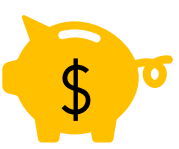

Income Social Connections
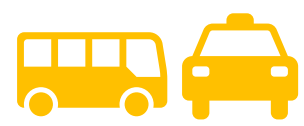

Transportation

Health: $\quad$ Mobility: $\quad$ Transportation Options:

\section{About}

John has an associate degree in culinary arts. He worked at various grocery stores and retired 5 years ago. He lives alone in a senior living facility that is 3.5 miles northeast of Downtown Dallas. John's current annual household income is $\$ 22,000$.

\section{Health Background}

John had to stand on his feet a lot for his work and he injured his back. Although he does targeted exercises for his back, walking can be hard at times.

\section{Social Connections}

John has never married, and he has been living alone since he was 25 . He used to spend time with a couple of close friends, but his friends moved closer to their children. John makes effort to socialize in senior events at the senior living facility.

\section{Transportation Options}

John gave up driving due to expenses and unnecessity of owning one. John uses public transportation three times a week on average and his trips take 15 to 20 minutes. However, there are many occasions he had to wait a long time for a bus. Also, he uses the scheduled bus service provided by senior living facility for local shopping. He worries about conditions of sidewalks and intersections since he may need to use an electric wheelchair in the future.

\section{Transportation Information}

John can ask the social worker in the facility about anything. He has an idea on how to secure

\section{Health Status}

- Have some difficulty with mobility

- Able to walk less than 0.25 miles at once

- Self-perceived physical health rating is good

\section{Social Status}

- Sometimes feels lonely and socially isolated

\section{Mobility Status}

- Missed a doctor visit due to lack of transportation

- Uneven sidewalks make it harder to walk

\section{Accessing Transportation Information}

- Social worker

- Advertisement

- Friends and neighbors, doctor offices 
transportation online, but also he finds it hard to

learn from others.

\section{Goals and Motivation}

John would like to establish more social connections within the senior living facility and at outside activities. He sometimes wishes to use Uber to go out in the evening, but its cost prevents him from riding with one. He wishes to have more frequent public transit services and a well-maintained environment to prevent injuries and accidents.

Satisfied:- Not Satisfied:- Disappointed:- 